The John D. and Catherine T. MacArthur Foundation Reports on

Digital Media and Learning

\title{
Documenting and Assessing \\ Learning in Informal and \\ Media-Rich Environments
}

Jay Lemke, Robert Lecusay, Michael Cole, and Vera Michalchik

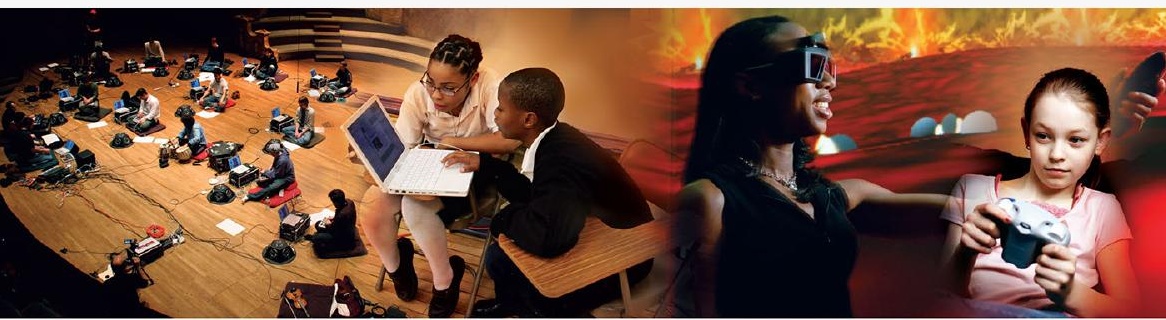

MacArthur Foundation 
Documenting and Assessing Learning in Informal and Media-Rich Environments 


\section{The John D. and Catherine T. MacArthur Foundation Reports on Digital Media and Learning}

Digital Youth with Disabilities, by Meryl Alper

We Used to Wait: Creative Literacy in the Digital Era, by Rebecca Kinskey

Documenting and Accessing Learning in Informal and Media-Rich Environments, by Jay Lemke, Robert Lecusay, Michael Cole, and Vera Michalchik Quest to Learn: Developing the School for Digital Kids, by Katie Salen, Robert Torres, Loretta Wolozin, Rebecca Rufo-Tepper, and Arana Shapiro

Measuring What Matters Most: Choice-Based Assessments for the Digital Age, by Daniel L. Schwartz and Dylan Arena

Learning at Not-School? A Review of Study, Theory and Advocacy for Education in Non-Formal Settings, by Julian Sefton-Green

Measuring and Supporting Learning in Games: Stealth Assessment, by Valerie Shute and Matthew Ventura

Participatory Politics: Next-Generation Tactics to Remake Public Spheres, by Elisabeth Soep

Evaluation and Credentialing in Digital Music Communities: Benefits and Challenges for Learning and Assessment on Indaba Music, by Cecilia Suhr The Future of the Curriculum: School Knowledge in the Digital Age, by Ben Williamson

For more information, including a complete series list, see http://mit press.mit.edu/books/series/john-d-and-catherine-t-macarthur-founda tion-reports-digital-media-and-learning. 
Documenting and Assessing Learning in Informal and Media-Rich Environments

Jay Lemke, Robert Lecusay, Michael Cole, and Vera Michalchik

The MIT Press

Cambridge, Massachusetts

London, England 
(c) 2015 Massachusetts Institute of Technology

All rights reserved. No part of this book may be reproduced in any form by any electronic or mechanical means (including photocopying, recording, or information storage and retrieval) without permission in writing from the publisher.

MIT Press books may be purchased at special quantity discounts for business or sales promotional use. For information, please email special_sales@mitpress.mit.edu.

This book was set in Stone by the MIT Press. Printed and bound in the United States of America.

Library of Congress Cataloging-in-Publication Data is available.

ISBN: 978-0-262-52774-3

$\begin{array}{llllllllll}10 & 9 & 8 & 7 & 6 & 5 & 4 & 3 & 2 & 1\end{array}$ 


\section{Contents}

Series Foreword vii

Introduction 1

Review of the Literature 15

Highlights of the Expert Meetings 81

Conclusions and Recommendations 89

Appendix A: Expert Meeting Participants 99

Appendix B: Bibliography 101

Appendix C: Online Resources: Assessment, Funding, and Research 141

Notes 145

References 147 



\section{Series Foreword}

The John D. and Catherine T. MacArthur Foundation Reports on Digital Media and Learning, published by the MIT Press in collaboration with the Monterey Institute for Technology and Education (MITE), present findings from current research on how young people learn, play, socialize, and participate in civic life. The reports result from research projects funded by the MacArthur Foundation as part of its $\$ 50$ million initiative in digital media and learning. They are published openly online (as well as in print) in order to support broad dissemination and to stimulate further research in the field. 



\section{Introduction}

In 2010, the authors of this report were asked to review the relevant literature and convene a series of expert meetings to make recommendations on the state of the art of, and the outstanding challenges in, documenting and assessing learning in informal and media-rich environments.

For several years now, efforts such as the MacArthur Foundation's Digital Media and Learning (DML) initiative have supported the development of a range of educational activities, media, and environments outside the classroom and its formal curriculum. The DML Connected Learning Research Network has elaborated the principles underlying the evolution of an openly networked learning ecology and is conducting studies to further define opportunities that support learning across contexts (Ito et al. 2013). Other large-scale efforts, such as the National Science Foundation-supported LIFE Center (Learning in Formal and Informal Environments), have also emphasized the complementarity of school and nonschool learning experiences and the potential for educational reform to benefit from knowledge gained in the study of learning outside school.

In a similar vein, the National Research Council produced a consensus report reviewing the knowledge base of science 
learning in informal environments (Bell et al. 2009), and the Noyce Foundation commissioned a report describing the attributes and strategies of cross-sector collaborations supporting science, technology, engineering, and math (STEM) learning (Traphagen and Trail 2014).

In all these efforts, there is agreement that the success and expansion of out-of-school initiatives depends on our ability to effectively document and assess what works in informal learning and what doesn't, as well as where, when, why, and how it works.

This report summarizes an extensive review of the literature on the assessment of learning in informal settings, with a focus on the following types:

- After-school programs These activities are not directly meant to serve school-based academic functions (e.g., playing an educational computer game and making innovative use of it for fun, with ancillary learning).

- Community center programs These activities are negotiated between learners and providers. They may have specific learning objectives as well as changing approaches to the goal (e.g., telementoring and the use of computer simulation of electric circuits, along with an on-site coach familiar with the student but not responsible for the content).

- Museum-based programs Visitors can choose to manipulate hands-on materials in the context of questions and explanations of phenomena observed or produced (e.g., young visitors connecting a battery to various electric devices to see the results of completing a circuit, with a coach, and showing the results to a parent; or a group of young visitors extracting insects from a bag to feed to a pet as part of a long-term project, and one participant overcoming a reluctance to touch the insects). 
- Online communities and forums Participants ask and answer questions on a specific area of competence or expertise and evaluate one another's answers or contributions. They may also engage in joint activity in a virtual space or mediated by tools and social interactions in that space (e.g., "modding" in World of Warcraft; learning to build in Second Life; "theory crafting" to identify technical characteristics of computer games by systematically playing many options within them; or raiding as joint play for a goal).

The research review generated an extensive bibliography, from which we selected for description and analysis a subset of studies and projects to illustrate both the diversity of approaches to the assessment of learning in informal activities and good assessment practices.

"Informal learning" is both a broad category and shorthand for a more complex combination of organized activities in faceto-face or online settings other than formal schools in which particular features are especially salient. Characteristically, participants choose and enjoy an informal learning activity for its own sake, often engaging in it intensely of their own accord and remaining committed to it of their own accord. The power relations in informal learning settings typically allow for the relatively equitable negotiation of learning goals and means.

The learning goals pursued by participants are generally open-ended, dependent in part on available resources and on repurposed ways to use those resources. Overall, because of the flexibility involved-and the complexity of relationships, means, and ends that emerge over time within the activity-many significant learning outcomes may be unpredictable in advance of the learner's participation in the central activities undertaken in nonformal environments. 
These features may, in principle, occur in both classroombased learning and other settings, but in different combinations and to different degrees. Each setting, and perhaps each kind of learning activity, will tend to have a particular combination and degree of each feature. The research literature may name activities or settings in which these features are present, dominant, constitutive, or highly significant (e.g., interest-based learning, free-choice learning, nonformal learning, or learning in passion communities). The literature may also make distinctions among these based on role relationships or types of institutional goals and constraints.

In addition to reviewing the literature, the authors convened three expert meetings involving a total of 25 participants to discuss key issues, identify successful approaches and outstanding challenges, and review summaries of prior meetings in the series. The results of these wide-ranging discussions are summarized in this report and were highly influential in formulating our recommendations.

Our aim is twofold: first, to offer to those who design and assess informal learning programs a model of good assessment practice, a tool kit of methods and approaches, and pointers to the relevant literature; and second, to offer program staffs, project funders, and other supporters recommendations of good practices in project assessment and identifiable needs for developing improved assessment techniques.

The members of our expert panels strongly urged us to deal with fundamental questions such as the purposes of assessment and the kinds of valued outcomes that should be considered. From discussions with the panel members and analysis of the research literature, as well as our own experience and judgment, we constructed a basic assessment model that encompasses at 
least 10 general types of valued outcomes, to be assessed in terms of learning at the project, group, and individual levels. Not all levels or outcome types will be equally relevant to every project, but we strongly believe that all assessment designs should begin by considering a conceptual model that is at least as comprehensive as what we propose here.

This is particularly important because the valued outcomes of informal learning tend to be less predictable and much more diverse than those of formal education. Formal education is designed to strongly direct learning into particular channels and produce outcomes that are specifiable in advance and uniform among students.

Informal learning experiences, in contrast, build on the diverse interests and curiosity of learners and support their selfmotivated inquiries. The valued outcomes of informal learning are often particularly rich in contributions to social and emotional development, to identity and motivation, to developing skills of collaboration and mutual support, and to persistence in the face of obstacles and in inquiry on time scales of weeks, months, and even years. Informal learning activities also often result in products and accomplishments of which students are justly proud and for which product-appropriate measures of quality are needed.

In the remainder of this introduction, we will present our outcomes-by-levels model for comprehensive assessment and briefly provide some definitions, distinctions, and principles as a general framework for what follows. In the main body of the report, we will provide a review of selected and representative research studies and project reports in order to illustrate a wide range of useful techniques for documenting and assessing informal learning across varied settings and to identify issues 
and challenges in the field. Finally, we will provide our overall conclusions and recommendations.

\section{Outcomes and Levels}

It was universally agreed in our expert panels and extensively illustrated in the research literature that simple declarative knowledge is only one valued outcome of learning and is too often overemphasized in assessment designs to the exclusion or marginalization of other equally or more important outcomes.

Likewise, assessment designs too often focus only on outcomes for individual learners and neglect group-level learning and project-level or organization-level learning. Documentation and assessment must be able to show how whole projects and supporting organizations learned to do better or didn't. The kinds of documentation and data of value for organizationallevel improvement are not limited to those that document individual learning.

Even individual learning is not simply a matter of domainspecific knowledge. As an aspect of human development-at the individual, group, or organizational level-the learning that matters is learning that is used. This type of learning plays a role in constructive activities: from posing questions to solving problems, from organizing a group to building a simulation model, or from exploring a riverbank to producing a video documentary. In all these cases, what matters is know-how; "know-that" matters only insofar as it is mobilized in practice. Such learning is consequential and underlies movement, organization, and change.

Activities of practical value usually require interaction and collaboration with other people. "Know-who" is as important as know-how in getting things done. Social networking and 
coming to understand who is good at what, and how a group of particular people can work together effectively, is an essential outcome of learning.

Nothing of value can be undertaken unless people are motivated to act and feel comfortable within the domains of know-how and know-who. A key outcome of learning is the development of identification with ideals, goals, groups, tools, media, genres, and styles that constitute our changing identities and motivations for action. Equally important is our social-emotional development in learning how to use our feelings-our emotional relations to others and our emotional reactions to events-for constructive purposes.

Collaborative groups learn, develop, and change over time. Membership may change; agreed-upon goals, processes of interaction, interpersonal feelings, agreed-upon procedures, and informal ways of doing things all change. In many cases they change adaptively so that the goals of the group are more effectively pursued. Just as individuals learn how to better function in collaborative groups, so groups learn how to make better use of the contributions of individual members-or they don't.

Whole projects, online communities, and larger organizations also learn, change, and adapt-or they don't. Documenting and assessing organizational learning is equally as important as assessing group and individual learning and development. It is likely, though not well understood, that learning processes at these three levels (individual, group, and project or organizational learning) are linked and that we cannot expect to understand why learning was successful or unsuccessful at any one of these levels unless we also have data about learning at the other two.

From these and similar considerations, we developed the following basic outcomes-by-levels model for documentation and assessment (see table 1). 


\section{Table 1}

Outcomes-by-Levels Model for Documentation and Assessment

Level of Analysis

\begin{tabular}{|c|c|c|c|}
\hline Outcomes & $\begin{array}{l}\text { Project or } \\
\text { Community }\end{array}$ & Group & Individual \\
\hline $\begin{array}{l}\text { Social-emo- } \\
\text { tional-identity } \\
\text { development }\end{array}$ & $\begin{array}{l}\text { Developing } \\
\text { social-emotional } \\
\text { climate; com- } \\
\text { munity or project } \\
\text { ethos, goals, and } \\
\text { local culture; sys- } \\
\text { tem of roles and } \\
\text { niches. }\end{array}$ & $\begin{array}{l}\text { Mutual sup- } \\
\text { port, challenge, } \\
\text { inspiration; joint } \\
\text { enjoyment and } \\
\text { engagement. }\end{array}$ & $\begin{array}{l}\text { Comfort } \\
\text { and sense } \\
\text { of agency } \\
\text { in domain; } \\
\text { engagement; } \\
\text { long-term } \\
\text { interest and } \\
\text { persistence } \\
\text { versus } \\
\text { obstacles and } \\
\text { frustration. }\end{array}$ \\
\hline $\begin{array}{l}\text { Cognitive- } \\
\text { academic } \\
\text { (know-how) }\end{array}$ & $\begin{array}{l}\text { Developing } \\
\text { strategies for } \\
\text { organizing and } \\
\text { distributing } \\
\text { know-how; work } \\
\text { practices and divi- } \\
\text { sion of labor. }\end{array}$ & $\begin{array}{l}\text { Shared, distrib- } \\
\text { uted know-how; } \\
\text { collective intel- } \\
\text { ligence; dialogue } \\
\text { and cooperation } \\
\text { skills; explanation } \\
\text { skills. }\end{array}$ & $\begin{array}{l}\text { Knowing } \\
\text { how to go } \\
\text { forward in } \\
\text { the domain; } \\
\text { knowing } \\
\text { how to } \\
\text { mobilize and } \\
\text { integrate } \\
\text { know-how } \\
\text { across } \\
\text { domains. }\end{array}$ \\
\hline
\end{tabular}

In addition to providing this basic outcomes-by-levels matrix, we also need to emphasize the importance of taking into account in assessment design the incorporation of relevant knowledge about the history of the project, the community, and the participating organizations and knowledge of the current wider institutional contexts (e.g., goals, organization, leadership, resources, and limitations).

We further identified a more specific set of outcomes as relevant within this overall model, which we have organized into 
four clusters emphasizing different aspects of learning. First is the personal increase of comfort with, and capacity to participate in, activities that involve inquiry, investigation, and representation of phenomena in a widening range of domains. This set of outcomes emphasizes progressive attunement to the types of discourse and practices commonly associated with knowledge within a given domain, leading to an increased sense of agency and the ability to further leverage resources for learning.

Second is the improved ability to act collaboratively, coordinating and completing tasks with others, assisting them, and productively using affective sensibilities in doing so. Third is learning to critically reflect on the nature and quality of products and other goal-oriented objectives, becoming able to more successfully iterate toward high-quality outcomes. And fourth is mobilizing social resources, networks, and capital, including across tasks and settings, to reach goals that may take extended periods to achieve.

For each of these four clusters, we include examples of outcomes at the project, group, and individual level (see table 2).

The research projects summarized in the review of the literature were selected for inclusion because they provide examples of methods for documenting and assessing one or more of the above outcome clusters at one or more of the three levels of analysis. In the review, we specify at the beginning of each project summary the outcomes and levels assessed in each project.

\section{A Framework of Basic Concepts}

The discussions in our expert panels frequently focused on an emerging reconceptualization of key concepts pertinent to documentation and assessment design for informal learning 
Table 2

Clusters of Informal Learning Outcomes by Level, with Examples

\begin{tabular}{|c|c|c|c|}
\hline Outcomes & Project & Group & Individual \\
\hline $\begin{array}{l}\text { Increasing } \\
\text { comfort with, } \\
\text { and the ability } \\
\text { to conduct, } \\
\text { independent } \\
\text { inquiry across a } \\
\text { widening range } \\
\text { of domains, } \\
\text { including } \\
\text { evaluating } \\
\text { sources and } \\
\text { contributions. }\end{array}$ & $\begin{array}{l}\text { The Colorado } \\
\text { Hybrid Proj- } \\
\text { ect's cultural } \\
\text { responsiveness } \\
\text { promotes girls' } \\
\text { identification } \\
\text { with STEM } \\
\text { practices. }\end{array}$ & $\begin{array}{l}\text { Families' } \\
\text { scientific sense } \\
\text { making at a } \\
\text { marine park, } \\
\text { demonstrated } \\
\text { by TOBTOT. }\end{array}$ & $\begin{array}{l}\text { Use of Zydeco } \\
\text { for "nomadic } \\
\text { inquiry" of con- } \\
\text { tent across learn- } \\
\text { ing settings. }\end{array}$ \\
\hline $\begin{array}{l}\text { Improving the } \\
\text { ability to learn } \\
\text { and act collabor- } \\
\text { atively, includ- } \\
\text { ing a relevant } \\
\text { understanding } \\
\text { of and support } \\
\text { for learning } \\
\text { partners. }\end{array}$ & $\begin{array}{l}\text { The GIVE } \\
\text { project prompts } \\
\text { groups of inter- } \\
\text { generational } \\
\text { museum visi- } \\
\text { tors to engage } \\
\text { in inquiry. }\end{array}$ & $\begin{array}{l}\text { Children } \\
\text { engage in } \\
\text { mutual helping } \\
\text { behavior at } \\
5 \text { th Dimension } \\
\text { sites. }\end{array}$ & $\begin{array}{l}\text { Collaborative } \\
\text { problem solving } \\
\text { for success in Lin- } \\
\text { eage and other } \\
\text { MMORPG play. }\end{array}$ \\
\hline $\begin{array}{l}\text { Improving the } \\
\text { quality of prod- } \\
\text { ucts, including } \\
\text { the ability to } \\
\text { critically reflect } \\
\text { on the quality } \\
\text { of one's own } \\
\text { and others' } \\
\text { productions. }\end{array}$ & $\begin{array}{l}\text { Digital Zoo, a } \\
\text { game designed } \\
\text { for the devel- } \\
\text { opment of } \\
\text { students' engi- } \\
\text { neering epis- } \\
\text { temic frames. }\end{array}$ & $\begin{array}{l}\text { Youth shape } \\
\text { one another's } \\
\text { programs in } \\
\text { Computer } \\
\text { Clubhouses. }\end{array}$ & $\begin{array}{l}\text { DUSTY par- } \\
\text { ticipants develop } \\
\text { agentive capacity } \\
\text { in creating their } \\
\text { digital life stories. }\end{array}$ \\
\hline $\begin{array}{l}\text { Increasing the } \\
\text { range of social } \\
\text { resources and } \\
\text { networking to } \\
\text { achieve goals. }\end{array}$ & $\begin{array}{l}\text { Programming at } \\
\text { the 5th Dimen- } \\
\text { sion sites is sus- } \\
\text { tained through } \\
\text { partnerships } \\
\text { and the scaling } \\
\text { of practices. }\end{array}$ & $\begin{array}{l}\text { YouMedia par- } \\
\text { ticipants work } \\
\text { with peers to } \\
\text { create products } \\
\text { relevant to their } \\
\text { shared interests. }\end{array}$ & $\begin{array}{l}\text { WINS par- } \\
\text { ticipants in } \\
\text { a museum } \\
\text { program draw on } \\
\text { resources to help } \\
\text { support STEM } \\
\text { career paths. }\end{array}$ \\
\hline
\end{tabular}


activities. There was broad consensus across the three expert meetings on how to employ the terms elaborated below, but the report's authors assume responsibility for the specific formulations provided here. Some key terms in the individual project studies reviewed in this report will be used differently from how we use them. We will try to make this difference clear in each case while otherwise maintaining our own consistent usage of the following terms:

Learning Learning that matters is learning that lasts and that is mobilized across tasks and domains. Our notion of learning includes social-emotional-identity development as well as knowhow and know-who; it should also include learning by groups and communities or organizations as well as by individuals.

Knowledge Knowledge that matters is knowing how to take the next step, for which declarative knowledge is merely one subsidiary component and greatly overemphasized in current assessment. Know-that matters only insofar as it is mobilized as part of know-how; know-how (cultural capital) matters for career futures and social policy only when effectively combined with know-who (social capital). The social networking aspects of relevant knowledge are underemphasized in current assessment.

Know-how and other aspects of knowledge have to be defined for groups and communities as well as for individuals. Groups and communities always know more, collectively, than any individual member knows, and collective intelligence and problem-solving skills, creativity, and innovation are also generally superior to what individuals are capable of.

Assessment The production of knowledge useful for individuals, groups, and communities to improve practices toward valued goals; distinguished from evaluation. 
Evaluation Judgments made on how well goals are being achieved and how valuable the totality of all the outcomes is.

Research The production of knowledge useful for the design of activities and communities capable of reaching stated goals and with enhanced potential for producing valuable outcomes beyond stated goals.

Documentation The collection of information useful for assessment, evaluation, and/or research.

Assessment, evaluation and research all build on documentation but may require different modes and foci of documentation. In more traditional terms, assessment aims at locating outcomes, evaluation aims at judgments about effectiveness and directions for improvement, and research aims at generalizable knowledge that may be used for future design.

Engagement Affective involvement in and commitment to an activity, goal, practice, group, or community that enhances the quality and quantity of participation despite obstacles, setbacks, or frustrations; distinguished from enjoyment.

Enjoyment The positive feeling accompanying an activity that makes it worth doing for its own sake. Both engagement and enjoyment are important aspects of learning and should be documented in assessment, although it should be recognized that negative feelings may also play a significant role in engagement and in learning.

Agency This term has several different meanings: actual effectiveness; a disposition toward taking action; a feeling of selfefficacy; and an aspect of one's identity as someone who can produced desired effects. All these meanings are task- and/ or role- and domain-specific, and also often group- or community-specific. The notion of agency also extends to what a 
group or community believes it can accomplish or can actually accomplish.

Outcome Conventionally, an (occasionally naïve) attribution of a valued condition to some specific cause (e.g., to an intervention). Rarely, however, are valued learning goals the outcome of discrete, identifiable causes. Moreover, posited outcomes observed at some moment in time or over a short interval do not necessarily persist or serve as a foundation for further development. They are frequently transitory phenomena, artificially produced by the procedure used to measure them. We will instead use the term outcome to refer to socially and personally valued ongoing processes that emerge in the milieu of some community and its activities. Note that we regard evidence of learning in progress as equally important as evidence of completed or stabilized learning.

Unit of analysis What should be the unit in focus in assessment design? We believe that it should be a system of activities and practices over time; these include the actions of individual learners as well as the roles of other participants, such as mediating tools, semiotic media, and local conditions directly relevant to and supportive of (or obstructing) the learning activities. The unit of analysis must be extended peripherally to wider contexts that make the learning activity possible institutionally, but with decreasing detail as their relevance to the specifics of learning trajectories decreases. Assessment at the level of individuals, groups, and whole projects are necessarily interdependent, and assessment design must include all three and their relations to one another. 



\section{Review of the Literature}

This section provides a detailed review of selected studies and projects in several domains of informal learning.

What is meant in this report by informal learning builds on a fundamental assumption: Learning in its broadest sense takes place in every activity of life insofar as what we do at a later time benefits from earlier experience. Informal learning is, more specifically, learning as an outcome of participation in organized activity that is characterized by its more voluntary, interest- and enjoyment-based, and open-ended nature compared to formal instruction.

This definition still leaves the potential scope of informal learning too broad for the purposes of this report. Within such a scope, we would have to include domains such as organized sports activities, learning in practical activities in the home, and leisure activities developed by organizations such as the Boy Scouts-all of which we exclude. The domains that are included in this research review are the following:

- Learning in after-school programs and community centers

- Short-term, focused, out-of-school activities 
- Activities in informal learning institutions (e.g., museums, aquariums, and zoos)

- Computer-based and online activities

For each domain or type of setting, this review looks at exemplary studies and projects, identifying particular approaches to assessment, methods of documentation, and techniques of analysis. The types of learning outcomes investigated by the original authors and the levels (individual, group, and organizational) referenced by them are identified. After the review, we include summaries of the discussions in the three expert meetings. Further details on the expert meetings and other resources identified during the project are available on the project wiki at http:// documentinglearningworkshop.wikispaces.com.

\section{After-School and Community Centers}

In this section, we discuss examples of after-school programs run in a variety of locations and with a variety of educational objectives.

A common source of social and scientific interest in educational programs conducted during nonschool hours arises specifically because the learning activities are not occurring in school. Although they vary greatly, the community-based programs described in this section all seek to leverage the fact that after-school settings are more flexible in schedule and social arrangement, allowing children the freedom to engage in peer interaction and less hierarchically codified interactions with adults. Because the activities take place between the home and the school, at a time of day that-since the advent of modern schooling-has given play a privileged position, the settings are places where having fun is an essential ingredient and where, to some extent, children participate voluntarily. 
This shared circumstance offers both the greatest promise and the greatest challenges to realizing the hope placed on afterschool activities for infusing meaningful learning into the lives of children. On the positive side, the organization of after-school settings is centered on activities that children and youth will want to engage in voluntarily; if you build it and it's unattractive, the kids might not come. One particular draw is that afterschool programs generally allow children and youth to work in groups with their peers and to choose the roles that they play in the various projects that are offered. Indeed, children and youth often have a voice in the projects that are offered or are allowed to walk away from those they find boring.

In this kind of social environment, children are free to speak with one another, often using the language they feel most comfortable speaking, and the staff members (who vary in age from their late teens to middle age) are freed of the obligation to know all the right answers; this allows them to position themselves in the roles of coaches and more experienced peers. As a result, participation is also a learning experience for the adult staff, including older youth.

Unfortunately, many of the characteristics that offer the greatest potential for after-school activities to promote learning are the same characteristics that offer the greatest challenges for using after-school settings to provide the kind of educational experiences for which they appear to be perfectly suited. For instance, because after-school activities are not part of the formal school system and children are not legally bound to attend, the funding sources to support such settings are scarce and uncertain; so too is the consistency of attendance by the schoolage population such settings are designed to serve. For the same reason, few staff members earn a living wage from this work, which leads to a high rate of staff turnover and a low level of 
education among the staff members with whom children and youth are in close contact.

These "structural" factors (Bevan and Michalchik 2012) go hand in glove with the promising social-organizational characteristics of after-school activities summarized above. If a learner's project is unfinished, it might not be taken up again in a later session, which creates difficulties for programs with goals, such as promoting science engagement. Projects often do remain unfinished, sometimes even unstarted, as children, restless after a long day of sitting in enforced quiet in school, are freed up to have fun in ways that have nothing to do with preplanned activities.

For our present purposes, a major challenge of informal, voluntary, peer-oriented, group-organized, after-school programs is that they are difficult to evaluate. Although evidence-based assessment has merely meant randomized trial research designs, as federal regulations have often been interpreted in evaluating formal education, the voluntary nature of informal learning activities precludes random assignment and makes the persistence of learners in a trial unreliable. Participants come and go, appear for some sessions but not all, change activity groups as their friendship networks evolve, and leave the activity if their participation is too controlled. Standardized assessments, moreover, are based on the assumption that the valued outcomes of an activity can be known in advance, whereas experience with informal learning programs shows that some of their most valued outcomes emerge unexpectedly.

Each of the programs reviewed here provides useful suggestions for ways to assess informal learning activities. A key lesson they teach is that one size does not fit all. As in the programs themselves, a variety of assessment strategies are the rule, not 
the exception (e.g., Bell et al. 2009; Bransford, Brown, and Cocking 2000; Harvard Family Research Project 2008; Mahoney, Larson, and Eccles, 2005; Michalchik and Gallagher 2010; Shaffer and Gee 2012).

We have chosen to focus on several programs that have achieved sufficient scale to provide a foundation for reaching conclusions that are potentially generalizable across a reasonable range of variation. These programs share the following characteristics:

- A focus on leveraging new technologies for learning after school

- A university-community partnership model for after-school learning and research

- The use of field notes, interviews, video analysis, and other site-specific evidence of learning and development

\section{The 5th Dimension: A Broad-Based Enrichment Program}

Levels of Analysis Individual, group, project

Valued Outcomes Improved literacy and numeracy, agentive participation, long-term sustainability

Methods Cognitive-ethnographic field notes of adult (including college student) participants, videography, quantitative data collected as part of normal practices

The 5th Dimension is an educational activity system that offers school-age children a specially designed environment in which to explore a variety of off-the-shelf computer games and gamelike educational activities during after-school hours. (The account here draws heavily on Cole and the Distributed Literacy Consortium 2006.) 
The 5th Dimension involves the participation of undergraduates enrolled in a practicum course and elementary school-age children in a community setting. Such settings are organized so that adults provide for the involvement of children in presumably prosocial, development-enhancing activities in nonschool hours in spaces that can house such activities (e.g., Boys and Girls Clubs, YMCAs and YWCAs, local libraries, and after-school programs in a school, church, or community center).

The 5th Dimension was modeled loosely on the idea of the game Dungeons and Dragons. The conceptual layout of the 5th Dimension includes a labyrinth that contains a variety of computer and noncomputer games that are part of a make-believe world. The 5th Dimension's materials and conventions are organized to achieve the kinds of objectives enumerated above. By intertwining fun and academic motivations, the activities promote children's engagement in reading and writing.

At the same time, this play world is designed to help participants (both children and undergraduate students) orient to the game's attractions and challenges, to form goals, and to chart progress toward becoming an expert. Other features are designed to provide motivation to write to someone, to look up information in an encyclopedia, to teach someone else what one has learned, and to reflect upon and criticize information.

As a means of balancing play and work, 5th Dimension sites often have an electronic entity (a wizard or wizardess) who lives on the Internet and writes to (and sometimes chats with) the children and undergraduates online. In the mythology of the 5th Dimension, the wizard(ess) acts as the participants' patron, provider of games, mediator of disputes, and source of computer glitches and other misfortunes. 
Because it is located in a community institution, 5th Dimension requires a local site coordinator who greets the participants as they arrive and supervises the flow of activity in the room. The site coordinator is trained to recognize and support the pedagogical ideals and curricular practices that mark the 5th Dimension as different-that is, a different way for kids to use computers, a different way of playing with other children, and a different way for adults to interact with children.

The presence of university students is a major draw for the children. The participating college students are enrolled in a course focused on fieldwork in a community setting where they act as buddies for the children. It is in these cross-generational collaborative activities, organized around solving puzzles and playing games, that the socioemotional aspects of the children's behavior are most clearly visible.

As a result of the wide range of institutional settings in which 5th Dimension has been implemented, an equally wide range of assessment strategies has been used (see Cole and the Distributed Learning Consortium 2006). Some of these strategies have involved a focus on outcomes of learning, whereas others focus on evidence of learning in process. Some focus on individual children, some on the success of the activity within its community setting (judged by children's attendance and levels of enthusiasm), and some on the degree of support and participation by the cooperating institutions. The particular mixture of methods crucially depends, as does the activity itself, on its context.

The outcomes-based assessments focused on individuals are most likely to be useful in situations where the local social ecology permits random assignment of children to participation in the 5 th Dimension. In such cases external criteria (i.e., statewide achievement tests provided by the schools as well as various 
tailored pre- or post-test tasks given as a condition for participation) have been implemented. In situations where no proper control group can be included but where there are more children who desire to participate than the facility can handle, various quasi-experimental tasks using 5th Dimension activities have been implemented.

Evaluations at this individual-focused level have included the following (Cole and the Distributed Learning Consortium 2006):

1. Computer literacy Paper-and-pencil computer knowledge tests, evaluation of memory for computer terminology, and hands-on computer-use proficiency merit badges.

2. Mathematical understanding and mathematical problem solving Understanding arithmetic word problems isomorphic to those in the computer games, and using math problem-solving strategies in the games themselves as evidenced by field notes.

3. Reading and linguistic skills Reading comprehension of instructions in novel games, notes read from and written to the wizard, live written chats with the Wizard, and success in a variety of record-keeping practices.

Since it is impractical to create control or comparison groups for group-level outcomes, researchers have used in situ, processfocused evidence of children taking greater control of the conduct of the activities; longitudinal studies of children's progress from beginner to excellent levels of performance within games; and data mining of large samples of field notes to reveal the frequency and sophistication of academic skills, such as reading, and of social skills, such as helping others.

The criteria for assessment of success at the level of the activities within cooperating institutions include whether supervisory personnel who are supported by the community organization 
participate in the activities at their site, and whether the university supports continuing practicum classes that supply supervised undergraduates as more capable peers or as buddies to work and play with the children and write detailed field notes. To attain the long-term goal of a sustainable new cultural practice, the cooperation of the implementing institutions in obtaining the additional funding required for the transaction costs of the collaboration provides a strict criterion for this objective.

For dozens of 5th Dimension programs, mixtures of appropriate evaluations of the kind sketched above have shown that the programs are effective at the individual level. Children like the activities and participate; they are generally agentive, argumentative, and engaged in observable and documentable ways. In many, but not all, of the social contexts in which the innovation has been tried, adults approve of the activities and make their children available. College students show marked improvement in understanding how to be effective supporters of children's and their own learning. At the group level, there is evidence of improved group collaboration and task success (Cole and Distributed Literacy Consortium 2006; Downing-Wilson 2006/2007).

One of the instructive features of the 5th Dimension project is the extent to which it has afforded assessment of learning at the level of the program as a whole in its socioecological contexts. No 5th Dimension program is a static, unchanging system of activity; instead, each changes in relation to itself and its institutional settings, which are themselves changing. For example, at one implementation of the 5th Dimension at a Boys and Girls Club over a 16-year period (Downing-Wilson et al. 2012), the careful documentation process reveals a dynamically changing relation between the 5 th Dimension itself and its host institution. Initially, the 5th Dimension is more or less self-contained 
in an accessible room. Then, over time, in response to changes in club policies and resources, the practices of the 5th Dimension gradually start to infuse all areas of club activity, engaging a wider range of children, involving club personnel more deeply in the program, and enlarging the role of the 5th Dimension in its setting.

Other 5th Dimension programs show different patterns of learning at the project and organizational level as they adapt to rapid changes in computer technology, turnover in personnel, changing funding streams from a variety of sources, and changing priorities of the collaborating institutions. It is no surprise that there are failures as well as successes in adapting. Many 5th Dimension projects run successfully for two, three, or more years, only to fall apart because of changes in institutional priorities or the departure of key personnel. Others manage to adapt to the changed conditions and have continued for many more years. At the time of this writing, some such systems have been in existence for more than 15 years, permitting analysis of the institutional and social-ecological conditions for sustainability.

\section{The Computer Clubhouse Network: Learning to Program}

Levels of Analysis Individual, group, project

Valued Outcomes Collaboration, quality of products, social resources

Methods Case study, Oakes's model of school reform, portfolios of activities

The Computer Clubhouse Network is another after-school program similar in organization and goals to the 5th Dimension program. Started in 1993 through a collaboration between MIT's Media Lab and Boston's Computer Museum, the network 
currently consists of more than 100 after-school learning centers dedicated to providing primarily high-end digital media instruction to help elementary school-age children through high school-age youth develop the expertise to express themselves fluently through new technologies (Resnick, Rusk, and Cooke 1998). To create and sustain an environment in which this communicative fluency is developed, Computer Clubhouses are designed to cultivate an "emergent community" that promotes opportunities for youth to engage in design projects that are driven by their own interests (Kafai, Peppler, and Chapman 2009).

Of the several innovative and technology-centered learning activities that have been developed and field-tested in Computer Clubhouses, the Scratch programming activity has generated particular attention. ${ }^{1}$ Scratch is a programming environment designed to help novices learn programming through easy desktop manipulation of digital images and sound files. Rather than type code, learners program by dragging and dropping blocks of preset programming commands in a jigsaw puzzle-like fashion, creating stacks of blocks. The commands control the actions of movable spritelike figures, each of which contains its own set of images, sounds, variables, and scripts (see figure 1 for an image of the Scratch interface).

Kafai, Peppler, and Chiu (2007) examined the organization of activities at a Computer Clubhouse before and after the introduction of Scratch as one of the activities in order to understand how after-school learning environments might be seeded with a computer-programming activity. Kafai and her colleagues drew on the model of school reform offered by Oakes (1992). According to Oakes, efforts to reform educational activities in a manner that ensures they are equitable must go beyond the technical aspects of implementing these activities. It is also necessary to 
(a)

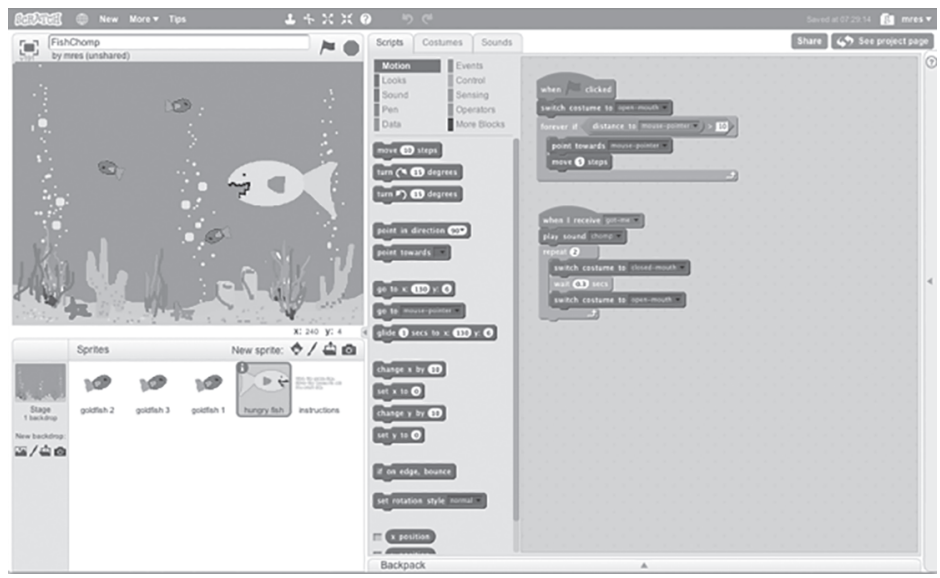

(b)

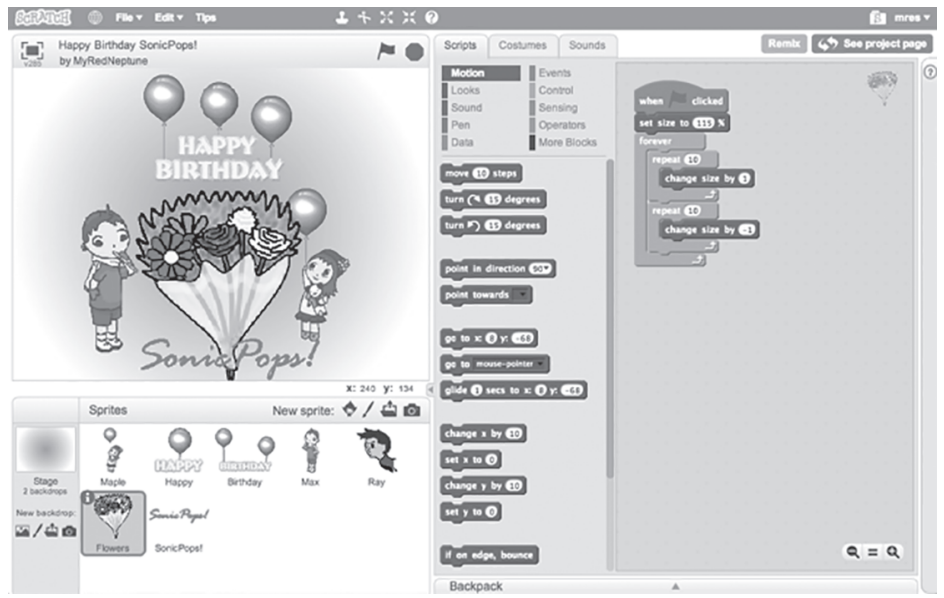

Figure 1

Screen captures of the Scratch program interface. Images courtesy of Mitchel Resnick. 
encourage changes in the normative and political dimensions of each activity - that is, its longstanding norms, values, and institutional support within the larger community.

Kafai et al. (2007) documented and analyzed the organization of activities at two Computer Clubhouse sites in Southern California. At the technical level, the researchers were interested in observing how, and to what degree, Scratch would be adopted as an activity, given specific conditions of implementation. These conditions included the incorporation of new activities like workshops and gallery presentations and the participation of undergraduates who acted as mentors but who knew little to nothing about programming. Parallel to the principles of the 5th Dimension model, the inclusion of inexperienced programmers as mentors was seen as contributing to the occasioning of opportunities for mentees to teach the novice mentors about programming in Scratch.

Normatively, the focus was on how participants (including youth, mentors, and parents) interpreted the meaning and value of computer programming (e.g., what participants considered prototypical programming projects) and how they interpreted the value of their own programming abilities. In the political dimension of the analysis, Kafai et al. (2007) reported the way in which a formal partnership developed between the university and the Computer Clubhouse's host organization. These changes were crucial, the researchers noted, in gaining the necessary support to create the infrastructure for the Computer Clubhouse's goal of achieving technological fluency.

The primary documentation data at the individual and group levels were researcher and mentor-produced field notes and sample products of participants' efforts. To address technical and normative questions about how Scratch was incorporated 
in the clubhouse and the role of the mentors in this process, the field notes were coded for different kinds of activities: design, Web, and personal (e.g., socializing). The resulting products at the clubhouse, consisting of projects of all kinds (including Scratch programs), were analyzed based on project type, such as animation, game, story, and graphics (Kafai et al. 2006). In addition, group interviews of clubhouse members and undergraduate mentors were conducted in order to capture how the young participants understood the development of their own programming skills.

From the analysis of field notes, projects, and interviews, portfolios of activities were generated to show changes in the kind and number of activities the youth engaged in before and after the introduction of Scratch. The identification of periods of increased production guided more focused analyses of the kind and distribution of projects. These steps, in turn, allowed Kafai et al. (2006) to identify and conduct case studies of Computer Clubhouse members who created projects, the structure and content of which appeared to influence the production of Scratch projects by other clubhouse members. (When we consider computer programming as an activity in itself in a later section of this review, we will return to examine how researchers also tracked the quantity and distribution of programming commands in Scratch projects throughout a particular period).

\section{Digital Storytelling and Media Production Programs}

In this section we examine two projects that seek to create environments in which youth gain exposure to new, academically relevant activities and technologies in ways that encourage the incorporation of the learners' interests. Both examples focus on 
assessing learning through careful examination of the process and products of youth efforts to produce digital media.

The first case, a digital storytelling after-school program, illustrates ways in which extensive ethnographic data, including participant-produced media, can be analyzed for insights into the development and enactment of the learner's authorial agency. The second case is an example of how data visualizations can be used to assess learning in participants' uses of online social media platforms in a technology-driven after-school program.

\section{The Digital Underground Story Telling Youth Project}

Levels of Analysis Individual, learning ecologies

Valued Outcomes Independent inquiry, collaboration, social resources, identity formation

Methods Case study, thematic analysis, narrative analysis, performative moments

The Digital Underground Story Telling Youth (DUSTY) project is an adult and youth multimedia literacy program run out of a community technology center located in the Bay Area of California. DUSTY differs from traditional, academically oriented after-school programs in its emphasis on the centrality of identity formation and meaning making in learning, particularly the role that semiotic systems in addition to language play as resources for "embodying and enacting a sense of self in relation to others" (Hull and James 2007). To this end, the creation of digital stories at DUSTY is aimed at positioning participants to use narrative reconstruction to reflect on their experiences and to be active agents in articulating their own aspirations.

This agency- and identity-centered framework for theorizing and assessing learning is described in detail by Hull and Katz 
(2006). The authors emphasize the importance of the various social contexts of learning (e.g., the DUSTY program, the school) and their contributions to a learner's digital story production. They argue that people can use their personal repertoire of tools and other resources to develop agency by creating "multimedia autobiographical narratives about self, family, community, and society ... to articulate pivotal moments in their lives and to assume agentive stances toward their present identities, circumstances and future" (44).

Hull and Katz (2006) report longitudinal case studies of youth participants using the following as documentation: field notes of participant activities in multiple settings, written by researchers and undergraduate mentors; interview data to characterize participant histories inside and outside DUSTY; and participantproduced media such as story boards, scripts, and digital stories.

To demonstrate how two such participants developed authorial agency through their creation of digital stories, Hull and Katz (2006) drew on a variety of concepts, originally proposed by scholars such as Bruner (1994), Urciuoli (1995), and Bauman and Briggs (1990), to identify displays of agency both in these youths' actions (captured through field notes and interview transcripts) and in their digital stories. They employed Bruner's idea of narrative turning points, when people "report sharp change in their lives and demonstrate accompanying dramatic changes in their representations of self" (Hull and Katz 2006, 45). From Urciuoli they adopted the idea of performative moments, which include "any activity that coordinates action to create a unity from many selves" (47). From Bauman and Briggs they adopted an agent-centered view of verbal performance, in which agency is exercised by a person through the decontextualization and recontextualization of verbal texts, and applied it to the multiple modalities of digital stories (see figure 2). 


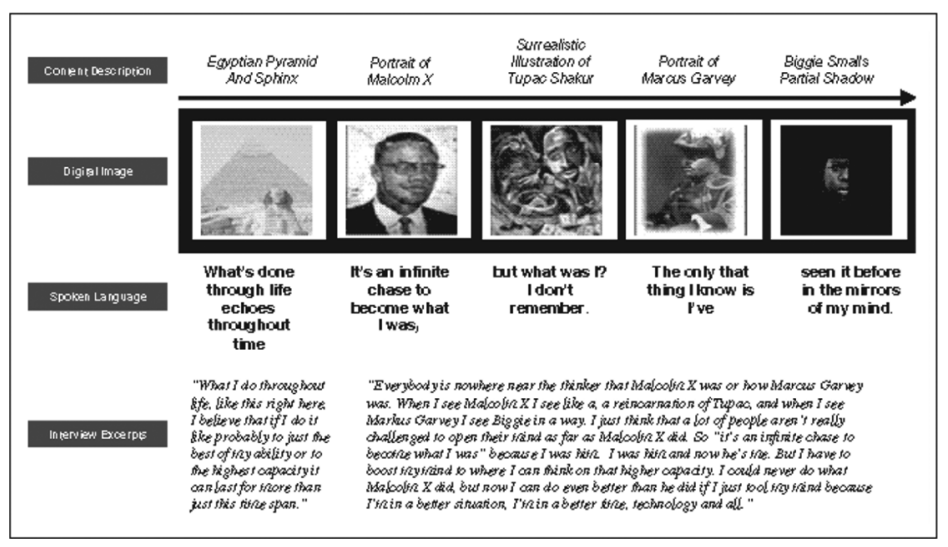

Figure 2

Excerpt of a graphic representation of a digital story by a participant named Randy. The representation was used as a tool to identify and analyze patterns relevant to the focus of analysis in Randy's case, authorial agency. The representation juxtaposes screen shots from the digital story, text of the corresponding voice-over, and excerpts of relevant comments from interviews. From Hull and Katz (2006), page 51. (C) 2014 by the National Council of Teachers of English. Reprinted with permission.

The case study subjects not only mastered the technical skills required to create digital stories, they also became more sensitive to the genres and poetic aspects of language, and they grew increasingly adept at combining multiple media (text, sound, and images) to create personally relevant narratives.

\section{YouMedia and iRemix: Data Visualizations in Online Networks}

Levels of Analysis Individual, group

Valued Outcomes Independent inquiry, collaboration, quality of products 
Methods Social learning network analysis, timeline structures for data visualizations

YouMedia is another example of a program dedicated to providing youth with the space, resources, and semistructured opportunities to use high-end digital media to explore new modes of self-expression. Housed in a centrally located urban library, YouMedia is a collaborative project of the Chicago Public Library and the Digital Youth Network, a Chicago-based digital literacy project that provides linked in-school and after-school media classes (http://www.digitalyouthnetwork.org). At YouMedia, teens from all parts of Chicago have access to a rich array of technological and social resources, including laptops, smart boards, video cameras, and an audio recording studio.

Based on similar theoretical principles as DUSTY (described above), the activities at YouMedia are organized to encourage teens to identify topics of interest and to explore telling stories about these topics through multiple media. Mentors from the Digital Youth Network visit YouMedia to share their media production expertise with the teens, who work on digital activities in music, design, photography, blogging, and video production.

Teens who wish to participate in YouMedia activities must register as members. As part of this process, the teens are invited to join a cloud-based, online social network, YouMedia Online, restricted to and accessible only by YouMedia members. ${ }^{2}$ Users of YouMedia Online can do things that are common on social networking sites, such as managing their profile pages, posting comments and media, and joining groups.

However, YouMedia Online differs from other social networking sites by being designed to support both structured and self-directed learning in ways that connect to the culture and expectations of the YouMedia community (Austin et al. 
2011). For example, one of the ways that learning is promoted is through the use of a virtual currency called Remix dollars. These dollars are awarded for, among other things, posting original content and providing feedback to others by posting comments on their projects. This currency can then be redeemed for such items as gift cards, USB drives, and MP3 players.

As a repository of vast amounts of information about the teens' YouMedia-related activities, the iRemix platform offers a rich source of data for exploring questions about learning and the development of expertise, interests, and social capital. Nichole Pinkard, who founded the Digital Youth Network, and her colleagues have taken the first steps in exploring the mechanics, ethics, and potential insights of mining data from social learning networks like the iRemix platform (Nacu et al. 2012). They have examined ways of adapting and applying to the iRemix platform the tools, metrics, and analytic frameworks typically used in the private sector for studying the use of online social networks.

The questions that drive Pinkard and her colleagues research center on the ways youth participate in the environment and interact with others, with particular attention on the way these interactions lead to learning. Both peers and mentors play a role in online learning interactions. Pinkard and colleagues have also tracked the relationship between actions such as media viewing or user profiles and subsequent production-oriented actions such as posting comments, critiques, media ratings, and original work. In addition, they have identified features of social learning networks that can be studied to address questions about the kinds of learning that unfold for users of these networks (see table 3).

In order to make sense of the large amount of documentation generated from logs of iRemix activity, Nacu et al. (2012) 


\section{Table 3}

Features of Online Social Learning Networks and Their Corresponding Forms of Data

\begin{tabular}{|c|c|c|c|}
\hline Participation & Consumption & Contribution & Production \\
\hline $\begin{array}{l}\text { Access and } \\
\text { membership }\end{array}$ & $\begin{array}{l}\text { Views of specific } \\
\text { items }\end{array}$ & $\begin{array}{l}\text { Content posted } \\
\text { to the network }\end{array}$ & $\begin{array}{l}\text { Posting of origi- } \\
\text { nal media }\end{array}$ \\
\hline Impact & Relationships & Expertise & Interests \\
\hline $\begin{array}{l}\text { Evidence of } \\
\text { impact by } \\
\text { individuals }\end{array}$ & $\begin{array}{l}\text { Social ties, } \\
\text { interactions, } \\
\text { and group } \\
\text { affiliations }\end{array}$ & $\begin{array}{l}\text { Evidence of skill } \\
\text { development }\end{array}$ & $\begin{array}{l}\text { Emergence and } \\
\text { development of } \\
\text { interests }\end{array}$ \\
\hline
\end{tabular}

Source: Nacu et. al. (2012)

developed operational definitions of actions and concepts they deemed relevant for addressing their research questions (see table 4). Using these definitions as tools for coding the data, they experimented with a number of techniques to visualize the results.

For example, to explore questions concerning the role that peer-peer and peer-mentor relationships play in facilitating learning, social network maps were generated to chart these relationships and their strengths at specific points in the history of the program and over time. Another technique creates timeline structures that show the kinds of activities individual participants have engaged in over extended periods and also how often and for what amount of time they have been involved. ${ }^{3}$

Figure 3 shows an example of a timeline structure for a Digital Youth Network participant's online activities during her junior and senior years in high school. The timeline covers a period of 18 months and is divided into three rows. The top row identifies the projects and workshops that the student participated in, with indications of the beginning and end of her participation. The middle row specifies activities (named on the far left) that 


\section{Table 4}

Definitions of Actions and Concepts Determined Relevant for Research Questions

\begin{tabular}{|c|c|}
\hline Social Learning Network Features & Kinds of Data \\
\hline $\begin{array}{l}\text { Structures to support informal } \\
\text { and formal interaction among } \\
\text { users }\end{array}$ & Social ties \\
\hline $\begin{array}{l}\text { Access to teachers, mentors, and } \\
\text { experts }\end{array}$ & $\begin{array}{l}\text { Interaction patterns among peers, } \\
\text { teachers, and mentors }\end{array}$ \\
\hline $\begin{array}{l}\text { Asynchronous, online } \\
\text { communication }\end{array}$ & Access and participation patterns \\
\hline $\begin{array}{l}\text { Creation, sharing, and discussion } \\
\text { of multimedia content }\end{array}$ & $\begin{array}{l}\text { Engagement with } \\
\text { content;connecting use patterns } \\
\text { with patterns of learning and } \\
\text { development }\end{array}$ \\
\hline $\begin{array}{l}\text { Ability to structure learning activi- } \\
\text { ties and projects }\end{array}$ & $\begin{array}{l}\text { Engagement and impact of specific } \\
\text { learning resources }\end{array}$ \\
\hline
\end{tabular}

Source: Nacu et al. (2012)

the student engaged in and that could be extrapolated from the students' activity on the iRemix platform (e.g., editing, uploading and commenting on videos and photos, posting blog entries, joining groups), with the size of the circle indicating the number of digital products uploaded. The bottom row describes badges that could potentially be awarded to the student for engaging in activities in a manner deemed successful or valuable by the local community.

\section{STEM-Focused Community-Based Programs}

The projects discussed in this section differ from those above by having been designed with specific content-area learning goals. 


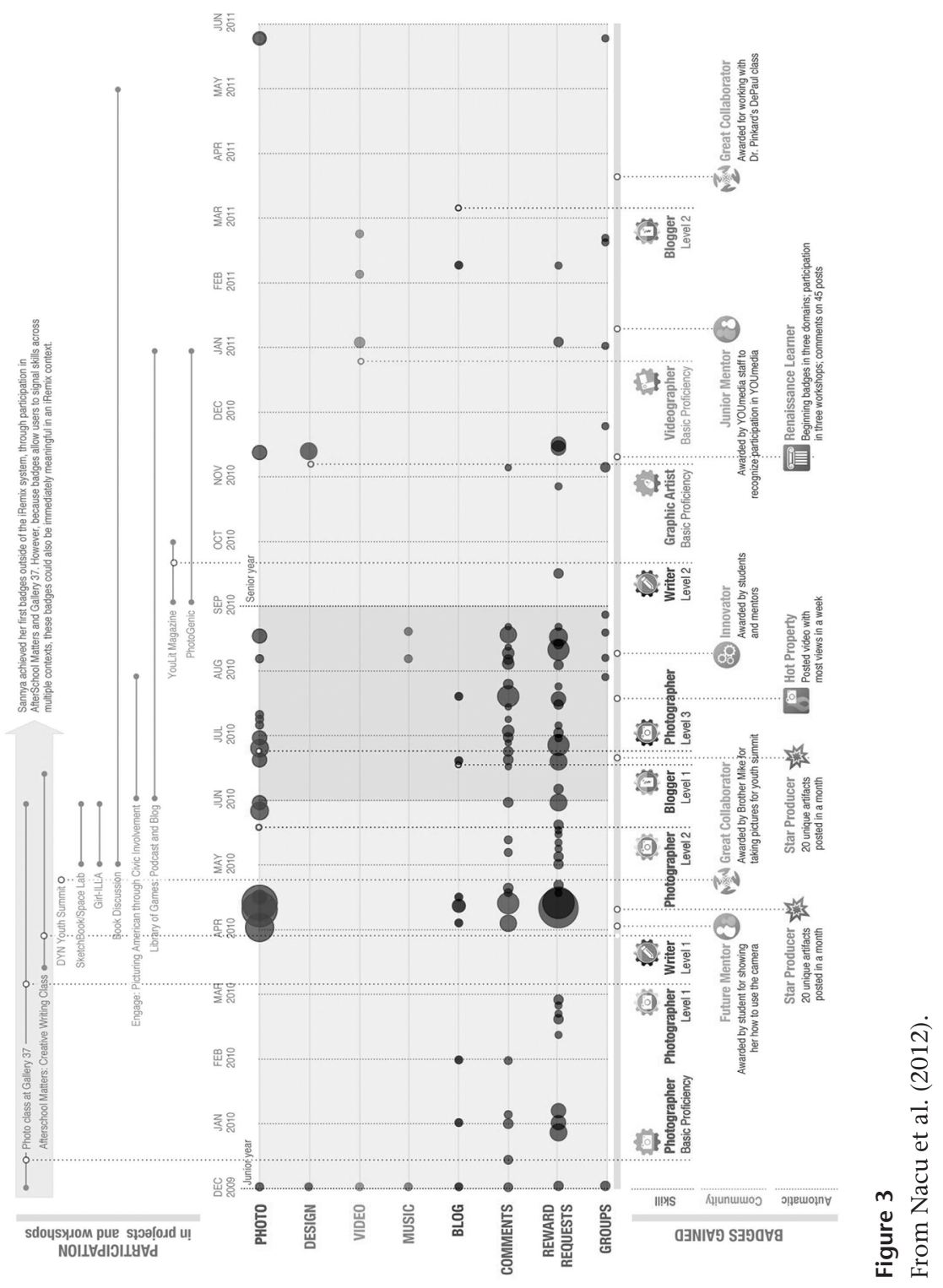


In each case, the content area was in the domain of science, technology, engineering, mathematics (STEM), or computer science.

\section{City Farmers: Emergent Learning in a Community Garden Program}

Level of Analysis Individual

Valued Outcomes Independent inquiry, social resources

Methods Case study, semantic domain analysis, discourse analysis

Rahm (2002) conducted an ethnographic study of an eightweek summer community youth program designed to teach plant science and entrepreneurship and develop the participants' teamwork skills. Based at a community garden site in an ethnically diverse, low-income, inner-city neighborhood, the program was structured so that participants rotated through two-week cycles in four kinds of activities: nurturing (soil preparation, planting, and watering), harvesting (identification, harvesting, and preparation of harvestable crops), marketing (contacting potential buyers, selling, and organizing delivery), and special projects (community outreach, artwork, and tree planting).

The aim of the study was to examine how opportunities to learn science emerged in the everyday interactions among the program participants. To this end, Rahm focused her research on the language and discursive practices that the participants used to make sense of program-related activities. The participants included the middle school students enrolled in the program as well as the adult members of the program including four team leaders, two Master Gardeners, and the program director.

As a participant-observer, Rahm simultaneously videotaped, kept field notes, and worked alongside a team of six 11- to 14-year-old participants as they engaged in the nurturing and harvesting activities. After the data collection phase, transcripts 
were made of the videos and integrated with the corresponding field notes. Rahm subjected these materials to domain analyses (Spradley 1980) in order to develop taxonomies of the kinds of learning opportunities supported by the program. These analyses revealed some of the discursive strategies that participants used to make meaning of the gardening activities (e.g., analogies, elaborations, questions, and comments). Rahm found that question strategies could be further subdivided into information questions, knowledge integration questions, and inquiry. In 95 percent of the cases studied, inquiry and knowledge integration questions were precursors to learning opportunities.

Rahm also explored the connections that the participants made between their experiences in the program and their experiences with science in school. She conducted pre- and post-experimental semistructured interviews of six participants whom she shadowed and of several other participants selected from the teams in the program. The interviews focused on the participants' notions of science and on their perspectives on learning science in the program and at school.

Post-experimental interviews were conducted with all of the adult program participants in order to document their perspectives on the learning that takes place in the program. The interview data revealed that both the youth and adult participants saw the activities of the program as providing authentic opportunities for learning science that were markedly different from those offered in the classroom.

\section{The Colorado Hybrid School-Community STEM Project}

Levels of Analysis Group, project

Valued Outcomes Independent inquiry, collaboration

Methods Design experiment, semantic domain analysis, vignette analysis 
Eisenhart and Edwards (2004) implemented and studied an after-school program designed to promote participation in computer technology and science activities by urban, African American, middle school girls. This university-community collaboration involved university researchers, representatives of community institutions, and local residents. The program also involved the iterative design and implementation of culturally sensitive science and technology-focused classes in the afterschool hours. Of the cases discussed thus far, this is the only one in which a deliberate effort was made to create a learning activity that met state curriculum content standards while also incorporating the participants' own goals and interests.

This research was organized to examine two issues: (1) the extent to which the participating girls' gender and ethnic identities were represented in the technology-driven activities of the program, and (2) the implications of this for understanding how to successfully engage the girls. The research asked these questions: What were particularly good examples of occasions when the girls seemed motivated to learn more science or technology? What did these occasions suggest about the conditions for successful work with the girls?

To address these issues, Eisenhart and Edwards (2004) followed a group of six African American girls (12 to 15 years old) for one academic year as they participated in science and technology activities in the after-school program. Documentation of these activities included researcher- and instructor-produced field notes and journals, audio and video transcripts of each session, audio transcripts of student interviews, the digital and concrete products (e.g., T-shirt designs) created by the students using the software provided to them, and computer logs of the students' activities with these software applications. 
To address the degree to which these girls' identities were reflected in the science and technology activities, Eisenhart and Edwards (2004) drew on Spradley's $(1979,1980)$ semantic domain analysis. The basic procedure involves identifying and coding semantic domains (participants' units of meaning) and constituents (the items that constitute the domains) through the application of nine universal semantic relationships to the data texts. Eisenhart and Edwards examined three domains that reveal how the girls marked gender identity, ethnic identity, and technological expertise: (1) statements and actions regarding interest in computers and technology, (2) actions regarding female identity, and (3) statements and actions regarding African American identity. By reviewing the contents of each domain and then examining the overlap between domains 1 and 2 and domains 1 and 3, the researchers obtained a general picture of how markers of sex and race intersect with activities involving technology.

Vignette analysis (Maxwell 1996) was used to investigate the question about occasions and related conditions in which the girls demonstrated a motivation to engage in science and technology learning. In vignette analysis, salient events that bear on the research question are excerpted from the data texts, simplified, related to one another, and retold in the form of short stories called vignettes. The objective is to develop a description of the context of the activity that links the data to a "coherent whole" (Van Maanen 1988).

The Eisenhart and Edwards (2004) analysis revealed the afterschool program to be a hybrid space between the formal space of the school classroom and the informal space of students' social lives outside school, in which participants are free to move outside the roles expected of them and participation can be more symmetrical (Gutiérrez, Rymes, and Larson 1995). This created 
opportunities for the girls to make connections between science and their own lives and values, connections that Eisenhart and Edwards found helped sustain the girls' engagement. They also found that the absence of such connections made it difficult for the girls to sustain engagement.

\section{Metacognition in an Amusement Park Physics Program}

Levels of Analysis Individual, group

Valued Outcomes Collaboration, independent inquiry

Methods Interpretive case study, semistructured interviews, pre- and post-experimental assessments

Anderson and Nashon (2007) studied an informal learning program that was organized to support school classroom work. The program took high school juniors and seniors who were enrolled in physics classes to an amusement park, where they were divided into teams to assess the kinematics of three rides using accelerometers, stopwatches, and protractors. This amusement park activity was combined with a classroom assignment in which the students, working in their original teams, were given prompts to encourage them to develop explanations, arguments, and models of the physics principles in the rides.

Grounded in an interpretive case study approach (Gallagher and Tobin 1991; Merriam 1998; State 1995), the study aimed to assess the students' metacognitive abilities (individually and as groups) and how these abilities influenced the development of the students' conceptual understanding of kinematics.

Although the authors describe metacognition and learning as idiosyncratic and dynamic processes, this research is centered on the psychological construct of metacognition, measured through a 53-item baseline questionnaire the researchers developed that 
allowed them to profile each student according to the constituent components of metacognition: awareness, control, evaluation, planning, monitoring, and self-efficacy. These baseline metacognitive levels became an important lens through which the researchers interpreted individual students' discursive interactions in subsequent activities, which in turn contributed to the validation of the baseline instrument.

After taking the baseline survey, the 11th and 12th graders in the study visited and conducted their experiments in small groups at the amusement park. During the visit, the research team developed field notes, video recordings of several smallgroup interactions, and individual audio recordings of conversations of the students participating in the in-depth case studies.

The case study students were given copies of their personal conversations and asked to listen to them in advance of group interviews about their metacognition and learning. These students participated in one group interview after the field trip, some in-class activities related to the physics explored on the field trip, and a second group interview after the in-class activities. Audio and video recordings were made of all these events.

In their analysis, Anderson and Nashon (2007) interpret students' discussions in learning activities and interviews through the lens of their particular metacognitive profiles. The researchers illustrate how these profiles interact with students' circumstances, dynamically influencing social processes within their small peer groups and concurrently influencing their individual and collective formation of physics concepts.

\section{Museum-Based Programs and Projects}

In this section we describe several museum-based, informal learning projects. Informal science institutions such as science 
and technology museums, aquariums, and zoos have long offered specific educational programs for children and youth as well as educationally oriented general exhibitions for the public of all ages. Research studies on learning in such institutions have focused on individual and group (especially family) learning and engagement with exhibits as well as learning in more specialized programs, including various youth-oriented ones in physical and online spaces (Herr-Stephenson et al. 2011). Because these settings do not especially afford opportunities for testing visitors' knowledge before and after, studies have often developed other means for assessing learning and other criteria for valued outcomes.

\section{GIVE: Facilitating Group Inquiry in Science Museums}

Levels of Analysis Individual, group, project

Valued Outcomes independent inquiry, collaboration

Methods Experimental design, video analysis

The GIVE (Group Inquiry by Visitors at Exhibits) research project was launched at the San Francisco Exploratorium, a leading informal science learning institution (Gutwill and Allen 2010). The project aimed to answer the following questions:

- Can intergenerational groups of museum visitors, such as families, be coached by the museum staff to learn a set of inquiry skills that they can use on their own at novel exhibits or even experiences beyond their visit?

- How does such an intervention affect visitors' inquiry behaviors at a novel exhibition? Does it support them to explore the exhibit more deeply?

- What properties of the staff-mediated intervention seem central to its design, and what is the evidence for them? 
To probe these questions, the GIVE team developed two inquiry games based on the following learning science-derived design principles: building on prior knowledge; teaching through modeling, scaffolding, and fading; identifying skills explicitly; supporting metacognition; supporting collaboration; making the activity intrinsically motivating; minimizing the cognitive load; supporting visitors' learning agendas; and supporting individual spontaneity. (The last four are specific to informal learning design.)

Because of constraints in the museum setting, the games the researchers developed targeted only the following two among the full range of inquiry skills:

- Proposing actions Asking a question or making a plan at the beginning of an investigation.

- Interpreting results Making observations, interpretations, or explanations during or after an investigation

The researchers chose these skills because they were simple enough to learn quickly and were not ones already commonly observed in museum visitors' behaviors. The researchers also viewed these two skills as possible gateways to other inquiry skills, such as questioning, predicting, analyzing, and explaining. Along with experimentation, an activity that visitors engage in spontaneously at interactive exhibits, proposing actions and interpreting results form a complete, if simplified, version of the inquiry cycle as it is typically presented in school curricula and characterized by science researchers.

After iteratively refining the games, the GIVE team conducted an experimental study comparing the two game conditions with two control conditions. They studied 50 families in each condition, for a total of 200 families, to determine whether the games 
promoted inquiry behavior at exhibits. Families in the treatment groups learned how to play the games with supports at two or more exhibits and then, as a post-test, were asked to use a final exhibit playing the game they had learned. Afterward, the research team conducted interviews with one adult and one child per family, selected at random. Researchers also collected demographic data on each participant.

The GIVE team video-recorded all families at their first and last exhibits and coded the participants' behavior according to the following codes: engagement, proposing actions, interpreting results, collaborative explanations, and coherent investigations. They also coded the data for the correctness of the science content. The results showed that the inquiry games succeeded in improving the participants' inquiry. The more structured and collaborative of the two games had the strongest effect, leading to longer engagements with the post-test exhibit, more abstract interpretations, and more collaborative and coherent inquiry investigations than controls. Based on their qualitative analyses, researchers attributed the greater success of this game to its inclusion of all family members in collaboration and its support of their explicit articulation of their interpretations of the exhibits.

\section{TOBTOT: Assessing Museum Learner Talk over Time}

Levels of Analysis Individual, group

Valued Outcomes Collaboration, independent inquiry

Methods Discourse analysis, thematic analysis

This study (Ash et al. 2007) was designed to explore dialoguebased methodological approaches, in particular the authors' Tool for Observing Biological Talk over Time (TOBTOT). The 
tool was used to analyze scientific sense making in biological talk in out-of-school settings and track the language people actually use in discussing life science themes over time.

The researchers' methodological concerns stem from several theoretical traditions, exemplified by the works of Lev Vygotsky, Michael Halliday, James Wertsch, Mikhail Bakhtin, Jay Lemke, and others that take a sociocultural view of conversation as both structured and dialogically emergent (Mahn and John-Steiner 2013; Wells and Claxton 2002). Their applications of the TOBTOT framework focused on testing ways to track thematic patterns in order to analyze, in both quantitative and qualitative terms, the development of scientific content in dialogic interaction. Ash et al. (2007) focus on the methodological tensions entailed by working along the dimensions that encompass content and process, everyday language and canonical scientific discourse, macro- and microlevels of analysis, and qualitative and quantitative representations of data.

During a three-year period, the research team audio- and video-recorded 20 Spanish-speaking and English-speaking family groups as they interacted for 20 to 80 minutes at exhibits in a marine biology center in northern California. The families were recruited from a local Head Start center, and each included at least one parent and two preschool- or elementary school-age children. The researchers also conducted interviews with family members after the data collection sessions at exhibits, asking for reflections on selected video clips of their naturalistic interactions as a member check.

The analytic tool used, the TOBTOT, consists of three superordinate thematic categories for coding dialogue related to biological phenomena: Staying Alive, Characterizing, and Ecological Interdependence. Staying Alive roughly corresponds to 
the concepts and discourse traditionally associated with the discipline of biology. Characterizing is the TOBTOT category for talk related to labeling or locating an animal. Ecological Interdependence categorizes talk thematically related to habitats, human impact, and, less typically for life-science disciplines, feelings and aesthetics (e.g., expressions of amazement or personal attraction to an organism).

On a macroanalytic level, TOBTOT's categorization scheme allowed the researchers to illustrate and provide graphic representations of how families discursively engage with abstract biological content differently from one another, as well as across exhibits and over time. The research team reported TOBTOTbased evidence that suggested several interesting findings and noted their implications.

First, the naturalistic family dialogue centered on Characterizing and Ecological Interdependence more than Staying Alive talk, emphasizing the importance in everyday talk-and science learning in informal settings - of becoming familiar with and feeling for living things.

Second, Characterizing and Ecological Interdependence tended to occur before Staying Alive talk at an exhibit, suggesting that "naming, using prior knowledge, and making personal connections must occur before the formal science can begin" (Ash et al. 2007, 1589).

Third, particular themes occurred as leitmotifs that changed over time, illustrating that "questions (e.g., about feeding) can permeate time and context, often acting as a central core of dialogic negotiation." Fourth, the touch tank generated the most family talk, prompted the researchers "to investigate the special role of living things as mediational means in dialogic activity" (Ash et al. 2007, 1591). 
Finally, the researchers also illustrated the ways in which the TOBTOT could be used to analyze and document differences between families in their patterns of discursive interaction at exhibits.

The TOBTOT proved useful in helping researchers demonstrate science content in everyday language, largely because it accommodates talk in the Characterizing and Ecological Interdependence categories. Ash et al. (2007) point out that "the general observations these families made were predicated on scientific principles" that are part of "cultural scripts based upon common scientific understandings" (1594).

However, they also note the difficulties they had in determining whether some instances of everyday talk were scientific or not. They further noted that although their data indicated that the "families used multiple resources to talk and act in new ways, and the use of these resources were dynamic, social, and discontinuous, not linear, direct or clear" (Ash et al. 2007, 1595), the TOBTOT was not able to capture the nuances of the families' dialogic interactions and the scientific insights they supported.

The authors also reported that the use of the TOBTOT did not resolve tensions related to particularistic treatment of conversational data or readily facilitate conversational segmenting. Therefore, the research team struggled with traditional standards of reliability and the quantitative representation of qualitative data.

The researchers conclude that the TOBTOT is a powerful tool for creating abstract interpretations and representations of actual lived experience in order to answer relatively simple questions. The TOBTOT did not help answer the hardest questions, especially regarding the cultural resources people use to make sense of and attach value to natural phenomena in their world. 
The Zydeco Tool: Inquiry in Museums and Classrooms

Levels of Analysis Individual, group

Outcomes Independent inquiry, collaboration

Methods Analysis of computer system logs, ethnographic field notes, interviews

Chris Quintana and his colleagues (2010) at the University of Michigan's Center for Highly Interactive Classrooms, Curricula, and Computing in Education have developed projects that combine tools and corresponding curricula for helping students engage in scientific inquiry in activities that combine museum and classroom activities.

The Zydeco project is one example of this work. It consists of three components: (1) a Web site where students develop and access study questions, hypotheses, and data, (2) a data collection and annotation component implemented as an iPhone or iPod app, and (3) an explanation component implemented as an iPad app to support students' visualization and use of the data they collected for constructing explanations relevant to the phenomena they are collaboratively exploring (Kuhn et al. 2012). The system was designed for what has been termed nomadic inquiry: structured inquiry across a variety of settings, including classrooms, museums, the outdoors, and in homes (Hsi 2003). The Zydeco system is designed to help learners easily transition from one setting to the next, including transitions between virtual (handheld devices) and physical (e.g., museum exhibits) contexts.

Kuhn et al. (2012) examined the role that annotations played in how students searched and evaluated data and how students identify and select the evidence that they use in their explanations. They followed a group of middle school students, grouped 
into pairs, who used the Zydeco system to collect data at a natural history museum for use in a classroom-based project. This project involved the students using the explanation construction component to examine their data along with all the data collected by other students during the museum visit, and using it to formulate their own explanations. Kuhn et al. found that the annotations made by the students did support inquiry activities, including data interpretation, identification, and search.

The documentary and assessment methods used for this study were a combination of interview data, field notes, and usage logs taken from the Zydeco system. Six pairs of the 54 students followed were given approximately five-minute, daily in-process interviews using a semistructured interview protocol while they used a tablet to do the explanation exercise.

The log data was studied together with researcher-generated field notes of the classroom activity. This included data collected by the students in the museum, which allowed the researchers to study the characteristics of the data, including the type of data (e.g., photos, audio notes, photo-audio note pairs) and the accuracy of the annotation titles, tags, and audio notes. A rubric was used to grade the students' final explanations.

\section{WINS: Career Support in a Science Museum After-School Program}

Levels of Analysis Individual, group

Valued Outcomes Social resources

Methods Longitudinal, survey, and interview-based study

Fadigan and Hammrich (2004) conducted a study to describe the educational and career trajectories of high school girls who participated in a structured museum-based natural science enrichment program know as WINS (Women in Natural 
Sciences). Developed for academically talented women from urban, low-income, single-parent families, the program's aim was to give participants "the information, encouragement, and confidence they need to consider pursuing careers in the natural sciences, to make informed decisions, and to shape their own futures" (840).

In addition to providing participants and their families with free access and transportation to the museum, the yearlong program put the participants in summer classes on environmental science, sent them on field trips to local parks, and allowed them to have extended stays at an environmental education center. During the academic year, students met at the museum once a week, attended monthly field trips to other science education institutions, and met scientists.

In order to describe the overall character of the educational and career trajectories for the program's participants, Fadigan and Hammrich (2004) selected a sample of former participants, examined the application materials submitted by these participants, and from these materials identified the educational and career trajectories that these participants had imagined for themselves. Surveys designed to capture details about the participants' actual educational and career trajectories (high school to the present) were mailed to the students in this sample.

After the analysis of the surveys, a representative subsample of the participants was invited to come in for interviews. The interview questions were developed to assess how and why these former participants had pursued the educational and career paths that they did, and to identify what if any effect WINS had had on the development of these paths. The design of the study and study instruments was based on Eccles (1994), a model of achievement-related choices that posits that an individual's 
choices about what career paths to pursue are constrained by the knowledge they possess about possible options, perceptions of gender-role positioning, and perceptions of the value and importance of the options.

The types of findings on valued outcomes that this approach permitted included the following:

- 93 percent of the participants had enrolled in a college program after completing high school.

- Careers in medical or health-related fields, followed by careers in STEM, emerged as the highest-ranking career paths, with about 20 percent of respondents pursuing careers in each of these areas.

The majority of participants named several WINS elements as influencing their educational and career decisions: having staff to talk to, learning job skills, and having the museum as a safe place to go.

\section{Computer-Based and Online Activities}

Computers make it possible to keep track of what a person does on them minute by minute. Whether a person is using a computer simulation, an online multiplayer virtual world, or a simple text editor, it is now possible to comb through log files or through lines of code to generate records of every action a person takes with these kinds of software. This information, when interpreted using the relevant conceptual frameworks, can reveal something about what and how a person is or is not learning.

A key advantage of this approach is that it permits learning assessment without disrupting the flow of learning activities. Another advantage is that these kinds of computer-based 
assessments can also be accomplished in real time, which allows for feedback to the learner in real time also, but again, not in a manner that makes the learners aware that they are being assessed.

In this section we describe examples of approaches to conducting this kind of embedded assessment: stealth assessment in commercially available games, Web and project analysis in Scratch programming, and learning analytics methods to assess programming and learning in heavily documented environments.

\section{Stealth Assessment in Commercially Available Games}

Level of Analysis Individual

Valued Outcome Independent inquiry

Method Evidence-centered design

Stealth assessment refers to a methodology for integrating learning assessments into the structure of computer game-based educational activities in such a way that relevant data about the learning process can be gathered in real time without disrupting student engagement in the activity. The main assumptions underlying stealth assessment research are that learning by active participation in the game improves outcomes, different learner attributes may be identified during game play, strengths and weaknesses of the learner may be addressed to improve learning, and formative feedback can be used to further support student learning (Gee 2003; Gee and Shaffer 2010; Shute 2007, 2008; Shute, Hansen, and Almond 2008; Shute and Ventura 2013; Squire 2006).

In addition to providing a rich context in which to study learning, video games are a central focus of stealth assessment 


\section{Box 1}

Evidence-Centered Design

Key projects reviewed here employ variants of a conceptual framework for creating learning assessment procedures known as evidence-centered design (ECD). ECD makes formal and explicit both the process of designing assessment procedures and the procedures themselves. It provides language and concepts for systematically developing interlinked models of the design, analysis, deployment, and measurement aspects of learning assessment (Behrens et al. 2004; Mislevy, Almond, and Lucas 2004; Mislevy and Haertel 2007).

The process of developing these assessments involves analysis of the target-learning domain in order to establish domain representations, categories, and features relevant to addressing assessment goals. This establishes what is called the competency model for a specific assessment and answers the question, What collection of knowledge and skills should be assessed? ECD also requires specifying the kinds of student behaviors and actions that will constitute evidence of learning, the evidence model, answering the question, What behaviors or performances should reveal those constructs? Finally, these two models are connected by a conceptualization of how the assessment will be implemented, the task model, which answers, What tasks should elicit those behaviors that constitute the evidence?

Whereas initial efforts to apply ECD centered on the development of assessments for use in formal educational settings, more recent efforts have applied the framework to activities and settings that fall within the scope of this report. We describe three examples: (1) so-called stealth assessment of player learning in commercially available first-person, role playing video games; (2) networked analyses for assessing learning in epistemic games; and (3) learning assessment of an innovative, large-scale implementation of a game-design curriculum. 
because, as activities instantiated through computer platforms, they afford convenient and reliable tools for continuously recording and analyzing student performance data in real time. Gathering this documentation is not generally a problem; however, making sense of the potentially massive amounts of data generated requires a principled conceptual framework.

Furthermore, once this data has been interpreted, there is the necessary and complex task of feeding this information back into the educational activity. For example, in computer gamebased environments, this information can be used to support real-time adaptive adjustments to the game in ways that promote and maintain player learning. On a long-term basis, it is also important to communicate to both students and teachers what was learned from these assessments so that the learning activity can be restructured for improved and sustained learning.

In the past several years, Valerie Shute and her colleagues have pioneered stealth assessment methods (Shute 2011; Shute et al. 2009). In this section we draw on this corpus of work to explain the application of the evidence-centered design (ECD) framework, described in box 1, in assessing learning in video games. Games that incorporate stealth assessment must elicit behaviors that provide evidence of the skills and knowledge being assessed, and they must afford principled interpretations of the evidence in terms of the aims of the assessment. As noted, ECD guides the researcher in developing a framework for collecting and analyzing data in terms of three interrelated models, the first of which is the competency model, which names the sets of knowledge and skills on which assessment inferences are to be based. We focus here on an example described by Shute et al. (2009), in which the researchers studied players' creative 
problem-solving abilities in Oblivion, a commercially available first-person, role-playing video game (Bethesda Softworks 2006).

Figure 4 shows a simplified competency model developed by Shute and her colleagues for modeling creative problem solving in the game. The model defines and situates creative problem solving in a restricted range of educationally relevant competencies that one could assess in Oblivion game play. Student-specific instantiations of competency models are termed student models. The values reported in these models, like profiles or report cards, denote assessor beliefs about the student's level on each of the variables in the competency model.

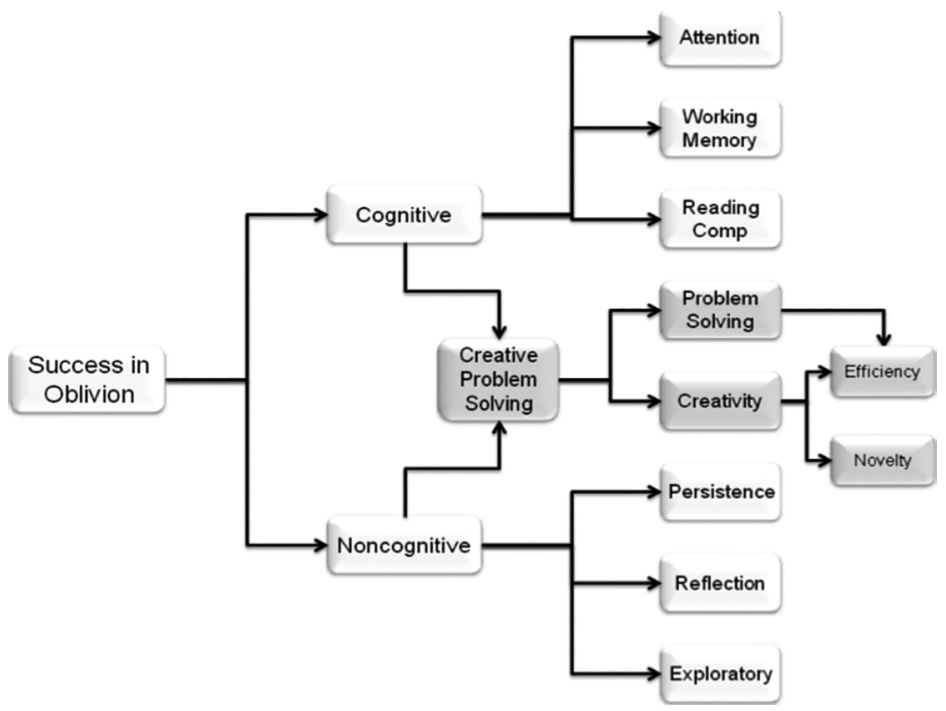

\section{Figure 4}

Simplified competency model for the commercially available role-playing game Oblivion. The areas shaded in gray represent the variables used to assess creative problem solving. From Shute (2011). 
Shute et al. (2009) operationally define creative problem solving as a contextually specific "mental process of creating a solution to a problem ... in which the solution is independently created rather than learned with assistance" (309). By emphasizing problem solving according to this definition, assessment is focused on the novelty and efficiency of approaches to accomplishing tasks in the game.

The evidence model here defines the line of argument describing how and why player performances in a given task situation constitute evidence about competency model variables. Two questions guide the development of the evidence model: What behaviors or performances reveal targeted competencies? What is the functional (or statistical) connection between those behaviors and the competency model variable(s)?

Looking specifically at video games like Oblivion, connections between game observables and their corresponding competencies require that the evidence model include (1) scoring rules for extracting observables from players' game play indicators found in log files, (2) the observables (i.e., scored data), and (3) measurement rules for accumulating evidence from the observables, which are then used to update the student model variables.

In the present example (creative problem solving), novelty and efficiency link actions in the game with competencies related to creative problem solving. Efficiency is defined in terms of the quality and quantity of steps taken to solve the problem; novelty is defined in terms of the frequency with which certain actions are taken (i.e., low-frequency actions are more novel).

The task model here serves as a framework for conceptualizing game-level situations that elicit player performances deemed to provide evidence of competency-related knowledge. Among other things, the model specifies what the player will be asked to 
do and what kinds of responses are allowed. In the specific case of stealth assessment, Shute et al. (2009) refer to the task model as the action model in order to highlight the fact that the modeling is focused on defining a player's action sequences and each action's indicators of success. Actions are defined as anything a player does to solve a particular problem contained within a scene in the game. Indicators are explicitly linked to each action, and these indicators can in turn be measured from the player's log file.

\section{The Scratch Community Web Site}

Levels of Analysis Individual, group

Valued Outcomes Collaboration, quality of product

Method Data mining (Web site)

Another area in which the documentation power of computers is being harnessed to assess student learning is programming and digital media production. We return here to the example of the Scratch programming platform (see Computer Clubhouse discussion above). Maloney et al. (2008) set out to describe which programming concepts the students (8 to 18 years old) at a Computer Clubhouse used in their projects, how they used these concepts, and the extent to which the community of the clubhouse as a whole increased its collective knowledge of computer programming over time.

Documentation consisted of both qualitative and quantitative measures. Scratch project summary files were exported and collected. These contained information about the number and kind of programming commands used along with records of the frequencies of stacks, sounds, and costumes used in the project. In addition, weekly field notes of Scratch activities were gathered by university students, who attended the Computer Clubhouse 
as both researchers and Scratch mentors. Finally, interviews with clubhouse members were conducted to document their impressions of Scratch and to obtain histories of their programming experience.

The summary files were analyzed for the frequency and distribution of Scratch commands in the corpus of projects studied. This allowed Maloney et al. (2008) to develop a profile of the programming commands in use over an 18-month period by clubhouse members as a group. The researchers compared the frequency of programming commands included in projects from one year to the next, and they analyzed the difference in percentages of projects containing targeted programming concepts. Significant gains were observed for the use of five out of seven targeted programming concepts.

One finding that highlights the importance of the relationship between the social dynamics at the clubhouse and what individuals in these settings do with these technologies is that the particular programming commands that were frequently used were commands that were important for creating programs that were seen as valuable by members. For example, in this particular clubhouse, games and animation were popular among the students. This in turn was reflected in the fact that many of the Scratch programs produced by the students included commands relevant for games and animations.

The university mentors selected to assist clubhouse members with Scratch knew little to nothing about programming. This was by design; with inexperienced programmers as mentors, clubhouse members were expected to feel more empowered in their learning, even bolstering their programming expertise in situations when they would be asked to help mentors learn about Scratch (Kafai et al. 2007). In their study, Maloney et al. 
(2008) argued that given the minimal role played by mentors at the clubhouse in terms of any direct instruction in Scratch, the Scratch environment itself was most likely responsible for the learning that resulted.

In order to assess the power of the Scratch environment as a stand-alone programming learning environment, Dahotre, Zhang, and Scaffidi (2010) studied Scratch programs created by youths who did not attend Computer Clubhouse. To do this they used a "screen scraper" program to download from the Scratch community Web site 100 random animation projects, their corresponding computer code, and user comments. The HTML for the repository Web page was also downloaded in order to assess usage statistics (i.e., counts of views, comments, downloads, and visitor remixes) for each animation project. These projects were then assessed in terms of three learning goals envisioned by the developers as being facilitated by Scratch: learning of technical programming skills, social skills for collaboration, and sociotechnical remixing skills related to adapting existing programs and community resources to produce new programs.

The projects that Dahotre et al. (2010) evaluated from the community Web site included key programming primitives at the same levels as the projects that were developed under partial supervision of undergraduate mentors (e.g., Maloney et al. 2008). In order to assess these projects against the general population, Dahotre et al. drew on findings from methodologically similar studies based on other repositories of end-user programming code (e.g., spreadsheet programming and macros). They found that the Scratch programs showed comparable or higher rates of use of programming primitives.

To assess collaborative and remixing skills, Dahotre et al. (2010) studied the comments posted by users to projects on the 
Web site and project download statistics, respectively. Although the majority of comments posted were helpful critiques, they did not indicate that students were actively collaborating with one another on projects. Regarding remixes, the authors found that the relatively low levels of remix activity were comparable to those found in the general population.

More recently, Scaffidi and Chambers (2012) extended the work of the above studies to examine the extent to which the Scratch environment, via the Web community, facilitated the development of social skills or elementary programming skills. To this end they studied data from more than 1,000 Scratch projects posted to the community Web site by 250 randomly selected users. Drawing on the existing literature, Scaffidi and Chambers adapted four models of end users to create a framework for investigating skill progression in Scratch. Two models addressed questions of programming skill related to the use of programming primitives, one examined social skills, and the last concerned programming efficiency based on the number of lines of code produced and the amount of time taken to produce them.

\section{Learning Analytics in Computer Programming}

Level of Analysis Individual

Valued Outcome Independent inquiry

Methods Learning analytics, data mining (programming code)

Paolo Blikstein and his colleagues at Stanford's Transformative Learning Technologies Lab have developed a number of automated learning analytics approaches for making quantitative assessments of the kinds of open-ended, nonscripted learning activities that, as this survey of the literature demonstrates, have been previously largely qualitative. One example 
of this work concerns the assessment of students' programming know-how.

Blikstein (2011) examined assignments completed by nine sophomores in an undergraduate programming class. The students were asked to choose a specific scientific phenomenon and write a program that modeled the phenomenon. Student programming logs were collected using the NetLogo (Wilensky 1999) programming environment. NetLogo is capable of logging to an XML file such user actions as key presses, button clicks, and changes in programming code.

Blikstein (2011) developed a special configuration file for specifying and logging the targeted programming actions. This file was distributed to the students, who were given instructions for enabling it so that log files could be collected and then processed, coded, and analyzed. The analysis focused on identifying the coding strategies that the students employed. Once identified, these strategies were combined with survey information about the students' previous programming knowledge to determine coding profiles for each student (e.g., copy-andpasters, self-sufficients, or mixed mode). The broader aim here was to draw on the students' observed programming patterns to improve the design of teaching and support materials and strategies, as well as to identify critical points in the process of writing software applications where support interventions might best be included.

\section{Ethnographic Studies of Online and Gaming Communities}

The next two studies represent a useful approach to the research and assessment of online communities in which the researcher acts as a member of the community or otherwise studies the 
online community as an ethnographer might study a traditional face-to-face community. Insofar as informal learning increasingly occurs today in such online communities, the methods of documentation and assessment developed within them are important for the field.

\section{Lineage, World of Warcraft, and Second Life}

Levels of Analysis Individual, group

Valued Outcomes Collaboration, independent inquiry, social resources

\section{Method Cognitive ethnography}

Steinkuehler (2008) has described a program of research for studying learning in massively multiplayer online role-playing games (MMORPGs) such as World of Warcraft, as well as nongame online virtual worlds like Second Life. The first phase of the research involved conducting a cognitive ethnography (Hutchins 1995) of the game and its community of players with the aim of identifying the forms of cognition and learning that lead to successful game playing.

Steinkuehler (2008) studied the fantasy-based MMORPG Lineage through 28 months of participant observation. This involved the study and documentation of naturally occurring game playing through video and field notes, interviews with players, and the archiving and analysis of game-related player communications (e.g., emails, chat room and instant-message conversations, and discussion-board posts) and community documents (e.g., fan Web sites and community-authored game fictions).

Five broad categories of social and intellectual practices that characterize successful MMORPG play were identified: 
(1) collaborative problem solving, (2) digital media literacy practices, (3) informal scientific and mathematical reasoning, (4) computational literacy (e.g., "modding"), and (5) cultural mechanisms for learning, including reciprocal apprenticeships (Steinkuehler 2004; Steinkuehler and Williams 2009) and collective intelligence (Steinkuehler 2006). See Steinkuehler (2005) for a full survey of the practices identified.

Note that for players of MMORPGs, there are normally two intersecting online communities: the in-game community of interactions with other players during actual game playing, and the out-of-game online guilds and associations in which information about the game and game planning and strategies are developed and exchanged.

In the second phase of research, Steinkuehler (2008) drew on the social and intellectual practices identified in the first phase and applied them as guiding themes for conducting targeted empirical investigations of World of Warcraft and Second Life. These studies yielded observations about collaborative problem solving and the multiple literacies that players develop as a result of participation in the game and the game community. Steinkuehler notes important parallels between the kind of collaborative problem solving required in games like World of Warcraft (e.g., group-organized "raiding") and those required in contemporary workplace environments. She also reports on the high degree of motivation that players show for developing multiple literacies, including computer literacies (e.g., creating "mods") and practices that overlap with more traditional literacies (e.g., writing prose in the form of fan fiction).

For an ethnographic study focused on collaborative problem solving in World of Warcraft, see Chen (2009). 


\section{Whyville}

Levels of Analysis Individual, group

Valued Outcomes Collaboration, independent inquiry, social resources

\section{Method Connective ethnography}

Online virtual worlds have become pervasive as educational tools, both in and out of school. Regardless of the setting, implementing these worlds and assessing their potential learning benefits remains a challenge. A key question raised by environments in which learners inhabit and travel between virtual and physical spaces is how this learning can be traced. To examine this question, Fields and Kafai (2007) conducted a connective ethnography of a summer after-school program in which fourth to sixth graders used an online virtual world, Whyville (see also Kafai 2010).

Citing work by Hines (2000) and Leander and McKim (2003), Fields and Kafai (2007) define connective ethnography as an approach that focuses on examining how everyday practices work to either segregate or blend social spaces. These processes are studied by tracing the flow of objects, text, and bodies and how this flow contributes to the construction of boundaries within and between virtual and physical spaces.

Within this framework, Fields and Kafai (2007) adopted a strategy of identifying forms of insider knowledge about the game that would afford insights into the kinds of learning that players experience within and between the virtual world and the physical space of the after-school center. This knowledge had to be traceable, discoverable by players through trial and error, and observable in and out of the virtual world. Understanding the particular insider knowledge that the researchers studied-teleporting-requires a brief introduction to the basics of the game. 
Whyville is a multiuser virtual environment for 8- to 16-yearolds in which the users are positioned to engage in a variety of science-themed activities. A player who successfully completes an activity earns virtual currency, which can then be used to buy and design features of the player's avatar as well as other goods useful in the world of the game. Social interaction in the game is mediated through "ymailing" (email within the Whyville universe) and avatar-to-avatar chat. Avatars interact in more than 30 different settings, each of which can be accessed through a pull-down menu (see figure 5).

Not all the locations that players can visit are visible in the menu (e.g., the Moon, Jupiter, and Saturn are not). These secret sites are accessible only by teleporting, an action that is accomplished by typing "teleport [place]" in the chat bubble above the avatar's head. Teleporting is not observable in the game because the avatars are transported to the new location before the typed commands are displayed, which prevents other players from knowing where and how the avatar disappeared. The locations of these secret sites and the ways of getting there are bits of information that can be obtained only through conversation with other players or from Whyville "cheat" Web sites. Consequently, these secret locations gain a special status among Whyville insiders as social hangouts free of newbies (new, relatively naive players).

To document learning over the course of the nine-week program, Fields and Kafai (2007) adopted a data multistreaming approach. Daily field notes were taken to document the overall activity at the after-school center, and video was used to capture interactions of small student groups as they played while clustered around a computer. Online tracking data was recorded for players' chats and the locations of their avatar throughout the game. Finally, individual postactivity interviews of the participants were conducted. 


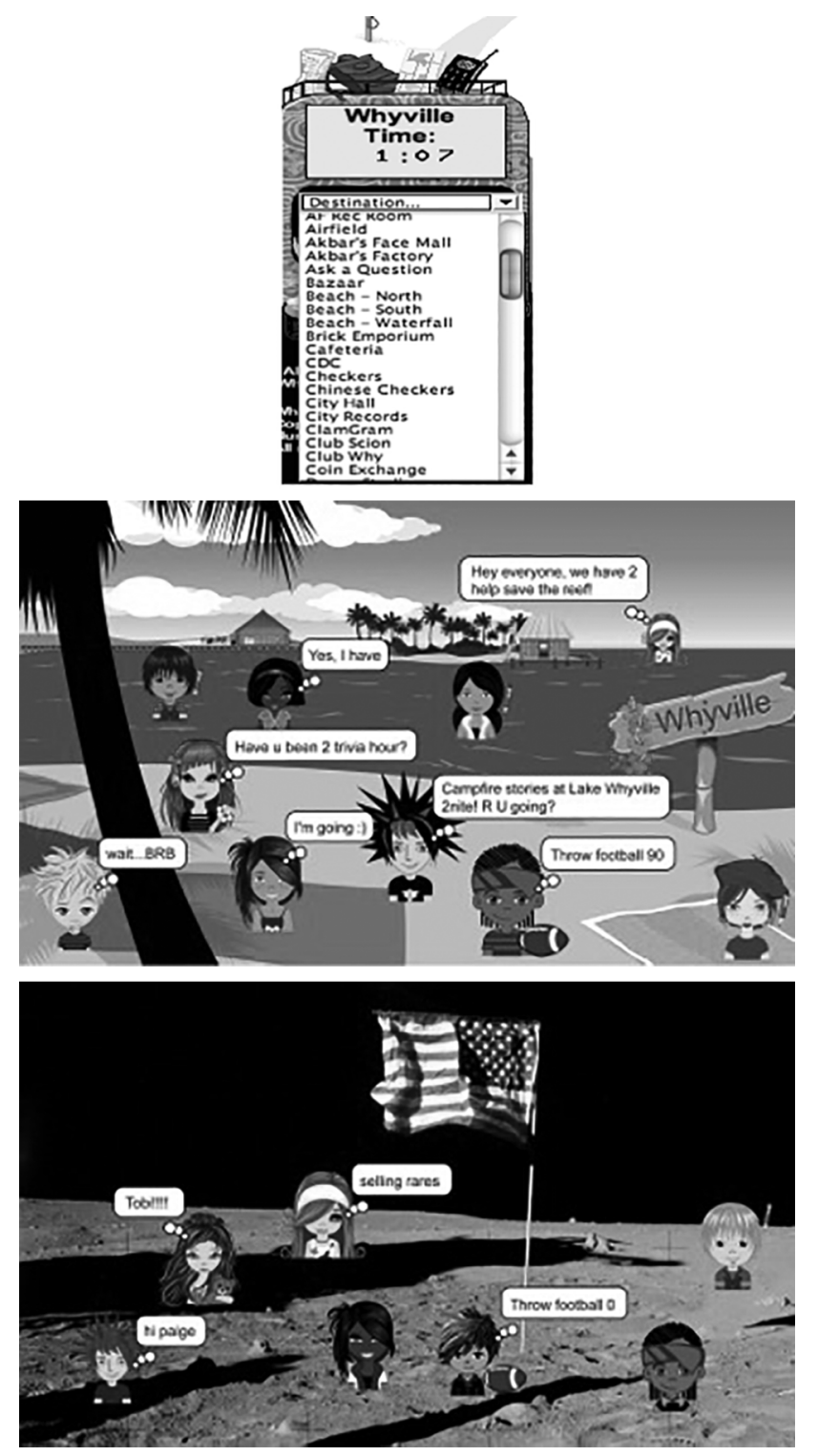

\section{Figure 5}

From top to bottom: the pull-down destination menu, and two of the 30 destinations where players can visit and interact-the beach and the moon. From Kafai and Fields (2013). Image (c) Numedon, Inc. 2013. Reprinted with permission. 
All text documentation was combed for instances in which teleportation was mentioned. This allowed for a mapping of each player's history of learning and using the teleportation function. For example, chat transcripts for each student were studied to identify the first time that students discussed teleportation in the game and when they first used the teleportation function. This information was in turn triangulated with the field notes and video data to paint a more detailed picture of the contexts in which players learned and implemented the teleportation function.

Fields and Kafai (2007) found that for the student players there was a seamless integration between online and offline interactions. What happened in Whyville was just as important as what happened in the after-school center. For this reason, Fields and Kafai propose referring to activity in these worlds as "synthetic play," as in the synthesis of online and offline worlds.

\section{Additional Studies of Interest}

In this section we include detailed accounts of two additional research projects that have developed relatively sophisticated approaches to the documentation and assessment of settings in which digital games provide key learning opportunities. In each case, these projects draw on and elaborate the ECD framework discussed earlier.

\section{Digital Zoo: Epistemic Games and Epistemography}

Levels of Analysis Individual, group

Valued Outcomes Independent inquiry, know-how, collaboration, social resources 
Methods Evidence-centered design, epistemography, epistemic network analysis

The research we describe here is drawn from the work of the multi-institutional Epistemic Games Research Group led by David Williamson Shaffer. The group includes researchers, faculty, staff, and students from the University of Wisconsin at Madison, the University of Maryland, the University of Memphis, the Massachusetts Audubon Society, the Danish School of Education, and the Open Universiteit Nederland.

Shaffer et al. (2009) study digital learning systems: systems constituted by a theory of learning and corresponding methods of assessment, which are linked into an evidence-based, digital intervention. The digital learning systems that Shaffer and his colleagues developed and studied are known as epistemic games.

Epistemic games are activities through which students learn the knowledge, skills, practices, and values of a particular professional domain. These activities are mediated through a variety of digital technologies, including virtual-world simulations of the tasks typically engaged in by professionals in the target field, as well as the computer applications used by the professionals in their everyday work. Players take on the role of apprentices in such professions as city planning, science journalism, and engineering.

The learners are guided through these worlds by the deliberate inclusion of game tasks that ask the learners to reflect on their work. This can involve interactions with peers and/or with actual professionals in the relevant fields. These interactions are designed by the game creators and researchers to model the kind of mentoring that professionals experience in their training and socialization. 
An example of an epistemic game is Digital Zoo. In Digital $Z o o$, players adopt the role of biomechanical engineers who are given the task of using specially designed software to create virtual objects and creatures for an animated film. Design specifications for the desired appearance and movement of these objects and creatures are delivered to the players, who are then tasked with creating these objects. Through the design elements of the activity as a whole and through the participation of knowledgeable mentors, the players are guided in following the roles and rules of engineering design based on research examining how real engineers in training learn to design.

The epistemic frames hypothesis (Shaffer 2006) is a theory of learning on which the design, implementation, and study of epistemic games are based. The hypothesis proposes that any community of practice (e.g., biomechanical engineers) has a culture with identifiable structuring features, including the things that people within the community do (skills); the understanding that people in the community share (knowledge); the way that members of the community see themselves (identity); the beliefs that members of the community hold (values); and the grounds that justify actions or claims as legitimate within the community (epistemology). For more details see Shaffer (2007) and Shaffer et al. (2009).

The skills, knowledge, identities, values, and epistemologies of the community of practice collectively constitute that community's epistemic frame. The epistemic frame hypothesis argues that participants engage in specific forms of training and socialization to become members of these communities. These processes lead participants to internalize these epistemic frames, which they can in turn deploy as tools for engaging with the world from the point of view of a community member (Shaffer 2006). 
A critical step in the implementation of an ECD approach is to conduct domain analyses in order to identify the target learning to be assessed (the competency model and the individual instantiation of this model, the student model). From an epistemic games perspective, the development of the competency model is guided by the epistemic frame hypothesis, and the model is constituted by those elements of the epistemic frame that one seeks to have players internalize.

How these elements are organized and engaged within the course of the activity is based on what is known about the professional practica in place for training and socializing members of the professional group. Drawing on Schön's (1983, 1985) research in professional development, Shaffer et al. (2009) argue that epistemic frames develop and are passed on through these practica: "Professional practica are environments in which a learner takes professional action in a supervised setting and then reflects on the results with peers and mentors. Skills, knowledge, identity, values, and epistemology become more and more closely tied together as the student learns to see the world using the epistemic frame of the community, as happens in capstone courses in engineering, internship and residency for doctors, or almost any graduate program in the sciences" (36).

Defining the elements of the epistemic frame to be replicated in the epistemic game requires that the researchers perform an epistemography, an in-depth study of the participant structures in a specific practicum environment for the purpose of identifying learning processes that facilitate a novice professional's development of a particular epistemic frame (Shaffer 2005). Participant structures are the forms of action and interaction, including reflective practices, typical of the profession. 
In the specific case of Digital Zoo, the designers conducted an epistemography of an undergraduate engineering design course (Svarovsky and Shaffer 2006a, 2006b). Using a variety of ethnographic methods (field observations, interviews, focus groups, artifact archiving, and analyses) the designers followed a student design team as it worked to develop a biomedical device for an actual client. Qualitative data from student design notebooks as well as from regular design meetings were collected. These data were then analyzed using an initial coding scheme developed from descriptions of practice in the literature (Burghardt 1999; Dym and Little 2000) and the definition of an epistemic frame (Shaffer 2006). Through the adoption of a grounded theory approach (Glaser and Strauss 1967; Strauss and Corbin 1998), the codes were iteratively refined.

Analysis revealed that design meetings, design notebooks, and meetings with clients were effective means for reflective activity. In particular, the design meetings and design notebooks proved to be rich sources of epistemic statements about engineering that were highly correlated with references to engineering skills, knowledge, and values. To the researchers, this suggested that these activities played an important role in the initial development of students' engineering epistemic frames and would therefore be incorporated as important activities in the epistemic game.

A storyboarding procedure (a frame board) was used to design and implement the systematic presentation of these activities (i.e., participant structures) in the game so that the students engaged in them in a reflexive manner. From the perspective of $\mathrm{ECD}$, the frame board functions as the task model. Each activity in the frame board described the relevant participant structures, defining them in terms of the features of the epistemic frame 
that are required to engage this structure at the particular point in the game as well as in terms of the forms of evidence necessary for claiming that these features have been developed and properly deployed.

Shaffer et al. (2009) argue that the kind of professional perspective that students develop from participation in epistemic games should not be thought of solely as a collection of the relevant skills, knowledge, values, identities, and epistemologies of the profession. It is also important to think of these elements as constituting a network of conceptual, practical, moral, personal, and epistemological relationships. It follows that assessing student learning requires not only carefully documenting instances of students engaging the different elements of the frame but also characterizing the strength of the relationships among these elements for each student.

One method that the Epistemic Games Research Group used to study these elements and their relationships was Epistemic Network Analysis. The approach involves a combination of social network analysis (Brandes and Erlebach 2005), concepts from frame analysis (Goffman 1974), and data visualization techniques. To explain the application of social network analysis in assessing learning in epistemic games, Shaffer et al. (2009) draw an analogy between using the technique to analyze interactions at a party and relations among the elements of an epistemic frame.

One way to examine the relationships among people meeting for the first time at the party would be to document at intervals who is interacting with whom. Assuming that a closer relationship develops among those who spend more time in the same conversational group, the social network that develops can be quantified by summing, for each pair of individuals over the 
course of the party, the number of times they are found in the same conversational group. Analogously, we can think of the people interacting at the party as the elements from an epistemic frame for one player in an epistemic game. The task then is to trace over time those elements of the epistemic frame that the player uses.

To understand how these networks of frame elements are visualized, we return to the Digital Zoo epistemography. The documentation collected included player design notebooks, documents, reports, and other work products produced during game play. Player-mentor interactions were also recorded. For each player, these records were then organized into play histories. Using working definitions of the five engineering epistemic frame elements (derived from the earlier qualitative coding process), these histories were studied to identify instances of these elements.

Shaffer et al. (2009) used network graphs as tools to create visualizations for individual players of the epistemic frame elements that emerged at specific moments in the individual's play history. These graphs showed not only which frame elements the player developed over time but also the nature of the relations among those elements. In a cumulative graph, the length of the line connecting the frame elements indicates the frequency with which each pair of elements occurred in a strip of activity: the closer the nodes, the more often they were linked during the game. Using this approach, graphs can be created for players at any point in the game, and these in turn can be used to perform developmental analyses of epistemic frames (see figure 6).

Statistical techniques can be applied to run a variety of analyses on these epistemic network maps, providing insights into the development of players' epistemic frames. For example, 


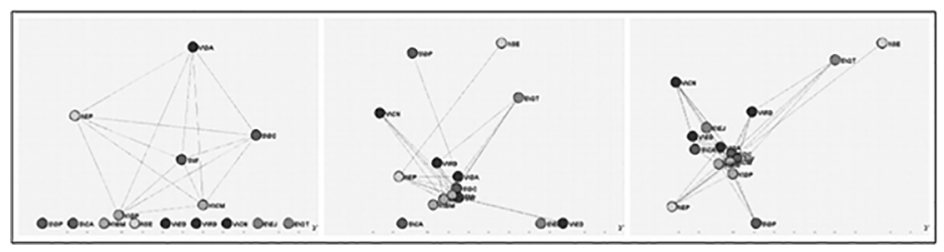

\section{Figure 6}

Network graphs from different slices of the play history for one player in Digital Zoo. From Shaffer et al. (2009).

linkages among nodes in a network can be measured at different time intervals to assess changes in the overall strength of association of the network (weighted density). These measures can in turn be applied to determine changes in an epistemic frame over time and to associate those changes with specific elements of game play.

\section{Quest to Learn}

Levels of Analysis Individual, group, project

Valued Outcomes Independent inquiry, collaboration

Methods Evidence-centered design, evidence-centered evaluation, content analysis

This example highlights assessment at all three levels for independent inquiry and collaboration. Although this case involves the assessment and evaluation of what would typically be considered a formal learning environment-a public schoolboth the models of assessment and evaluation applied (ECD and evidence-centered evaluation, or ECE) and the unusual nature of the curriculum around which the activities at the school are organized (video game design) make this project relevant also 
for the design and implementation of assessments of informal learning activities.

Quest to Learn (Q2L) is an innovative New York City public school whose curriculum is organized around the principles of game design. It is the first school of its kind, a product of the growing movement in education and education research to study and apply principles of game design to create motivating learning activities (see, e.g., Shaffer and Gee 2012).

Given the school's unique curriculum, one obvious question that emerges is how to assess learning in an environment that has never been formally assessed before. Shute and Torres (2012) took on this challenge by adopting a two-pronged approach: to assess learning at the individual level and to evaluate the success of the Q2L project overall. They used ECE, described below, to evaluate and model the goals of Q2L, and ECD (previously discussed) to develop and implement assessments of individual student performance.

Shute and Torres (2012) describe ECE as an extension of ECD. Both approaches are designed to guide the researcher and practitioner in specifying the structures and supporting rationales for the evidentiary argument of an assessment. Argument structures encompass, among other things, the claims (inferences) one wishes to make, the observables (performance data) that provide support for those claims, the task performance situations that elicit the observables, and the rationales for linking them all together.

As with ECD, the procedure for applying ECE involves first defining a set of three interrelated models for objectives, evidence, and data. The objectives model identifies the goals of the organization. It is a description of what is of value to the school and its extended community. As such, it guides the development 
of the metrics and criteria for evaluating what works, what doesn't, and why.

The first step in modeling Q2L's goals is data collection. For seven months, Shute and Torres (2012) conducted semistructured interviews, surveys, focus groups, and observations with and about the relevant stakeholders: teachers, students, administrators, and curriculum designers. They also studied the school's design documents (Salen et al. 2010). Dominant themes were identified in the interview data by using content analysis. These themes were summarized in a document that was shared with all the participants. The participants were then given a survey to record their responses to and feedback about the document. After these surveys were reviewed, focus groups were organized as a means of further refining the themes. The Q2L objectives model was developed based on this set of themes (see figure 7).

Assessment of student-level variables centered on three competencies valued by the Q2L community: systems thinking, teamwork, and time management. In line with an ECD approach,

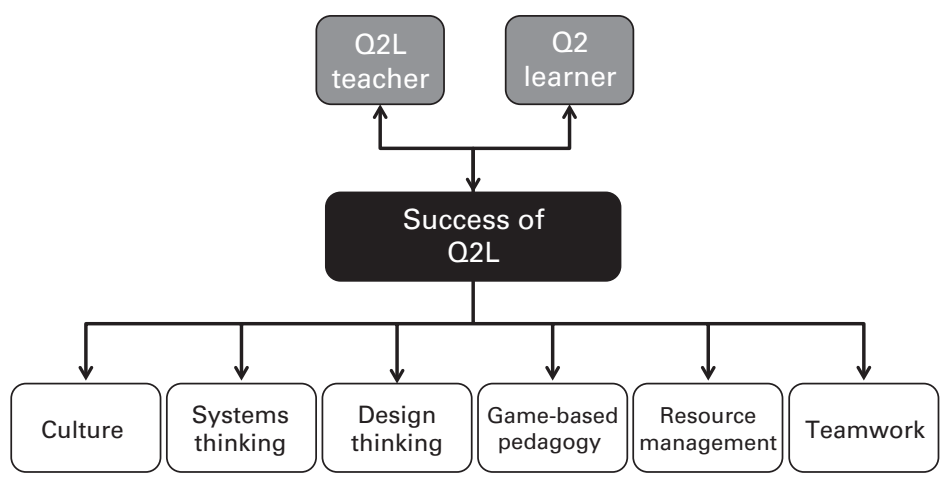

Figure 7

Quest to Learn objectives model. From Shute and Torres (2012). 
competency models for each variable were developed. Shute and Torres (2012) derived these specific models from the research literature, and these models were in turn used to develop corresponding assessment instruments (figure 8).

These instruments, which were administered to Q2L students at six-month intervals, were just one component in a battery of assessments that mixed qualitative and quantitative measures. A qualitative observation protocol was also implemented in which two independent observers conducted biweekly observations in classrooms, the cafeteria, and the school's after-school program.

The focus of these observations included the following: (1) the thinking skills afforded by each node of the model (e.g., data on systems thinking, observations focused on evidence related to dynamic thinking, closed-loop thinking, and skills for transferring learned models across multiple situations and settings); (2) the type and frequency of specialized language used within each domain or node; (3) the kinds of social activity evident per node; and (4) other relevant information, such as the learning tools used, the identities afforded by each site, the artifacts produced, shared norms, physical (or virtual) space, and time allocated per activity in a given location (Shute and Torres 2012).

The research team found that students' systems thinking skills improved significantly and showed signs of improvement in time management as well (Shute, Ventura, and Torres 2012).

Mindful of concerns about the relationship between participation in the innovative activities at Q2L and achievement in traditional academic domains, Shute and Torres (2012) also planned to compare the performance on state-mandated standardized tests between Q2L students and groups of demographically matched students at two New York City public schools. 
(a)

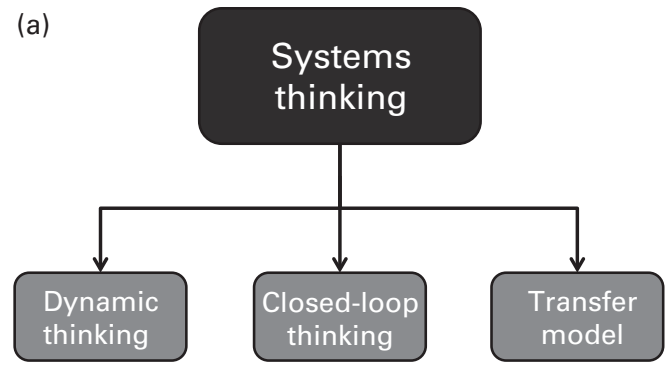

(b)

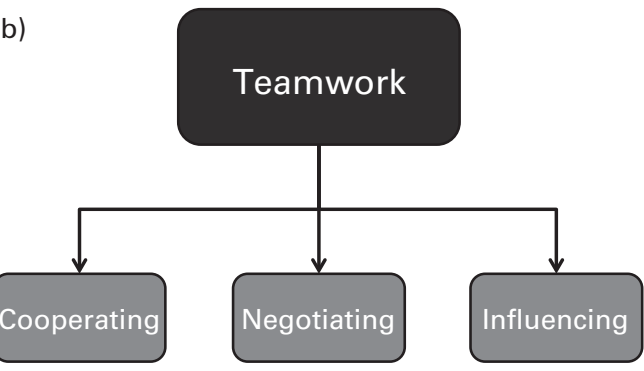

(c)

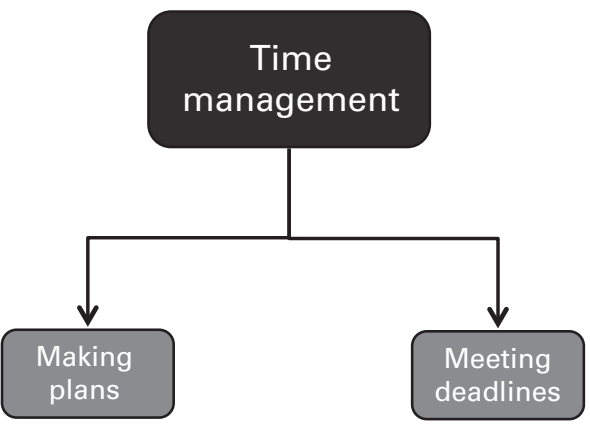

Figure 8

Three competency models for student assessment at Quest to Learn. From Shute and Torres (2012). 



\section{Highlights of the Expert Meetings}

From June 2011 through February 2012, three expert meetings with a total of 25 senior researchers were convened: at the Exploratorium in San Francisco, at Northwestern University in Evanston, Illinois, and at the University of California at San Diego (see appendix A). The participating researchers brought rich experience with project design and development, assessment and outcomes research, and external evaluations of programmatic initiatives across a wide range of informal learning settings. We included scholars with experience in conceptualizing and theorizing learning and assessment as well as those whose primary focus is conducting empirical research.

The participants shared pertinent readings in advance of each meeting, and all materials were collected cumulatively on a project wiki. Together we viewed videos of learning in diverse settings and sought to connect our conceptual discussions to these concrete examples. We also sought and received from the meeting participants suggestions on significant research projects (both completed and in progress), names of other leading researchers to consult, and citations to relevant reports and published literature. This effort resulted in a bibliography (see appendix B), which is more extensive than the list of studies chosen for 
review in the previous section, and it also resulted in a list of other relevant resources, including Web sites (see appendix C).

To focus the scope of the report in relation to available project resources, we collectively decided to locate research related to four primary types of settings: after-school programs, community-based organizations, museums and science centers, and online communities. This focus meant that we consciously excluded learning in the home through everyday activities or activities not specified by the requirements of some other educational institution (e.g., doing and discussing mathematics during home remodeling). We also excluded team sports (both live action and "fantasy," or virtual-world mediated) and both online and offline hobbies communities (such as those dedicated to cooking or crafting, such as Ravelry.com).

Certain themes recurred with varying nuance throughout the meetings, such as the affective dimensions of learning, learning at project and group levels, new modes of documentation, digital technologies in assessment, trajectories of learning over time, and the diversity of kinds of valued outcomes.

One of the key issues organizing our approach was that of the unit of assessment. The consensus of the group was that this unit is a system over time that includes individual learners, other participants, mediating tools, semiotic media, and local conditions directly relevant to and supportive of the learning activities. Such an analysis must extend to wider contexts that make the setting of learning possible institutionally, but with decreasing detail as relevance to the specifics of learning trajectories decreases.

This type of approach was later applied to the question of metadata or backstories for video records of learning activities. A critical issue, the answers to which may vary by type of setting or 
type of activity, centers on how much and what kinds of information are relevant to identifying valued learning and the specific aspects of activity that support it as seen in any given video.

In any records of learning activity over time, some valued learning may be more readily visible to more observers and with less detailed analysis or less experienced professional vision, whereas other instances may be less readily visible. Different kinds of learning may become visible when records of learning activities are studied over longer rather than shorter periods. One way to estimate the role of background information is to have a group view the video first without background, view it again with partial background, and then view it a third time with much more complete background.

However, video alone is often not a sufficient documentation of learning activity because of the inferences that must be made to identify valued learning. Ideally, video should be supplemented by field notes from participant observation or observant participation, interviews with participants, and relevant histories of the setting and the participants. Documentation should cover activity in a setting for a period long enough to show the origins of participation, the evolution of the activity, the learning in the activity, and the consequentiality of learning for some other activity. An individual episode captured on video may be significant as part of a longer trajectory of learning and development, and/or as an instance of a frequently repeated pattern of learning and activity in other cases in the same or similar settings. Video can be a useful tool for documenting an important learning event that is recognized retrospectively.

Another key issue in the meetings was identifying the criteria for the value of and significance of learning. A primary criterion is that there is evidence of value for the participants, such as the 
length of time they focus on a task or activity, their reluctance to leave or end the activity, their displays of intense or positive affect during the activity, and any comments on the activity during and after explicitly elicited evaluations.

Beyond this, there are additional criteria that may be applied, such as the judgment of expert educators or others (such as parents) on what is of value to the learners and/or to society and any evidence of consequentiality of learning for more conventional academic activities (e.g., increased interest, increased participation, more positive affect, more effective completion of tasks, the ability to teach content and skills to others, or the ability to solve problems collaboratively).

In order to do assessment across settings, cumulatively or comparatively, we need to identify features, factors, or considerations that traverse the boundaries of the settings. Many common assumptions about this are flawed-identities change across settings, and so do modes of learning, purposes, and what is valued from the learning activities. Moreover, communities are not bound, fixed entities but are abstracted from the flow of practices among participants in many communities. Learning cannot be defined as progress toward mastery in a community, given this fact. Consequently, efforts to fully assess the effects of learning experiences must be based on longitudinal, ethnographic records, such as collections of material objects and semiotic products with in-progress versions over time.

New and promising approaches may prove to be particularly helpful in better understanding the diverse, widely distributed, and interrelated nature of learning experiences. New or underutilized methods include digital storytelling as a mode of documentation, spatial tracking, agent-based modeling, longitudinal assessment over periods of 5 to 10 years, the tracking of learning 
across programs and settings, the collection and sharing of data about learners across programs, data mining, machine-learning analysis, and richly instrumented spaces.

Many researchers are now orienting to indices of affective engagement, such as interest, commitment, and persistence, because these are assumed to be common across settings and therefore important for wider assessment. Others see the relationship between learning experiences and the possibility of taking up subsequent opportunities as the critical element for assessment and look to measuring changes in the distribution of practices across networks as evidence of system-level learning (including individual learning).

The meeting participants noted the importance of understanding learning communities in order to adequately document, assess, evaluate, and research them. Learning communities may differ from one another in their basic goals and values, strategies, and organization of learning as well as in the roles they make available for members and the new niches members may create for themselves in the community.

Learning communities also differ in how outcomes for individuals, groups, and the communities as a whole are negotiated or established, and therefore such outcomes must be documented, assessed, and evaluated relative to the different goals and values (e.g., those of individual participants, those the community considers appropriate to various roles, those of the group and community itself, and those of external entities such as sponsoring organizations).

Informal learning communities often differ from schoolbased learning groups in the degree to which learning outcomes are unpredictable-in addition to other differences such as age 
mixing, flexible pacing, division of labor and goals according to role, self-guided learning, and voluntary participation.

Within many informal learning communities, learning goals focus on the drivers of learning more than on the learning of specific content. These communities aim to improve motivation, engagement, and enjoyment; to broaden areas of interest and expand zones of comfort; and to improve the skills of selfguided learning, sustained learning, and collaborative learning. Some communities and some roles may emphasize activities that the participants already value and enjoy, whereas others may draw the participants out of their comfort zones to expand their know-how and its range of mobilization. Some learning communities are also organized in such a way that groups and the community as a whole learn and change over time, whereas others are organized mainly to facilitate individual learning.

The meeting participants engaged in an extensive discussion of badges as a means of recognizing achievements both in nontraditional settings and in relation to the kinds of know-how for which there may not be formal recognition systems. Badges used within communities, awarded by each community and its members, serve both to recognize achievement and to make the achievers recognizable to others as potential sources of expertise and assistance. Badges can also help to define ladders of participation, which indicate for the learners the existence and nature of higher levels of skill. The value of a badge depends on the reputation of the community awarding it and the procedure by which it is awarded, especially if the badge is to operate and be recognized outside a specialized community.

Badges are an example of the crowdsourcing of assessment. Within a community, this mode of evaluation and recognition may indicate community or group consensus rather than an 
exercise of power and thus avoid some of the resistance-based invalidation of other forms of evaluative judgments. But if a wide-scale system of endorsement of badges or badge awarders (e.g., by government authority) prefers its own criteria of value to those of the awarding communities, it could undermine the authenticity of badges as endogenous evaluations and trigger the same reactions and invalidation seen with traditional external power-based evaluations (e.g., grades, standardized testing).

Such an occurrence could lead to badge-seeking without engagement, badge inflation (lowering the perceived and practical value of the badge as well as the criteria for awarding it), and efforts to obtain badges without durable, mobilizable learning.

We see manipulation or degradation in recognition systems today with the relatively low standards for accreditation in the for-profit sector of higher education, the purchasing of institutions with already accredited programs, the likelihood of bribery, and so forth. It is not clear what the likely effects on an open badge system would be if badges were awarded by for-profit institutions or organizations as a source of revenue. This should be a major concern.

Another issue raised was the difference between localized and interoperable means for assessing learning. Some methods of documentation and procedures for assessment produce value insofar as they are designed specifically in relation to the goals and practices of a particular community. Other methods and procedures can be used equally well for different projects and thus support comparisons and generalizations. It is important to balance these approaches in relation to the goals of local improvement and generalizable knowledge.

For example, a coding scheme to identify a particular category of events in a video archive documenting a project may 
focus on types of events that are highly specific to that project and its goals and that may not be in evidence or be relevant to any other project; or it may try to focus on types of events that are very likely to occur in other projects and be relevant to a wide range of goals. It seems desirable to try to include both kinds of focus in assessment.

This example highlights the need to balance the goals of assessment (improvement) and the goals of research (knowledge relevant to future design). But the relation is not as simple as might be imagined. In-depth assessment of a project on its own terms may be of enormous value for research purposes insofar as it produces knowledge about how particular outcomes were achieved, what worked and what didn't, what was sustained over time and what got changed, and so on.

This knowledge can potentially be combined with similar knowledge from other projects to improve future designs, even if it was not itself set up for this purpose. Likewise, existing research-based generalizations can be localized to serve the needs of assessment and improvement for particular projects (and in general they must be localized to be effective). 


\section{Conclusions and Recommendations}

The principal finding and recommendation of this report is that the scope of valued learning outcomes for informal learning activities should include social, emotional, and developmental outcomes as well as content knowledge and should include learning by groups and whole projects as well as by individuals. We note that many of the valued learning outcomes that are reported were not predictable or aimed for at the start of the projects.

Effective documentation and assessment of informal learning activities should observe several general principles as much as possible. Such assessment should take into account the social and cultural context of the communities and institutions that support and constrain the activities being assessed. The assessment of informal learning activities must be specific to the goals of each project and activity and take account of the history of the project, its supporting organizations, and the surrounding community. It should aim to provide insight into how and why various features of the projects and activities have or have not supported valued learning outcomes and learning in progress for individuals, groups, and whole projects or organizations.

Effective documentation and assessment should also take into account community acceptance and the prospects for long-term 
sustainability, aiming to provide a basis for estimating the likelihood that a project is sustainable under various expectable conditions and the likelihood that its successful practices can be adapted to other specified contexts. Key indices of sustainability include the forms and extent of community cosponsorship and financial and in-kind contributions.

Overall, we believe that the unit of analysis for assessment should be a system of activities and practices and take place on multiple time scales-from hours to months or years. These systems may be a cluster of related activities across a range of time scales: a single instance; a sequence of activities that build on one another's content, themes, and skills; the duration of a working group; the entire time of an individual's participation in the project; or the full time span of the project. This means that the assessment should be built on the recognition that groups and projects as well as individuals learn to do better and that it should aim to generate information that will be of practical use to individual learners, groups, projects, and organizations.

To attend to multiple time scales, assessment for informal learning activities should adopt a longitudinal design, following changes and gains from the inception of a project and documenting the processes by which desirable outcomes occur in addition to the outcomes themselves. Such longitudinal approaches should include consideration of the processes of improvement on the part of groups and teams, whole projects, and participating organizations over the range of time scales, from what is learned by individuals in an hour to what may be learned by organizations over several years.

Professional quality assessment should provide information and interpretations that have practical value for individuals in gauging their changing strengths and weaknesses, for groups in 
gauging and improving their effectiveness, and for projects and organizations in determining whether their goals are being met. The results should be represented in ways that allow for changes that better support the learning and development of participants, of groups, and of the project or organization as a whole.

Assessment information is useful not only in identifying outcomes but also in planning for future improvements for the design and development of learning environments. Assessments that are made only at the end of a project are not likely to be sensitive to learning about how to do things better, nor can they identify the processes by which improvements came to be made. Assessments based only on the initial goals of a project may not capture other valued learning outcomes that emerged unpredictably over time. Documentation and assessment that sample outcomes only on short time scales (e.g., by standardized testing) cannot assess practices that inherently take much longer to be enacted (e.g., designing a product or refining an experiment).

Assessment must also be organized so that it can recognize unanticipated valuable outcomes and processes in progress. We propose a synthesis of assessment approaches that encompasses many general types of valued outcomes, to be assessed at each of three organizational levels: project, group, and individual (see Table 1). We find that outcomes at each level are frequently influenced by those at other levels, such as when groups learn how to better support the learning of individual members and when projects learn how to better enable participants to identify and achieve their own learning goals.

Valued outcomes include more than just acquired knowledge. The definition of knowledge for assessing informal learning should be broad enough to include know-how and know-who as well as know-that. The assessment should examine evidence 
that knowledge is being used (knowing how to take the next step in an activity) and that this use persists, grows, and cumulates over relatively long periods. Relevant knowledge includes such socially oriented capabilities as assisting others to achieve valued learning outcomes, completing tasks cooperatively, and knowing how to build relationships and negotiate social networks.

In addition to knowing how to collaborate with others, important capabilities in most settings include knowing who can contribute to meeting a need (know-who). Important outcomes also include the capacity to mobilize learning across a widening range of tasks, domains, and settings and an improvement in one's ability to successfully guide one's own learning.

Other forms of socioemotional development include increased emotional maturity, the productive use of affective sensibilities, and comfort with and sense of agency in a domain. Informal learning environments typically seek to support participants' self-respect, responsibility, initiative, and sense of agency. These might be assessed in conjunction with forms of knowledge and skills particular to epistemic frames or content domains, such as the capacity to generate high-quality products or to evaluate the credibility of claims and information sources. In learning environments well attuned to the social and cultural context, it would be valuable to document learners' persistence and resilience in the face of specific obstacles, setbacks, and frustrations and their continued development and application of learning over long stretches of time.

Documentation activities should support the assessment of both anticipated and unanticipated outcomes as well as recording the processes over time by which the outcomes are produced. In the review of the literature provided in this report, we highlight the variety of methods of documentation and assessment 
that have proven valuable or are considered promising and worthy of further support and investigation.

Among these are broad approaches, such as Evidence Centered Design (ECD) of assessment and methods derived from it, the use of video documentation and both close analysis and category-based data mining methods of video archives, embedded and unobtrusive integrated assessment in learning games and simulations, longitudinal collections of learner and group products, ethnographic observation and field notes, and interviews with participants and organizational stakeholders.

In addition to the accounts of particular projects reviewed here, we have also included a comprehensive bibliography that focuses on projects and discussions of assessment of informal learning activities that have been influential or deserve to be, many of which were recommended to us by members of our expert panels and from which we made our selection of the studies to be reviewed. ${ }^{1}$

\section{Promising Directions and Recommendations}

In the course of the review of the literature and the meetings of our expert panels, we identified promising new directions for informal learning activities, projects, and methods of documentation and assessment that are deserving of support and further investigation into their effectiveness and usefulness.

These efforts include projects developed and implemented by partnerships between sponsoring organizations (such as universities and informal science education institutions) and local, community-based organizations whose leaders and members can represent the perspectives and perceived needs of the community in which the project will operate. These projects often 


\section{Box 2}

A Comment on Standardized Testing

In the projects we have reviewed, standardized measures and test scores play a very small role in assessment, and in the discussions in our expert panel meetings, there was little or no sentiment expressed favoring the relevance or greater use of such measures.

Our view is that the validity of standardized testing measures has not been established for informal learning activities, in large part because these activities do not have fixed, predictable curricular outcomes and because the valued outcomes they do have are either unpredictable or do not have existing valid standard measures that can be used in the informal learning context without being disruptive of other goals and commitments (e.g., enjoyment, creative production, maintenance of a free-choice community). Thus their use, though not excluded and sometimes of value, should not be considered a norm or an ideal of good assessment for informal learning. In fact, when they are used, the outcome may say as much about whether the test fits the activity (i.e., its content and context validity for this particular use) as whether the activity is producing higher scores on what the test tries to measure.

Policymakers and funders do need assessments that provide a basis for comparison across projects and approaches. The development of such assessments for informal learning activities will require research that can compare and align project-specific assessments across multiple sites and projects over time (see below). It may also be useful to identify the common characteristics of successful informal learning activities across projects and use these as benchmarks when considering new proposals, while still encouraging innovation. 
expand the number and kinds of mentors (such as undergraduates, older students, and noneducation professionals), rethinking the roles of those who can assist in activities and redesigning their training and experience.

We also see promise in the development of comprehensive documentation of activities and processes in richly instrumented spaces designed for assessment purposes. One mode for this is computer-assisted learning games that automatically and unobtrusively document learning progress. These can have a wide range of application if they can be accessed through mobile computing devices (phones and tablets), even if they run on a remote server.

Such approaches lend themselves to data mining and machine-learning analysis of logs of interaction with computer programs, video archives, field note archives, and databases of participant products to identify patterns of successful and unsuccessful practices on the part of participants and project organizers. Ethnographic research in online virtual worlds, where new kinds of social learning are taking place, can lay the foundation for developing comprehensive documentation and assessment in these new environments. Data mining approaches must be accompanied by the development of tools to analyze the wealth of data collected in new and useful ways.

Other new approaches show promise as well-for example, the use of agent-based modeling to interrogate and attempt to simulate the key processes and practices of participants that contribute to valued outcomes. The crowdsourcing of assessment (e.g., the awarding of badges that recognize achievement by peers or senior peers in a project community) can enlist the knowledge and judgment of those closest to an activity. Care should be taken, however, that peer judgments are not superseded by external, standardized criteria. 
The adaptation of the ECD model to planning more comprehensive documentation and assessment of projects provides another avenue for advancing the field. In particular, the theoretical requirements in ECD for developing assessment arguments help make explicit the types of considerations pertinent to informal learning settings as they are discussed in this report.

In addition to our general conclusions and findings on promising practices, we have developed more specific recommendations for the research, practice, and funding communities:

- We suggest that funding for informal learning projects should include set-aside funds for professional evaluation and assessment-to begin as early in the work of the project as possible, to document learning across the range of outcomes and levels identified in this report, to develop and apply project-specific and activity-specific measures, to modify these as new elements in the project emerge, and to iteratively improve the local assessment model in close interaction with project participants in all roles.

- We recommend follow-up assessments of the valued consequences of participating in projects one year or more after the end of participation. We believe that longitudinal and ongoing assessment of projects with multiyear durations is necessary, with a focus on change, improvement, and sustainability.

- We see particular value in the same assessment team having the opportunity to work with more than one project in order to help develop indices and measures with validity for more than one project, or to document why this strategy may have limited usefulness.

- We further support the development of data mining and learning analytics tools that can be applied to a range of data types, including video and field note documentation archives 
and participant work portfolios, and that can produce results that have practical, useful interpretations.

- Research on the nature and distinctive features of informal learning communities and how they may differ from school-based learning groups is important for improving our understanding of social learning in informal activities and for estimating the transferability of successful practices from informal to formal settings. It also would be valuable to have more research that examines the relationship between play and learning, and learning trajectories in activities in which playfulness and enjoyment are the dominant mood and motive, rather than more exclusively serious approaches to learning for its own sake.

We wish to thank the MacArthur Foundation for sponsoring this effort and the many generous colleagues who have contributed to deepening our understanding. The effective documentation and assessment of informal learning activities has much to teach us about how and why a wide range of valued outcomes result from such activities. It may have much to contribute in the future to rethinking assessment in formal education as well. We hope that this report provides a basis for thoughtful discussion, a useful account of the current state of the art, and a challenge to all of us to do better. 



\section{Appendix A: Expert Meeting Participants}

San Francisco, June 10-11, 2011

Bronwyn Bevan (Exploratorium)

Michael Cole (University of California [UC], San Diego)

Shelley Goldman (Stanford University)

Louis Gomez (UC, Los Angeles)

Kris Gutierrez (UC, Los Angeles)

Robert Lecusay (UC, San Diego)

Jay Lemke (UC, San Diego)

Barbara Means (SRI International)

Ray McDermott (Stanford University)

Vera Michalchik (SRI International)

Bonnie Nardi (UC, Irvine)

Evanston, IL, October 21-22, 2011

Sasha Barab (Arizona State University)

Michael Cole (UC, San Diego)

Kevin Leander (Vanderbilt University)

Robert Lecusay (UC, San Diego) 
Jay Lemke (UC, San Diego)

Vera Michalchik (SRI International)

Nichole Pinkard (DePaul University)

Jan Plass (New York University)

Laura Salus (Northwestern University)

Reed Stevens (Northwestern University)

Carla Seal Wanner (Flickerlab)

Stanton Wortham (University of Pennsylvania)

\section{San Diego, February 3-4, 2012}

Philip Bell (University of Washington)

Paulo Blikstein (Stanford University)

Michael Cole (UC, San Diego)

James Paul Gee (Arizona State University)

Mizuko (Mimi) Ito (UC, Irvine)

Robert Lecusay (UC, San Diego)

Jay Lemke (UC, San Diego)

Vera Michalchik (SRI International)

Bill Penuel (University of Colorado, Boulder)

Nichole Pinkard (DePaul University)

Reed Stevens (Northwestern University)

Jennifer Vadeboncoeur (University of British Columbia) 


\section{Appendix B: Bibliography}

Afterschool Alliance. "A Summary of Formal Evaluations of Afterschool Programs' Impact on Academics, Behavior, Safety and Family Life," 2011. http://afterschoolalliance.org/documents/EvaluationsBackgrounder2011 .pdf.

Afterschool Alliance. "21st Century Learning Centers Providing Supports to Communities Nationwide." 2008. http://www.afterschoolal liance.org/researchFactSheets.cfm.

Akilli, G. K. "Games and Simulations: A New Approach in Education?" In Games and Simulations in Online Learning: Research and Development Frameworks, edited by D. Gibson, C. Aldrich, and M. Prensky, 1-20. Hershey, PA: Information Science, 2007.

Aldrich, C. Simulations and the Future of Learning. San Francisco: Pfeiffer, 2004 .

Allen, S. "Looking for Learning in Visitor Talk: A Methodological Exploration." In Learning Conversations in Museums, edited by G. Leinhardt, K. Crowley, and K. Knutson, 259-303. Mahwah, NJ: Erlbaum, 2002.

Allen, S., and J. Gutwill. "Designing with Multiple Interactives: Five Common Pitfalls." Museum Journal 47, no. 2 (2004): 199-212.

Anderson, D., K. B. Lucas, and I. S. Ginns. "Theoretical Perspectives on Learning in an Informal Setting." Journal of Research in Science Teaching 40, no. 2 (2003): 177-199. 
Anderson, D., and S. Nashon. "Predators of Knowledge Construction: Interpreting Students' Metacognition in an Amusement Park Physics Program." Science Education 91, no. 2 (2007): 298-320.

Ang, C. S., and P. Zaphiris. "Social Learning in MMOGs: An Activity Theoretical Perspective." Interactive Technology and Smart Education 5 (2008): 84-102.

Ansbacher, T. "If Technology Is the Answer, What Was the Question? Technology and Experience-Based Learning." Hand to Hand 11, no. 3 (1997): 3-6.

Ash, D. "Dialogic Inquiry in Life Science Conversations of Family Groups in a Museum." Journal of Research in Science Teaching 40, no. 2 (2003): 138-162.

Ash, D., R. Crain, C. Brandt, M. Loomis, M. Wheaton, and C. Bennett. "Talk, Tools, and Tensions: Observing Biological Talk over Time." International Journal of Science Education 29, no. 12 (2007): 1581-1602.

Astor-Jack, T., K. K. Whaley, L. D. Dierking, D. Perry, and C. Garibay. "Investigating Socially Mediated Learning." In In Principle, in Practice: Museums as Learning Institutions, edited by J. H. Falk, L. D. Dierking, and S. Foutz, 217-228. Walnut Creek, CA: AltaMira Press, 2007.

Augustin, T., C. Hockemeyer, M. Kickmeier-Rust, and D. Albert. "Individualized Skill Assessment in Digital Learning Games: Basic Definitions and Mathematical Formalism." IEEE Transactions on Learning Technologies 4, no. 2 (2011):138-148.

Austin, K., S. Ehrlich, C. Puckett, and J. Singleton. YouMedia Chicago: Reimagining Learning, Literacy, and Libraries. Chicago: YouMedia, 2011.

Azevedo, F. S. "Personal Excursions: Investigating the Dynamics of Student Engagement." International Journal of Computers for Mathematical Learning 11, no. 1 (2006): 57-98.

Azevedo, F. S. Serious Play: A Comparative Study of Learning and Engagement in Hobby Practices. Berkeley: University of California Press, 2004. 
Bainbridge, W. "The Scientific Research Potential of Virtual Worlds." Science 317 (2007): 472-476.

Banks, J. A., K. H. Au, A. F. Ball, P. Bell, E. W. Gordon, K. Gutiérrez, S. B. Heath, et al. Learning In and Out of School in Diverse Environments: Lifelong, Life-Wide, Life-Deep. Seattle: University of Washington Center for Multicultural Education, 2007.

Barab, S. A., T. Dodge, A. Ingram-Goble, K. Peppler, P. Pettyjohn, C. Volk, and M. Solomou. "Pedagogical Dramas and Transformational Play: Narratively Rich Games for Learning." Mind, Culture, and Activity 17, no. 3 (2010): 235-264.

Barab, S. A., M. S. Gresalfi, T. Dodge, and A. Ingram-Goble. "Narratizing Disciplines and Disciplinizing Narratives: Games as 21st Century Curriculum." International Journal of Gaming and Computer-Mediated Simulations 2, no. 1 (2010): 17-30.

Barab, S. A., M. S. Gresalfi, and A. Ingram-Goble. "Transformational Play: Using Games to Position Person, Content, and Context." Educational Researcher 39, no. 7 (2010): 525-536.

Barab, S., M. Thomas, T. Dodge, R. Carteaux, and H. Tuzun. "Making Learning Fun: Quest Atlantis, a Game without Guns." Educational Technology Research and Development 53, no. 1 (2005): 86-107.

Barab, S., S. Warren Zuiker, D. Hickey, A. Ingram-Goble, E. J. Kwon, I. Kouper, and S. Herring. "Situationally Embodied Curriculum: Relating Formalisms and Contexts." Science Education 91, no. 5 (2007): 750-782.

Barron, B. "Interest and Self-Sustained Learning As Catalysts of Development: A Learning Ecology Perspective." Human Development 49, no. 4 (2006): 153-224.

Bartko, W. T. "The ABCs of Engagement in Out-of-School-Time Programs." New Directions for Youth Development 105 (2005): 109-120.

Barton, A. C. "Reframing 'Science for All' through the Politics of Poverty." Educational Policy 12 (1998): 525-541. 
Beals, D. E. "Explanatory Talk in Low-Income Families' Mealtime: Preschoolers' Questions and Parents' Explanations; Causal Thinking in Everyday Parent-Child Activity." Hispanic Journal of Behavioral Sciences 19, no. 1 (1993): 3-33.

Beaumont, L. Summative Evaluation of Wild Reef-Sharks at Shedd. John G. Shedd Aquarium, 2005. http://www.informalscience.com/download/ case_studies/report_133.doc.

Behrens, J. T., R. J. Mislevy, M. Bauer, D. M. Williamson, and R. Levy. "Introduction to Evidence-Centered Design and Lessons Learned from Its Application in a Global E-Learning Program." International Journal of Testing 4, no. 4 (2004): 7.

Bell, P., L. A. Bricker, T. R. Lee, S. Reeve, and H. T. Zimmerman. "Understanding the Cultural Foundations of Children's Biological Knowledge: Insights from Everyday Cognition Research." In Proceedings of the Seventh International Conference of the Learning Sciences, edited by S. A. Barab, K. E. Hay, and D. Hickey, 1029-1035. Mahwah, NJ: Erlbaum, 2006.

Bell, P., B. Lewenstein, A. W. Shouse, and M. A. Feder, eds. Learning Science in Informal Environments: People, Places, and Pursuits. Washington, DC: National Academies Press, 2009.

Bell, P., H. T. Zimmerman, L. A. Bricker, and T. R. Lee. The Everyday Cultural Foundations of Children's Biological Understanding in an Urban, HighPoverty Community. Seattle: University of Washington Everyday Science and Technology Group, n.d.

Bevan, B. and V. Michalchik. "Out-of-School-Time STEM: It's Not What You Think." In LOST Opportunities: Learning in Out-of-School Time, edited by B. Bevan, P. Bell, R. Stevens, and A. Razfar, 201-218. New York: Springer-Verlag, 2012.

Bevan, B., J. Dillon, G. E. Hein, M. Macdonald, V. Michalchik, D. Miller, D. Root, L. Rudder, et al. Making Science Matter: Collaborations between Informal Science Education Organizations and Schools. Washington, DC: Center for the Advancement of Informal Science Education, 2010. 
Bieber, A. E., P. Marchese, and D. Engelberg. "The Laser Academy: An After-School Program to Promote Interest in Technology Careers." Journal of Science Education and Technology 14, no. 1 (2005): 135-142.

Birmingham, J., E. Pechman, C. Russell, and M. Mielke. Shared Features of High-Performing After-School Programs: A Follow-Up to the TASC Evaluation. Washington, DC: Policy Studies Associates, 2005.

Black, A. R., F. C. Doolittle, P. Zhu, R. Unterman, and J. B. Grossman. "The Evaluation of Enhanced Academic Instruction in After-School Programs: Findings after the First Year of Implementation." NCEE 20084021. Washington, DC: US Department of Education, Institute of Education Sciences, National Center for Education Evaluation and Regional Assistance, 2008.

Blackburn, M. V. "Disrupting the (Hetero) Normative: Exploring Literacy Performances and Identity Work with Queer Youth." Journal of Adolescent \& Adult Literacy 46, no. 4 (2002): 312-324.

Blanton, W., R. Mayer, M. Gallego, G. McNamee, and M. Shustack. "The Quantitative Effects of Fifth-Dimension Participation on Children's Cognitive and Academic Skills." In The Fifth Dimension: An After-School Program Built on Diversity, edited by M. Cole and the Distributed Literacy Consortium, 107-128. New York: Russell Sage Foundation, 2006.

Blanton, W. E., G. B. Moorman, B. A. Hayes, and M. L. Warner. "Effects of Participation in the Fifth Dimension on Far Transfer." Journal of Educational Computing Research 16, no. 4 (1997): 371-396.

Boud, D. "Sustainable Assessment: Rethinking Assessment for the Learning Society." Studies in Continuing Education 22, no. 2 (2000): 151-167.

Boud, D., R. Cohen, and J. Sampson. "Peer Learning and Assessment." Assessment and Evaluation in Higher Education 24, no. 4 (1999): 413-426.

Boudria, T. J. "Implementing a Project-Based Technology Program for High School Women." Community College Journal of Research and Practice 26, no. 9 (2002): 709-722.

Bouffard, S., and P. Little. "Detangling Data Collection: Methods for Gathering Data." Harvard Family Research Projects Reports Series Out- 
of-School-Time Evaluation Snapshot, no. 5. Cambridge, MA: Harvard Family Research Project, 2004.

Bouffard, S., P. Little, and H. Weiss. "Building and Evaluating Out-ofSchool-Time Connections." Evaluation Exchange 12, nos. 1-2 (2006): 2-6.

Bouillion Diaz, L. “Creating Opportunities for Ubiquitous Learning with Geospatial Technologies: Negotiating Roles at the Borders of Youth and Adult Practice." In Ubiquitous Learning, edited by B. Cope and M. Kalantzis, 100-108. Champaign: University of Illinois Press, 2009.

Bourgonjon, J., K. Rutten, R. Soetaert, and M. Valcke. "From CounterStrike to Counter-Statement: Using Burke's Pentad as a Tool for Analyzing Video Games." Digital Creativity 22, no. 2 (2011): 91-102.

Bremme, D., W. Blanton, M. Gallego, L. C. Moll, R. Rueda, and O. Vásquez. "The Dynamics of Change in Children's Learning." In The Fifth Dimension: An After-School Program Built on Diversity, edited by M. Cole and the Distributed Literacy Consortium, 107-128. New York: Russell Sage Foundation, 2006.

Brody, M., A. Bangert, and J. Dillon. "Assessing Learning in Informal Science Contexts." Commissioned paper by the National Research Council for Science Learning in Informal Environments Committee, 2009. http://informalscience.org/images/research/Brody_Commissioned _Paper.pdf.

Bronte-Tinkew, J., K. Moore, and R. Shwalb. Measuring Outcomes for Children and Youth in Out-of-School-Time Programs: Moving beyond Measuring Academics. Washington, DC: Child Trends, 2006.

Brosi, E. Measurement Tools for Evaluating Out-of-School-Time Programs: An Evaluation Resource. Cambridge, MA: Harvard Family Research Project, Harvard Graduate School of Education, 2011. http://www.hfrp.org/ out-of-school-time/publications-resources/measurement-tools-forevaluating-out-of-school-time-programs-an-evaluation-resource2.

Brown, B. A. "'It Isn't No Slang That Can Be Said about This Stuff': Language, Identity, and Appropriating Science Discourse." Journal of Research in Science Teaching 43, no. 1 (2006): 96-126. 
Brown, A. L., and R. A. Ferrara. "Diagnosing Zones of Proximal Development: An Alternative to Standardized Testing." In Culture, Communication, and Cognition: Vygotskian Perspectives, edited by J. Wertsch, 273-305. New York: Cambridge University Press, 1985.

Bruce, B. C., S. Bruce, R. L. Conrad, and H. J. Huang. "University Science Students as Curriculum Planners, Teachers, and Role Models in Elementary School Classrooms." Journal of Research in Science Teaching 34 (1997): 69-88.

Buckingham, D. Youth, Identity, and Digital Media. Cambridge, MA: MIT Press, 2008.

Buckingham, D., and M. Scanlon. Education, Entertainment and Learning in the Home. Milton Keynes, UK: Open University Press, 2003.

Bull, G., A. Thompson, M. Searson, J. Garofalo, J. Park, C. Young, and J. Lee. "Connecting Informal and Formal Learning: Experiences in the Age of Participatory Media." Contemporary Issues in Technology and Teacher Education 8, no. 2 (2008): 100-107.

Burke, A., and R. F. Hammett. Assessing New Literacies: Perspectives from the Classroom. Vol. 34. New York: Peter Lang, 2009.

Callanan, M. A., and L. Oakes. "Preschoolers' Questions and Parents' Explanations: Causal Thinking in Everyday Activity." Cognitive Development 7 (1992): 213-233.

Campbell, P. "Evaluating Youth and Community Programs." In Framework for Evaluating Impacts of Informal Science Education Projects, edited by A. Friedman, 69-75. Washington DC: National Science Foundation, 2008. http://informalscience.org/documents/Eval_Framework.pdf

Carnegie Council on Adolescent Development. A Matter of Time: Risk and Opportunity in the Nonschool Hours. Carnegie Council, 1992. http:// carnegie.org/fileadmin/Media/Publications/A_matter_of_time.pdf.

Catterall, J. "Involvement in the Arts and Success in Secondary School." In Critical Links: Learning in the Arts and Student Achievement and Social Development, edited by R. Deasy, 68-69. Washington, DC: AEP, 2002. 
Chen, M. "Communication, Coordination, and Camaraderie in World of Warcraft." Games and Culture 4 (2009): 47-73.

Choontanom, T., and B. Nardi. "Theorycrafting: The Art and Science of Using Numbers to Interpret the World." In Games, Learning, and Society, edited by C. Steinkuehler, 185-209. London: Cambridge University Press, 2010.

Chung, A., and E. Hillsman. "Evaluating After-School Programs." The School Administrator 62, no. 5 (2005): 18-21.

Clarke, J., and C. Dede. "Design for Scalability: A Case Study of the River City Curriculum." Journal of Science Education and Technology 18, no. 4 (2009): 353-365.

Cobern, W. W., and G. S. Aikenhead. "Cultural Aspects of Learning Science." In International Handbook of Science Education, edited by B. Fraser and K. Tobin. Vol. 1, 39-52. Dordrecht, Netherlands: Kluwer Academic, 1998.

Colardyn, D., and J. Bjornavold. "Validation of Formal, Nonformal, and Informal Learning: Policy and Practices in EU Member States." European Journal of Education 39, no. 1 (2004): 69-89.

Cole, M., and the Distributed Literacy Consortium. The Fifth Dimension: An After-School Program Built on Diversity. New York: Russell Sage Foundation, 2006.

Coleman, J. "Learning through Games." In The Study of Games, edited by E. Avedon and B. Sutton-Smith, 322-329. New York: Wiley, 1971.

Colley, H., P. Hodkinson, and J. Malcolm. Informality and Formality in Learning. London: Learning and Skills Research Centre, 2003.

Colley, H., P. Hodkinson, and J. Malcolm. Nonformal Learning: Mapping the Conceptual Terrain. Leeds, UK: University of Leeds Lifelong Learning Institute, 2002. http://www.infed.org/archives/etexts/colley_informal_ learning. htm.

Connolly, T.M., E.A. Boyle, M.H. Stansfield, T. and Hainey. "A Survey of Students' Computer Game Playing Habits," Journal of Advanced Technology for Learning 4 (2007): 218-223. 
Connolly, T. M., M. H. Stansfield, and T. Hainey. "Toward the Development of a Games-Based Learning Evaluation Framework." In GamesBased Learning Advancement for Multisensory Human Computer Interfaces: Techniques and Effective Practices, edited by T. M. Connolly, M. H. Stansfield, and E. Boyle, 251-273. Hershey, PA: IGI Publishing, 2009.

Cosmos Corporation. A Report on the Evaluation of the National Science Foundation's Informal Science Education Program. Washington, DC: National Science Foundation, 1998. http://www.nsf.gov/pubs/1998/ nsf9865/nsf9865.htm.

Costa, V. B. "When Science Is 'Another World': Relationships between Worlds of Family, Friends, School, and Science." Science Education 79 (1995): 313-333.

Crane, V., H. J. Nicholson, M. Chen, and S. Bitgood. Informal Science Learning: What the Research Says about Television, Science Museums and Community-Based Projects. Dedham, MA: Research Communications, 1994.

Crowley, K., and J. Galco. "Everyday Activity and the Development of Scientific Thinking." In Designing for Science: Implications from Everyday, Classroom, and Professional Settings, edited by K. Crowley, C. D. Schunn, and T. Okada, 123-156. Mahwah, NJ: Erlbaum, 2001.

Crowley, K., and J. Galco. "Family Conversations and the Emergence of Scientific Literacy." In Designing for Science: Implications from Everyday, Classroom, and Professional Settings, edited by K. Crowley, C. Schunn, and T. Okada, 393-413. Mahwah, NJ: Erlbaum, 2001.

Crowley, K. D., C. D. Schunn, and T. Okada. Designing for Science: Implications from Everyday, Classroom, and Professional Settings. Mahwah, NJ: Erlbaum, 2001.

Curtis, D., and M. Lawson. "Computer Adventure Games as ProblemSolving Environments." International Education Journal 3, no. 4 (2002): 43-56.

Dahotre, A., Y. Zhang, and C. Scaffidi. "A Qualitative Study of Animation Programming in the Wild." In Proceedings of the 2010 ACM-IEEE 
International Symposium on Empirical Software Engineering and Measurement, 1-10. New York: ACM Press. 2010.

Dancu, T. "Comparing Three Methods for Measuring Children's Engagement with Exhibits: Observations, Caregiver Interviews, and Child Interviews." Paper presented at the annual meeting of the Visitor Studies Association, Grand Rapids, MI, 2006.

Darling-Hammond, L., and J. Snyder. "Authentic Assessment of Teaching in Context." Teaching and Teacher Education 16, nos. 5-6 (2000): 523-545.

Davidson, A. L. "Negotiating Social Differences: Youths' Assessments of Educators' Strategies." Urban Education 34, no. 3 (1999): 338-369.

Davidson, C. N., and D. T. Goldberg. The Future of Learning Institutions in a Digital Age. Cambridge, MA: MIT Press, 2009.

Davidson, C. N., and D. T. Goldberg. The Future of Thinking: Learning Institutions in a Digital Age. Cambridge, MA: MIT Press, 2010.

Dede, C. "Scaling Up: Evolving Innovations beyond Ideal Settings to Challenging Contexts of Practice." In Cambridge Handbook of the Learning Sciences, edited by R. K. Sawyer, 551-566. Cambridge, UK: Cambridge University Press, 2006.

Dede, C., S. Rockman, and A. Knox. "Lessons Learned from Studying How Innovations Can Achieve Scale." Threshold 5, no. 1 (2007): 4-10.

Derry, S. Guidelines for Video Research in Education: Recommendations from an Expert Panel. Chicago: University of Chicago Data Research and Development Center, 2007.

Derry, S. J., R. D. Pea, B. Barron, R. A. Engle, F. Erickson, R. Goldman, R. Hall, et al. "Conducting Video Research in the Learning Sciences: Guidance on Selection, Analysis, Technology, and Ethics." Journal of the Learning Sciences 19, no. 1 (2010): 3-53.

Diamond, J. Practical Evaluation Guide: Tools for Museums and Other Educational Settings. Walnut Creek, CA: AltaMira Press, 1999. 
Dickey, M. D. "Girl Gamers: The Controversy and Relevance of FemaleOriented Design for Instructional Design." British Journal of Educational Technology 37, no. 5 (2006): 785-793.

Dierking, L. D., L. M. Adelman, J. Ogden, K. Lehnhardt, L. Miller, and J. D. Mellen. "Using a Behavior Changes Model to Document the Impact of Visits to Disney's Animal Kingdom: A Study Investigating Intended Conservation Action." Curator 47, no. 3 (2004): 322-343.

Dierking, L. D, and J. H. Falk. "Family Behavior and Learning in Informal Science Settings: A Review of the Research." Science Education 78, no. 1 (1994): 57-72. doi:10.1002/sce.3730780104.

Dierking, L. D., and J. H. Falk. "Optimizing Out-of-School Time: The Role of Free-Choice Learning." New Directions for Youth Development 97 (2003): 75-88.

Diversi, M., and C. Mecham. "Latino(a) Students and Caucasian Mentors in a Rural After-School Program: Towards Empowering Adult-Youth Relationships." Journal of Community Psychology 33, no. 1 (2005): 31-40.

Downing-Wilson, D. "Revealing Shifts in Attitude among Undergraduates Participating in Academic Service Learning Programs." Operant Subjectivity 30, nos. 1-2 (2006/2007): 23-51.

Durlak, J., and R. Weissburg. The Impact of After-school Programs That Promote Personal and Social Skills. Chicago: Collaborative for Academic, Social, and Emotional Learning, 2007.

Easton, L. B. Annotated Bibliography on Learning. Denver, CO: Education Commission of the States, 2005.

Eisenhart, M., and L. Edwards. "Red-Eared Sliders and Neighborhood Dogs: Creating Third Spaces to Support Ethnic Girls' Interests in Technological and Scientific Expertise." Children, Youth and Environments 14, no. 2 (2004): 156-177.

Ekman, P., and E. Rosenberg, eds. What the Face Reveals: Basic and Applied Studies of Spontaneous Expression Using the Facial Action Coding System. New York: Oxford University Press, 2005. 
Ellenbogen, K. M. "Museums in Family Life: An Ethnographic Case Study." In Learning Conversations in Museums, edited by G. Leinhardt, K. Crowley, and K. Knutson, 81-102. Mahwah, NJ: Erlbaum, 2002.

Ellenbogen, K. M., J. J. Luke, and L. D. Dierking. "Family Learning Research in Museums: An Emerging Disciplinary Matrix?" Wiley InterScience, 2004. http://www3.interscience.wiley.com/cgi-bin/fulltext/ 109062559/PDFSTART.

Eraut, M. "Nonformal Learning and Tacit Knowledge in Professional Work." British Journal of Educational Psychology 70, no. 1 (2000): 113136.

Erbstein, N., and J. Bookmyer. "Afterschool Evaluation Practices in California: Site-level Perspectives.” Davis, CA: Center for Community School Partnerships, 2005.

Fadigan, K. A., and P. L. Hammrich. "A Longitudinal Study of the Educational and Career Trajectories of Female Participants of an Urban Informal Science Education Program." Journal of Research in Science Teaching 41, no. 8 (2004): 835-860.

Fadjo, C. L., M. T. Lu, and J. B. Black. "Instructional Embodiment and Video Game Programming in an After School Program." In Proceedings of the World Conference on Educational Multimedia, Hypermedia and Telecommunications 2009, 4041-4046. Chesapeake, VA: Association for the Advancement of Computing in Education, 2009.

Falk, J. H. Free-Choice Science Education: How We Learn Science outside School. New York: Teachers College Press, 2001.

Falk, J. H., and L. M. Adleman. "Investigating the Impact of Prior Knowledge and Interest on Aquarium Visitor Learning." Journal of Research in Science Teaching 40, no. 2 (2003): 163-176.

Falk, J. H., and L. D. Dierking. Learning from Museums: Visitor Experiences and the Making of Meaning. Lanham, MD: Rowman \& Littlefield, 2000.

Falk, J. H., and L. D. Dierking. The Museum Experience. Washington, DC: Whalesback Books, 1992. 
Falk, J. H., T. Moussouri, and D. Coulson. "The Effect of Visitors' Agendas on Museum Learning." Curator 41, no. 2 (1998): 107-120.

Falk, J. H., and M. Storksdieck. "Using the "Contextual Model of Learning' to Understand Visitor Learning from a Science Center Exhibition." Science Education 89 (2005): 744-778.

Fancsali, C. What We Know about Girls, STEM, and Afterschool Programs. New York: Academy for Educational Development, 2002.

Fashola, O. S. "Review of Extended-Day and After-School Programs and Their Effectiveness." Report No. 24. Baltimore, MD: Center for Research on the Education of Students Placed at Risk, 1998.

Feldon, D. F., and J. Gilmore. "Patterns in Children's Online Behavior and Scientific Problem-Solving: A Large-N Microgenetic Study." In Advances in Studying and Designing (Computer-Based) Powerful Learning Environments, edited by G. Clarebout and J. Elen, 117-125. Rotterdam, Netherlands: Sense, 2006.

Fender, J. G., and K. Crowley. "How Parent Explanation Changes What Children Learn from Everyday Scientific Thinking." Journal of Applied Developmental Psychology 28, no. 3 (2007): 189-210.

Fenichel, M., and H. A. Schweingruber. Surrounded by Science: Learning Science in Informal Environments. Washington DC: National Academies Press, 2010.

Ferreira, M. The Effect of an After-School Program Addressing the Gender and Minority Achievement Gaps In Science, Mathematics, and Engineering. Arlington, VA: Educational Research Services, 2001.

Fields, D., and Y. Kafai. "Tracing Insider Knowledge across Time and Spaces: A Comparative Ethnography in a Teen Online Game World." In Proceedings of the Eighth International Conference on Computer Supported Collaborative Learning, 199-208. New York: ACM Press, 2007.

Frake, C. O. "Notes toward a Cultural Analysis of Formal." Text-Interdisciplinary Journal for the Study of Discourse 3, no. 3 (1983): 299-304. 
Fredricks, J. A., P. C. Blumenfeld, and A. H. Paris. "School Engagement: Potential of the Concept, State of the Evidence." Review of Educational Research 74, no. 1 (2004): 59.

Freeman, J., R. Dorph, and B. S. Chi. Strengthening After-School STEM Staff Development: A Final Report to the Noyce Foundation. Coalition for Science after School. Berkeley: University of California, 2009.

Freitas, S. de, and M. D. Griffiths. "The Convergence of Gaming Practices with Other Media Forms: What Potential for Learning? A Review of the Literature." Learning, Media and Technology 33, no. 1 (2008): 11-20.

Freitas, S. de, and M. D. Griffiths. "Massively Multiplayer Online RolePlay Games to Support Learning and Training Communities." In Handbook of Research on Effective Electronic Gaming in Education, edited by R. Ferdig, 51-66. Hershey, PA: Information Science Reference 2009.

Freitas, S. de, and M. Oliver. "How Can Exploratory Learning with Games and Simulations within the Curriculum Be Most Effectively Evaluated?" Computers \& Education 46, no. 3 (2006): 249-264.

Freitas, S. de, G. Rebolledo-Mendez, F. Liarokapis, G. Magoulas, and A. Poulovassilis. "Learning as Immersive Experiences: Using the Four Dimensional Framework for Designing and Evaluating Immersive Learning Experiences in a Virtual World." British Journal of Educational Technology 41, no. 1 (2010): 69-85.

Friedman, A., ed. Framework for Evaluating Impacts of Informal Science Education Projects. Washington, DC: National Science Foundation, 2008.

Fusco, D. "Creating Relevant Science through Urban Planning and Gardening." Journal of Research in Science Teaching 38, no. 8 (2001): 860-877.

Gallagher, J., and K. Hogan. "Intergenerational, Community-Based Learning and Science Education." Journal of Research in Science Teaching 37, no. 2 (2000): 107-108.

Gee, J. P. "Human Action and Social Groups as the Natural Home of Assessment: Thoughts on 21st Century Learning and Assessment." In Innovative Assessment for the 21st Century: Supporting Educational Needs, 
edited by V. Shute and B. J. Becker, 13-39. New York: Springer-Verlag, 2010 .

Gee, J. P. New Digital Media and Learning as an Emerging Area and "Worked Examples" as One Way Forward. Cambridge, MA: MIT Press, 2010.

Gee, J. What Video Games Have to Teach Us about Learning and Literacy. New York: Palgrave Macmillan, 2003.

Gerber, B. L., A. M. Cavallo, and E. A. Marek. "Relationships among Informal Learning Environments, Teaching Procedures and Scientific Reasoning Ability." International Journal of Science Education 23, no. 5 (2001): 535-549.

Gerber, B. L., E. A. Marek, and A. M. Cavallo. "Development of an Informal Learning Opportunities Assay." International Journal of Science Education 23, no. 6 (2001): 569-583.

Gibson, H., and C. Chase. "Longitudinal Impact of an Inquiry-Based Science Program on Middle School Students' Attitudes towards Science." Science Education 86, no. 5 (2002): 693-705.

Goldman, S. "A New Angle on Families: Connecting the Mathematics in Daily Life with School Mathematics." In Learning in Places: The Informal Education Reader, edited by Z. Bekerman, N. Burbules, and D. SilbermanKeller, 55-76. Bern, Switzerland: Peter Lang, 2006.

Goldman, S., and A. Booker. "Making Math a Definition of the Situation: Families as Sites for Mathematical Practices." Anthropology and Education Quarterly 40 (2009): 369-387.

Goodwin, M. H. "Occasioned Knowledge Exploration in Family Interaction." Discourse and Society 18, no. 1 (2007): 93-110.

Gration, M., and J. Jones. "From Intent to Impact: Building a Culture of Evaluation." ASTC Dimensions, May 16, 2008. http://www.astc.org/ blog/2008/05/16/from-intent-to-impact-building-a-culture-of-evaluation/.

Gray, B. "Informal Learning in an Online Community of Practice." Journal of Distance Education 19, no. 1 (2004): 20-35. 
Green, J., and A. Luke. "Rethinking Learning: What Counts as Learning and What Learning Counts." Review of Research in Education 30, no. 1 (2006): xi-xiv.

Greenfield, P. M. "Technology and Informal Education: What Is Taught, What Is Learned." Science 323, no. 5910 (2009): 69-71.

Greenfield, P., and J. Lave. "Cognitive Aspects of Informal Education." In Cultural Perspectives on Child Development, edited by D. A. Wagner and H. W. Stevenson, 181-207. San Francisco: Freeman, 1982.

Gresalfi, M. S. "Taking Up Opportunities to Learn: Constructing Dispositions in Mathematics Classrooms." Journal of the Learning Sciences 18, no. 3 (2009): 43.

Griffin, J. "Learning to Learn in Informal Science Settings." Research in Science Education 24, no. 1 (1994): 121-128.

Grossman, J. B., J. Goldmith, J. Sheldon, and A. J. A. Arbreton. "Assessing After-School Settings." New Directions for Youth Development, 121 (2009): 89-108.

Guichard, H. "Designing Tools to Develop the Conception of Learners." International Journal of Science Education 17, no. 2) (1995: 243-53.

Gutnick, A. L., M. Robb, L. Takeuchi, and J. Kotler. "Always Connected: The New Digital Media Habits of Young Children." New York: Joan Ganz Cooney Center Sesame Workshop, 2011.

Gutwill, J. P., and S. Allen. "Facilitating Family Group Inquiry at Science Museum Exhibits." Science Education 94, no. 4 (2010): 710-742. doi:10.1002/sce.20387.

Halpern. R. The Means to Grow Up: Reinventing Apprenticeship as a Developmental Support in Adolescence. New York: Routledge, 2009.

Halpern, R., J. Spielberger, S. Robb, and Chapin Hall Center for Children. Evaluation of the MOST (Making the Most of Out-of-School Time) Initiative. Chicago: University of Chicago Chapin Hall Center for Children, 2001. 
Harris, E. Afterschool Evaluation 101: How to Evaluate an Expanded Learning Program. Cambridge, MA: Harvard Family Research Project, 2012. http://www.hfrp.org/out-of-school-time/publications-resources/after school-evaluation-101-how-to-evaluate-an-expanded-learning-program.

Harris, E., S. Deschenes, and A. Wallace. "Helping Older Youth Succeed through Expanded Learning Opportunities." Cambridge, MA: Harvard Family Research Project, 2011. http://www.acanorcal.org/sites/default/ files/images/ELO\%20brief\%201-\%20Older\%20Youth\%20FINAL.pdf.

Hasan, R. "Semiotic Mediation and Mental Development in Pluralistic Societies: Some Implications for Tomorrow's Schooling." In Learning for Life in the Twenty-First Century: Sociocultural Perspectives on the Future of Education, edited by G. Wells and G. Claxton, 112-126. Oxford, UK: Blackwell, 2002.

Heath, S. "Diverse Learning and Learner Diversity in 'Informal' Science Learning Environments." Committee on Science Education for Learning Science in Informal Environments, 2007. http://www7.nationalacade mies.org/bose/Learning_Science_in_Informal_Environments_Commis sioned_Papers.html.

Heath, S. "Making Learning Work." Afterschool Matters 1, no. 1 (2000): 33-45.

Herr-Stephenson, B., D. Rhoten, D. Perkel, and C. Sims. Digital Media and Technology in Afterschool Programs, Libraries, and Museums. Cambridge, MA: MIT Press, 2011.

Hickey, D. T., M. A. Honeyford, K. A. Clinton, and J. McWilliams. "Participatory Assessment of 21st Century Proficiencies." In Innovative Assessment for the 21st Century: Supporting Educational Needs, edited by V. Shute and B. J. Becker, 107-138. New York: Springer-Verlag, 2010.

Hirshfeld, L. A. "Why Anthropologists Don't Like Children." American Anthropologist 104, no. 2 (2002): 611-627.

Hmelo-Silver, C. E., E. Katic, A. Nagarajan, and E. Chernobilsky. "Soft Leaders, Hard Artifacts, and the Groups We Rarely See: Using Video to Understand Peer Learning Processes." In Video Research in the Learning 
Sciences, edited by R. Goldman, R. D. Pea, B. Barron, and S. J. Derry, 255-270. Mahwah, NJ: Erlbaum, 2007.

Honey, M. A., and M. Hilton, eds. Computer Games, Simulations, and Education: Learning Science through Computer Games and Simulations. Washington, DC: National Academies Press, 2010.

Honig, M., and M. McDonald. From Promise to Participation: Afterschool Programs through the Lens of Socio-Cultural Learning Theory. Afterschool Matters, 2005. http://www.niost.org/2005-Fall/from-promise-to-partici pation-afterschool-programs-through-the-lens-of-socio-cultural-learn ing-theory.

Hsu, H. Y., and S. K. Wang. "Using Gaming Literacies to Cultivate New Literacies." Simulation and Gaming 41, no. 3 (2010): 400-417.

Hull, G. A., and J. G. Greeno. "Identity and Agency in Nonschool and School Worlds." In Learning in Places: The Informal Education Reader, edited by Z. Bekerman, N. Burbules, and D. S. Keller, 77-97. New York: Peter Lang, 2006.

Hull, G. A., and M. L. Katz. "Crafting an Agentive Self: Case Studies of Digital Storytelling." Research in the Teaching of English 41 (2006): 43-81.

Hull, G. A., and M. E. Nelson. "Locating the Semiotic Power of Multimodality." Written Communication 22, no. 2 (2005): 224.

Hull, G., and K. Schultz. "Literacy and Learning Out of School: A Review of Theory and Research." Review of Educational Research 71, no. 4 (2001): 575 .

Isen, A. M. "Some Perspectives on Positive Feelings and Emotions: Positive Affect Facilitates Thinking and Problem Solving." In Feelings and Emotions: The Amsterdam Symposium, edited by A. S. R. Manstead, N. Frijda, and A. Fischer, 263-281. New York: Cambridge University Press, 2004.

Ito, M., S. Baumer, and M. Bittanti, d. boyd, R. Cody, B. Herr-Stephenson, H. A. Horst, et al. Hanging Out, Messing Around, and Geeking Out: Kids Living and Learning with New Media. Cambridge, MA: MIT Press, 2009. 
Ito, M., H. Horst, M. Bittanti, d. boyd, B. Herr-Stephenson, P. G. Lange, C. J. Pascoe, et al. Living and Learning with New Media: Summary of Findings from the Digital Youth Project. Cambridge, MA: MIT Press, 2008.

Jackson, A., and H. R. Leahy. "'Seeing It for Real?': Authenticity, Theater and Learning in Museums." Research in Drama Education 10, no. 3 (2005): 303-325.

Jarman, R. "Science Learning through Scouting: An Understudied Context for Informal Science Education." International Journal of Science Education 27 , no. 4 (2005): 427-450.

Jenkins, H. Confronting the Challenges of Participatory Culture: Media Education for the 21st Century. Cambridge, MA: MIT Press, 2009.

Jeong, A. "A Guide to Analyzing Message-Response Sequences and Group Interaction Patterns in Computer-Mediated Communication." Distance Education 26, no. 3 (2005): 367-383.

Jolly, E., P. Campbell, and L. Perlman. Engagement, Capacity, Continuity: A Trilogy for Student Success. St. Paul: GE Foundation and Science Museum of Minnesota, 2004.

Jordan, B., and A. Henderson. "Interaction Analysis: Foundations and Practice." Journal of the Learning Sciences 4, no. 1 (1995): 39-103.

Kafai, Y. "Gender Differences in Children's Constructions of Video Games." In Interacting with Video, edited by P. Greenfield and R. Cocking, 39-52. New York: Ablex, 1995.

Kafai, Y. B. Minds in Play: Computer Game Design as a Context for Children's Learning. Mahwah, NJ: Erlbaum, 1994.

Kafai, Y. B. "Playing and Making Games for Learning: Instructionist and Constructionist Perspectives for Game Studies." Games and Culture 1, no. 1 (2006): 34-40.

Kafai, Y. B., and D. A. Fields. "Cheating in Virtual Worlds: Transgressive Designs for Learning." On the Horizon 17, no. 1 (2009): 12-20. 
Kafai, Y. B., K. A. Peppler, and G. M. Chiu. "High Tech Programmers in Low-Income Communities: Creating a Computer Culture in a Community Technology Center." In Communities and Technologies: Proceedings of the Third Communities and Technologies Conference, edited by C. Steinfeld, B. T. Pentland, M. Ackerman, and N. Contractor, 545-563. London: Springer. 2007.

Kahne, J., Nagaoka, J., Brown, A., J. O'Brien, T. Quinn, and K. Thiede. "Assessing After-School Programs as Contexts for Youth Development." Youth and Society 32, no. 4 (2001): 421.

Kane, T. J. The Impact of After-School Programs: Interpreting the Results of Four Recent Evaluations. New York: William T. Grant Foundation, 2004.

Kickmeier-Rust, M. D., and D. Albert. "Emergence in Digital Educational Games: A World of Incidents in a Universe of Rules." In Proceedings of the Third European Conference on Games-Based Learning (ECGBL), October 12-13. Graz, Austria, edited by M. Pivec, 220-226. Reading, UK: Academic Publishing Limited, 2009.

Kickmeier-Rust, M. D., and D. Albert. "Emergent Design: Serendipity in Digital Educational Games." In Virtual and Mixed Reality, edited by R. Shumaker, 206-215. Berlin: Springer-Verlag, 2009.

Kickmeier-Rust, M. D., and D. Albert. "Micro Adaptivity: Protecting Immersion in Didactically Adaptive Digital Educational Games." Journal of Computer Assisted Learning 26 (2010): 95-105.

Kickmeier-Rust, M. D., C. Hockemeyer, D. Albert, and T. Augustin. "Micro Adaptive, Noninvasive Assessment in Educational Games." In Proceedings of the Second IEEE International Conference on Digital Game and Intelligent Toy Enhanced Learning, November 17-19, 2008, Banff, Canada, edited by M. Eisenberg, Kinshuk, M. Chang, and R. McGreal, 135-137. New York: IEEE, 2008.

Kickmeier-Rust, M. D., B. Marte, S. B. Linek, T. Lalonde, and D. Albert. "Learning with Computer Games: Micro Level Feedback and Interventions." In Proceedings of the International Conference on Interactive Computer Aided Learning (ICL), September 24-27, edited by M. E. Auer. Villach, Austria. Kassel: Kassel University Press, 2008. 
Kickmeier-Rust, M. D., C. M. Steiner, and D. Albert. "Noninvasive Assessment and Adaptive Interventions in Learning Games." Paper presented at the International Conference on Intelligent Networking and Collaborative Systems, Barcelona, Spain, November 4-6, 2009.

Kirriemuir, J., and A. McFarlane. "Literature Review in Games and Learning: A Report for NESTA Futurelab." Report no. 8. Bristol, UK: National Endowment for Science, Technology and the Arts (NESTA), 2004. http://archive.futurelab.org.uk/resources/documents/lit_reviews/ Games_Review.pdf.

Klopfer, E. Augmented Learning; Research and Design of Mobile Educational Games. Cambridge, MA: MIT Press, 2008.

Koran, J. J., M. L. Koran, and J. S. Foster. "Using Modeling to Direct Attention." Curator 31, no. 1 (1988): 36-42.

Kow, Y. M., and B. Nardi. "Forget Online Communities? Revisit Cooperative Work!" In Proceedings of the Eleventh International Conference on Computer-Supported Cooperative Work, 351-354. New York: ACM Press, 2011.

Kow, Y. M., and B. Nardi. "Culture and Creativity: World of Warcraft Modding in China and the U.S." In Online Worlds: Convergence of the Real and the Virtual, edited by W. Bainbridge, 21-41. New York: SpringerVerlag, 2009.

Lauver, S., and P. Little. "Finding the Right Hook: Strategies for Attracting and Sustaining Participation in After-School Programs." School Administrator 62, no.5 (2005): 27-31.

Lauver, S., P. Little, and H. B. Weiss. "Moving beyond Barriers: Attracting and Sustaining Youth Participation." Harvard Family Research Projects Reports Series Issues and Opportunities in Out-of-School Time Evaluation, no. 6. Cambridge, MA: Harvard Family Research Project, 2004.

Lave, J. "Teaching, as Learning, in Practice." Mind, Culture, and Activity 3, no. 3 (1996): 149-164. 
Law, E., M. Kickmeier-Rust, D. Albert, and A. Holzinger, "Challenges in the Development and Evaluation of Immersive Digital Educational Games." In HCI and Usability for Education and Work, edited by A. Holzinger, 19-30. Heidelberg, Germany: Springer-Verlag, 2008.

Learning Point Associates. 21st Century Community Learning Centers Analytic Support for Evaluation and Program Monitoring: An Overview of the 21st CCLC Program, 2004-05. Naperville, IL: Learning Point Associates, 2006.

Lee, C. "Toward a Framework for Culturally Responsive Design in Multimedia Computer Environments: Cultural Modeling as a Case." Mind, Culture, and Activity 10, no. 2 (2003): 42-61.

Lee, O., and S. Fradd. "Interactional Patterns of Linguistically Diverse Students and Teachers: Insights for Promoting Science Learning." Linguistics and Education 8, no. 3 (1996): 269-297.

Lehn, D. vom, C. Heath, and J. Hindmarsh. "Video-Based Field Studies in Museums and Galleries." Visitor Studies 5, no, 3 (2002): 15-23.

Leinhardt, G., K. Crowley, and K. Knutson. Learning Conversations in Museums. Mahwah, NJ: Erlbaum, 2002.

Leinhardt, G., and K. Knutson. Listening in on Museum Conversations. Walnut Creek, CA: AltaMira Press, 2004.

Leinhardt, G., C. Tittle, and K. Knutson. "Talking to Oneself: Diaries of Museum Visits." In Learning Conversations in Museums, edited by G. Leinhardt, K. Crowley, and K. Knutson, 103-133. Mahwah, NJ: Erlbaum, 2002.

Lemke, J. “Appropriate Assessment in a Living Activity System." Unpublished Laboratory of Comparative Human Cognition paper, 2011.

Little, P., S. Dupree, and S. Deich. Documenting Progress and Demonstrating Results: Evaluating Local Out-of-School-Time Programs. New York: Finance Project, 2002.

Little, P., and E. Harris. "A Review of Out-of-School Time Program Quasi-Experimental and Experimental Evaluation Results." Harvard 
Family Research Projects Reports Series Out-of-School-Time Evaluation Snapshot, no. 1. Cambridge, MA: Harvard Family Research Project, 2003. Little, P., E. Harris, and S. Bouffard. "Performance Measures in Out-ofSchool-Time Evaluation." Harvard Family Research Projects Reports Series Out-of-School-Time Evaluation Snapshot, no. 3. Cambridge, MA: Harvard Family Research Project, 2004.

Little, P., and S. Lauver. "Engaging Adolescents in Out-of-School-Time Programs: Learning What Works." Prevention Researcher 12, no. 2 (2005): 7-10.

Little, P., C. Wimer, and H. B. Weiss. "After-School Programs in the 21st Century: Their Potential and What It Takes to Achieve It." Harvard Family Research Reports Series Issues and Opportunities in Out-of-SchoolTime Evaluation, no. 10. Cambridge, MA: Harvard Family Research Project, 2008.

Livingstone, D. W. "Exploring the Icebergs of Adult Learning: Findings of the First Canadian Survey of Informal Learning Practices." Canadian Journal for the Study of Adult Education 13, no. 2 (1999): 49-72.

Loh, C. S., A. Anantachai, J. Byun, and J. Lenox. "Assessing What Players Learned in Serious Games: In Situ Data Collection, Information Trails, and Quantitative Analysis." In Proceedings of the Tenth International Conference for Computer Games: AI, Animation, Mobile, Educational, and Serious Games, edited by Q. Mehdi. Wolverhampton, UK: University of Wolverhampton, 2007.

Macdonald, J. "Assessing Online Collaborative Learning: Process and Product." Computers and Education 40, no. 4 (2003): 377-391.

Mahiri, J. Digital Tools in Urban Schools: Mediating a Remix of Learning. Ann Arbor: University of Michigan Press, 2011.

Mahoney, J., R. Larson, and J. S. Eccles, eds. Organized Activities as Contexts of Development: Extracurricular Activities, After-School, and Community Programs. Hillsdale, NJ: Erlbaum, 2005. 
Maloney, J. H., K. Peppler, Y. Kafai, M. Resnick, and N. Rusk. "Programming by Choice: Urban Youth Learning Programming with Scratch." ACM SIGCSE Bulletin 40, no, 1 (2008): 367-371.

Martin, L. M. "An Emerging Research Framework for Studying Informal Learning and Schools." Science Education 88, suppl. 1 (2004): S71-S82.

Martin, L., and S. Goldman. "Family Inheritance: Parallel Practices of Financial Responsibility in Families." In Educating Comprehensively: Varieties of Educational Experiences. Vol. 3, edited by L. Lin, H. Varenne, and E. W. Gordon, 257-280. Lewiston, NY: Edwin Mellen Press, 2010.

Martin, L., S. Goldman, and O. Jimenez. "The Tanda: A Practice at the Intersection of Mathematics, Culture, and Financial Goals." Mind, Culture, and Activity 16, no. 4 (2009): 338-352.

Martin, L., and R. Toon. "Narratives in a Science Center: Interpretation and Identity." Curator 48, no. 4 (2005): 407-426.

Maxwell, L. E., and G. W. Evans. "Museums as Learning Settings: The Importance of the Physical Environment." Journal of Museum Education 27, no. 1 (2002): 3-7.

Mayer, R. E. "Multimedia Learning: Are We Asking the Right Questions?" Educational Psychologist 32, no. 1 (1997): 1-19.

Mayer, R. E., J. Quilici, R. Moreno, R. Duran, S. Woodbridge, R. Simon, D. Sanchez, and A. Lavezzo. "Cognitive Consequences of Participation in a Fifth Dimension After-School Computer Club." Journal of Educational Computing Research 16, no. 4 (1997): 353-369.

Mayer, R. E., M. W. Schustack, and W. E. Blanton. "What Do Children Learn from Using Computers in an Informal, Collaborative Setting?" Educational Technology 39 (1999): 27-31.

McLaughlin, M. W. Community Counts: How Youth Organizations Matter for Youth Development. Washington, DC: Public Education Network, 2000 .

McPherson, T. Digital Youth, Innovation, and the Unexpected. Cambridge, MA: MIT Press, 2008. 
Means, B., Y. Toyama, R. Murphy, M. Bakia, and K. Jones. "Evaluation of Evidence-Based Practices in Online Learning: A Meta-Analysis and Review of Online Learning Studies." Washington, DC: U.S. Department of Education, Office of Planning, Evaluation, and Policy Development, 2009.

Michalchik, V., and L. Gallagher. "Naturalizing Assessment." Curator 53, no. 2 (2010): 209-219.

Miller, B. M. Critical Hours: Afterschool Programs and Educational Success. Quincy, MA: Nellie Mae Education Foundation, 2003.

Miller, B. M. "The Promise of After-School Programs." Educational Leadership 58, no. 7 (2001): 6-12.

Miller, S. "Ends, Means and Galumphing: Some Leitmotifs of Play." American Anthropologist 75 (1971): 87-98.

Mislevy, R. J., R. G. Almond, and J. F. Lukas. "A Brief Introduction to Evidence-Centered Design." Los Angeles, CA: Center for Research on Evaluation, Standards, and Student Testing, 2004.

Mitchell, A., and C. Savill-Smith. The Use of Computer and Video Games for Learning: A Review of the Literature. London: Learning and Skills Development Agency, 2005.

Moje, E. B., and J. S. Eccles. Out-of-School Programs for Literacy Development: Review of the Literature. New York: Carnegie Corporation Adolescent Literacy Council, 2005.

Moje, E. B., and N. Tysvaer. Adolescent Literacy Development in Out-ofSchool Time: A Practitioner's Guide. New York: Carnegie Corporation, 2010 .

Moll, L., C. Amanti, D. Neff, and N. Gonzalez. "Funding of Knowledge for Teaching: Using a Qualitative Approach to Connect Homes and Classrooms." In Funds of Knowledge: Theorizing Practices in Households, Communities, and Classrooms, edited by L. Moll, C. Amanti, and N. Gonzalez, 71-88. London: Routledge, 2005. 
Moussouri, T. "The Use of Children's Drawings as an Evaluation Tool in the Museum." Museological Review 4 (1997): 40-50.

Naismith, L., P. Lonsdale, G. Vavoula, and M. Sharples. Literature Review in Mobile Technologies and Learning, Report no. 11. Bristol, UK: National Endowment for Science, Technology and the Arts (NESTA), 2004. http:// archive.futurelab.org.uk/resources/documents/lit_reviews/Mobile _Review.pdf.

Nardi, B., S. Ly, and J. Harris. "Learning Conversations in World of Warcraft." In Proceedings of the Thirty-Third Annual Hawaii International Conference on Systems Science, 1-10. New York: Institute of Electrical and Electronics Engineers (IEEE) Press, 2007.

Nasir, N. S. "Individual Cognitive Structuring and the Sociocultural Context: Strategy Shifts in the Game of Dominoes." Journal of the Learning Sciences 14, no. 1 (2005): 5-34.

Nasir, N. S., A. S. Rosebery, B. Warren, and C. D. Lee. "Learning as a Cultural Process: Achieving Equity through Diversity." In The Cambridge Handbook of the Learning Sciences, edited by R. K. Sawyer, 489-504. New York: Cambridge University Press, 2006.

National Institute on Out-of-School Time (NIOST) and the Academy for Educational Development Center for Youth Development and Policy Research. Strategic Plan: Building a Skilled and Stable Out-of-School-Time Workforce. Wellesley, MA: NIOST, 2003.

National Research Council. Learning Science in Informal Environments: People, Places, and Pursuits. Washington, DC: National Academies Press, 2009.

Nelson-Barber, S., and E. Estrin. Culturally Responsive Mathematics and Science Education for Native Students. Washington, DC: Native Education Initiative of the Regional Educational Labs, 1995.

Neulight, N., Y. B. Kafai, L. Kao, B. Foley, and C. Galas. “Children's Participation in a Virtual Epidemic in the Science Classroom: Making Connections to Natural Infectious Diseases." Journal of Science Education and Technology 16, no. 1 (2007): 47-58. 
Newman, D., P. Griffin, and M. Cole. The Construction Zone: Working for Cognitive Change in School. Cambridge, UK: Cambridge University Press, 1989.

New York State Afterschool Network (NYSAN). Program Quality SelfAssessment Tool: Planning for Ongoing Program Improvement. Albany, NY: NYSAN, 2005.

Nixon, A. S. "Mediating Social Thought through Digital Storytelling." Pedagogies 4, no. 1 (2009): 63-76.

Noam, G. G., ed. After-School Worlds: Creating a New Social Space for Development and Learning. San Francisco: Jossey-Bass, 2004.

Nocon, H. D. "Sustainability as Process: Community Education and Expansive Collaborative Activity." Educational Policy 18, no. 5 (2004): 710.

O'Connor, K., and W. R. Penuel. "Introduction: Principles of a Human Sciences Approach to Research on Learning." Yearbook of the National Society for the Study of Education 109 (2010): 1-16.

Oblinger, D. G. "Learning Spaces." Educause, 2006. http://www .educause.edu/LearningSpaces.

O’Neill, M. C., and C. Dufresne-Tasse. "Looking in Everyday Life: Gazing in Museums." Museum Management and Curatorship 16, no. 2 (1997): 131-142.

Osborne, J., and J. Dillon. "Research on Learning in Informal Contexts: Advancing the Field?" International Journal of Science Education 29, no. 12 (2007): 1441-1445.

Partee, G. Lessons Learned about Effective Policies and Practices for Out-ofSchool-Time Programming. Washington, DC: American Youth Policy Forum, 2003.

Peirce, N., O. Conlan, and V. Wade. "Adaptive Educational Games: Providing Noninvasive Personalised Learning Experiences." In Second IEEE International Conference on Digital Games and Intelligent Toys-Based Education, 28-35. New York: IEEE, 2008. 
Pellegrino, J. W., N. Chudowsky, and R. Glaser. Knowing What Students Know: The Science and Design of Educational Assessment. Washington, DC: National Academies Press, 2001.

Penuel, W., B. Fishman, B. Cheng, and N. Sabelli. "Organizing Research and Development at the Intersection of Learning, Implementation, and Design." Educational Researcher 40 (7) (2011): 331-337.

Peppler, K. A., and Y. B. Kafai. "From SuperGoo to Scratch: Exploring Creative Digital Media Production in Informal Learning." Learning, Media and Technology 32, no. 2 (2007): 149-166.

Perry, D. L. "Measuring Learning with the Knowledge Hierarchy." In Visitor Studies: Theory, Research and Practice, ed. D. Thompson, S. Bitgood, A. Benefield, H. Shettel, and R. Williams, 73-77. Jacksonville, AL: Visitor Studies Association, 1993.

Phipps, M. "Research Trends and Findings from a Decade (1997-2007) of Research on Informal Science Education and Free-Choice Science Learning." Visitor Studies 13, no. 1 (2010): 3-22.

Pivec, M., ed. Affective and Emotional Aspects of Human-Computer Interaction: Game-Based and Innovative Learning Approaches. Vol. 1, The Future of Learning. Amsterdam: IOS Press, 2006.

Plass, J. L., B. D. Homer, and E. O. Hayward. "Design Factors for Educationally Effective Animations and Simulations." Journal of Computing in Higher Education 21, no. 1 (2009): 31-61.

Policy Studies Associates (PSA). "Identifying Staffing Needs and Recruiting Qualified After-School Staff." In The After-School Corporation Research Brief, 1-4. Washington, DC: PSA, 2000.

Polman, J. L. "Mastery and Appropriation as Means to Understand the Interplay of History Learning and Identity Trajectories." Journal of the Learning Sciences 15, no. 2 (2006): 221-259.

Posner, J. K., and D. L. Vandell. "Low-Income Children's After-School Care: Are There Beneficial Effects of After-School Programs?" Child Development 65, no. 2 (1994): 440-456. 
Prensky, M. Digital Game-Based Learning. New York: McGraw-Hill, 2000.

Rahm, J. "Emergent Learning Opportunities in an Inner-City Youth Gardening Program." Journal of Research in Science Teaching 39, no. 2 (2002): 164-184.

Randol, S. M. "The Nature of Inquiry in Science Centers: Describing and Assessing Inquiry at Exhibits." Unpublished doctoral dissertation, University of California, Berkeley, 2005.

Reisner, E. R., R. N. White, C. A. Russell, and J. Birmingham. Building Quality, Scale and Effectiveness in After-School Programs. Washington, DC: Policy Studies Associates, 2004.

Rennie, L. J., E. Feher, L. D. Dierking, and J. H. Falk. "Toward an Agenda for Advancing Research on Science Learning in Out-of-School Settings." Journal of Research in Science Teaching 40, no. 2 (2003): 112-120.

Rennie, L. J., and D. J. Johnston. "The Nature of Learning and Its Implications for Research on Learning From Museums." Science Education 88, suppl. 1 (2004): S4-S16.

Rennie, L. J., and T. P. McClafferty. "Learning in Science Centres and Science Museums: A Review of Recent Studies." Research in Science Education 23, no. 1 (1993): 351.

Renninger, K., S. Hidi, and A. Krapp. The Role of Interest in Learning and Development. Mahwah, NJ: Erlbaum, 1992.

Resnick, L. B. "The 1987 Presidential Address: Learning in School and Out." Educational Researcher 16, no. 9 (1987): 13-54.

Rhodes, J. E. "The Critical Ingredient: Caring Youth-Staff Relationships in After-School Settings." New Directions for Youth Development 101 (2004): 145-161.

Rideout, V. J., U. G. Foehr, and D. F. Roberts. Generation M2: Media in the Lives of 8- to 18-Year-Olds. Menlo Park, CA: Henry J. Kaiser Foundation, 2010 . 
Robelen, E. W., S. D. Sparks, S. Cavanagh, K. Ash, M. P. Deily, and C. Adams. "Science Learning outside the Classroom." Education Week 30, no. 27 (2011): 1-16.

Robertson, A. E. "Learning about Culture, Language, and Power: Understanding Relationships among Personhood, Literacy Practices, and Intertextuality." Journal of Literacy Research 30, no. 4 (1998): 449-487.

Robinson, G. and L. Fenwick. More Than Homework, a Snack, and Basketball: Afterschool Programs as an Oasis of Hope for Black Parents in Four Cities. Washington, DC: Black Alliance Educational Options, 2007.

Rockman, S., K. Bass, and J. Borse. "Media-Based Learning Science in Informal Environments." National Research Council, 2007. http:// www7.nationalacademies.org/bose/Rockman_et\%20al_Commissioned_ Paper.pdf.

Rogoff, B., R. Paradise, R. Mejía-Arauz, M. Correa-Chávez, and C. Angelillo. "Firsthand Learning by Intent Participation." Annual Review of Psychology 54 (2003): 175-203.

Ross, N., D. Medin, J. D. Coley, and S. Atran. "Cultural and Experiential Differences in the Development of Folkbiological Induction." Cognitive Development 18, no. 1 (2003): 35-47.

Roth, J. L., L. M. Malone, and J. Brooks-Gunn. "Does the Amount of Participation in Afterschool Programs Relate to Developmental Outcomes? A Review of the Literature." American Journal of Community Psychology 45, no. 3 (2010): 310-324.

Rounds, J. "Meaning-Making: A New Paradigm for Museum Exhibits?" Exhibitionist 18, no. 2 (1999): 5-8.

Roussou, M., A. Johnson, T. Moher, J. Leigh, C. Vasilakis, and C. Barnes. "Learning and Building Together in an Immersive Virtual World." Presence: Teleoperators and Virtual Environments Journal 8, no. 3 (1999): 247263.

Roussou, M., M. Oliver, and M. Slater. "Exploring Activity Theory as a Tool for Evaluating Interactivity and Learning in Virtual Environments 
for Children." Journal of Cognition, Technology and Work 10, no. 2 (2007): 141-153.

Roussou, M., M. Oliver, and M. Slater. "The Virtual Playground: An Educational Virtual Reality Environment for Evaluating Interactivity and Conceptual Learning." Journal of Virtual Reality 10, nos. 3-4 (2006): 227-240.

Sabo-Flores, K. A Dynamic Framework for Understanding the Complex Work of Quality Out-of-School Programs. New York: Robert Bowne Foundation, 2009.

Sabo-Flores, K. "A Vygotskian Perspective on Youth Participatory Evaluation: A Field in the Making." New Directions for Evaluation 98 (2003): 13-24.

Salen, K. The Ecology of Games: Connecting Youth, Games, and Learning. Cambridge, MA: MIT Press, 2008.

Salen, K., R. Torres, L. Wolozin, R. Rufo-Tepper, and A. Shapiro. Quest to Learn: Developing the School for Digital Kids. Cambridge, MA: MIT Press, 2010 .

Sandoval, W. A. "Understanding Students' Practical Epistemologies and Their Influence on Learning through Inquiry." Science Education 89, no. 4 (2005): 634-656.

Scaffidi, C., and C. Chambers. "Skill Progression Demonstrated by Users in the Scratch Animation Environment." International Journal of HumanComputer Interaction 28, no. 6 (2011): 383-398.

Scanlon, E., A. Jones, and J. Waycott. "Mobile Technologies: Prospects for Their Use in Learning in Informal Science Settings." Journal of Interactive Media in Education 21, no. 5 (2005): 1-17.

Schauble, L., G. Leinhardt, and L. Martin. "Organizing a Cumulative Research Agenda in Informal Learning Contexts." Journal of Museum Education 22, nos. 2-3 (1998): 3-7.

Schwartz, D. L., and D. Arena. Measuring What Matters: Choice-Based Assessments for the Digital Age. Cambridge, MA: MIT Press, 2013. 
Schwartz, D. L., and G. Noam. Informal Science Learning in Afterschool Settings: A Natural Fit. National Research Council, 2007. http://sites. nationalacademies.org/DBASSE/BOSE/DBASSE_080133.

Schwier, R. A. "Focusing Educational Technology Research on Informal Learning Environments." Contemporary Educational Technology 1, no. 1 (2010): 90-92.

Scott-Little, C., M. S. Hamann, and S. G. Jurs. "Evaluations of AfterSchool Programs: A Meta-Evaluation of Methodologies and Narrative Synthesis of Findings." American Journal of Evaluation 23, no. 4 (2002): 387-419.

Scribner, S., and M. Cole. "Cognitive Consequences of Formal and Informal Education." Science 182, no. 4112 (1973): 553-559.

Seal-Wanner, C. "eTEENS: Teens and Technology: The Perfect Storm?" Television Quarterly 37, no. 2 (2007): 5-16.

Sefton-Green, J. "Informal Learning: Substance or Style?" Teaching Education 14 , no. 1 (2003): 37-51.

Sefton-Green, J. Learning at Not-School: A Review of Study, Theory, and Advocacy for Education in Non-Formal Settings. Cambridge, MA: MIT Press, 2013.

Sefton-Green, J. "Literature Review in Informal Learning with Technology outside School." Report no. 7. Bristol, UK: National Endowment for Science, Technology and the Arts (NESTA), 2004. Futurelab. http:// www2.futurelab.org.uk/resources/documents/lit_reviews/Informal_ Learning_Review.pdf.

Sefton-Green, J. "Youth, Technology, and Media Cultures." Review of Research in Education 30 (2006): 279-306.

Shaffer, D. W. How Computer Games Help Children Learn. New York: Palgrave Macmillan, 2006.

Shaffer, D. W., and J. P. Gee. "The Right Kind of GATE: Computer Games and the Future of Assessment." In Technology-Based Assessments for 21st Century Skills: Theoretical and Practical Implications from Modern 
Research, edited by M. Mayrath, J. Clarke-Midura, and D. H. Robinson, 211-228. Charlotte, NC: Information Age, 2012.

Shaffer, D. W., D. Hatfield, G. N. Svarovsky, P. Nash, A. Nulty, E. Bagley, K. Frank, et al. "Epistemic Network Analysis: A Prototype for 21st-Century Assessment of Learning." International Journal of Learning 1, no. 2 (2009): 33-53.

Shepard, L. "The Role of Assessment in a Learning Culture." Educational Researcher 29, no. 7 (2000): 4-14.

Shernoff, D. J., and D. L. Vandell. "Engagement in After-School Program Activities: Quality of Experience from the Perspective of Participants." Journal of Youth and Adolescence 36, no. 7 (2007): 891-903.

Shute, V. J. "Simply Assessment." International Journal of Learning and Media 1, no. 2 (2009): 1-11.

Shute, V. J. Stealth Assessment in Computer-Based Games to Support Learning: Computer Games and Instruction. Charlotte, NC: Information Age, 2011.

Shute, V. J., and B. J. Becker. "Prelude: Issues and Assessment for the 21st Century." In Innovative Assessment for the 21st Century: Supporting Educational Needs, edited by V. J. Shute and B. J. Becker, 1-11. New York: Springer-Verlag, 2010.

Shute, V. J., I. Masduki, O. Donmez, V. P. Dennen, Y. J. Kim, A. C. Jeong, and C. Y. Wang. "Modeling, Assessing, and Supporting Key Competencies within Game Environments." In Computer-Based Diagnostics and Systematic Analysis of Knowledge, edited by D. Ifenthaler, P. Pirnay-Dummer, and N. M. Seel, 281-309. New York: Springer-Verlag, 2010.

Shute, V. J., and R. Torres. "Where Streams Converge: Using EvidenceCentered Design to Assess Quest to Learn." In Technology-Based Assessments for 21st Century Skills: Theoretical and Practical Implications from Modern Research, edited by by M. C. Mayrath, J. Clarke-Midura, and D. H. Robinson, 91-124. Charlotte, NC: Information Age, 2012.

Shute, V. J., M. Ventura, M. I. Bauer, and D. Zapata-Rivera. "Melding the Power of Serious Games and Embedded Assessment to Monitor and 
Foster Learning: Flow and Grow." In Serious Games: Mechanisms and Effects, edited by U. Ritterfeld, M. Cody, and P. Vorderer, 295-321. Mahwah, NJ: Routledge, Taylor and Francis, 2009.

Simkins, D., and C. Steinkuehler. "Critical Ethical Reasoning and Role Play." Games and Culture 3 (2008): 333-355.

Simon, H. A. "'Seek and Ye Shall Find': How Curiosity Engenders Discovery." In Designing for Science: Implications from Everyday, Classroom, and Professional Settings, edited by K. Crowley, C. Schunn, and T. Okada, 5-20. Mahwah, NJ: Erlbaum, 2001.

Siyahhan, S., S. Barab, and M. Downton. "Using Activity Theory to Understand Intergenerational Play: The Case of Family Quest." International Journal of Computer-Supported Collaborative Learning 5, no. 4 (2010): 415-432.

Smith, B. K., P. Sharma, and P. Hooper. "Decision Making in Online Fantasy Sports Communities." Interactive Technology and Smart Education 3, no. 4 (2006): 347-360.

Spielberger, J., and R. Halpern. The Role of After-School Programs in Children's Literacy Development. Chicago: University of Chicago Chapin Hall Center for Children, 2002.

Squire, K. "Changing the Game: What Happens When Video Games Enter the Classroom." Innovate: Journal of Online Education 1, no. 6 (2005). http://citeseer.ist.psu.edu/viewdoc/summary?doi=10.1.1.101.993.

Squire, K. "From Content to Context: Videogames as Designed Experience." Educational Researcher 35, no. 8 (2006): 19-29.

Squire, K. "Open-Ended Video Games: A Model for Developing Learning for the Interactive Age." In The Ecology of Games: Connecting Youth, Games, and Learning, edited by K. Salen, 167-198. Cambridge, MA: MIT Press, 2008.

Squire, K. D. "Resuscitating Research in Educational Technology: Using Game-Based Learning Research as a Lens for Looking at Design-Based Research." Educational Technology 45, no. 1 (2005): 8-14. 
Squire, K. D. "Toward a Theory of Games Literacy." Telemedium 52, no. 1-2 (2005): 9-15.

Squire, K. "Video Games in Education." International Journal of Intelligent Games and Simulation 2, no. 1 (2003): 49-62.

Squire, K. D., M. Jan, J. Matthews, M. Wagler, J. Martin, B. Devane, and C. Holden. "Wherever You Go, There You Are: The Design of Local Games for Learning." In The Design and Use of Simulation Computer Games in Education, edited by B. Sheldon and D. Wiley, 265-296. Rotterdam, Netherlands: Sense, 2007.

Squire, K., and N. Patterson. "Games and Simulations in Informal Science Education." Paper presented at the National Research Council Workshop on Gaming and Simulations, Washington, DC, October 6-7, 2009. http://www7.nationalacademies.org/bose/Gaming_Sims_Commis sioned_Papers.html.

Stake, J. E., and K. R. Mares. "Evaluating the Impact of Science-Enrichment Programs on Adolescents' Science Motivation and Confidence: The Splashdown Effect." Journal of Research in Science Teaching 42, no. 4 (2005): 359-375.

Steinkuehler, C. "Cognition and Literacy in Massively Multiplayer Online Games." In Handbook of Research on New Literacies, edited by D. Leu, J. Coiro, C. Lankshear, and K. Knobel, 611-634. Mahwah, NJ: Erlbaum, 2008.

Steinkuehler, C. "Learning in Massively Multiplayer Online Games." In Proceedings of the Sixth International Conference of the Learning Sciences, edited by Y. B. Kafai, W. A. Sandoval, N. Enyedy, A. S. Nixon, and F. Herrera, 521-528. Mahwah, NJ: Erlbaum, 2004.

Steinkuehler, C., and S. Duncan. 2008. "Scientific Habits of Mind in Virtual Worlds." Journal of Science Education and Technology 17: 530543.

Steinkuehler, C. and S. Duncan. "Scientific Habits of Mind in Virtual Worlds." Journal of Science Education and Technology 17, no. 6 (2008): 530-543. 
Stevens, R. "Capturing Ideas in Digital Things: The Traces Digital Annotation Medium." In Video Research in the Learning Sciences, edited by R. Goldman, B. Barron, and R. Pea, 547-563. Cambridge, UK: Cambridge University Press, 2007.

Stevens, R. "Learning as a Members' Phenomenon: Toward an Ethnographically Adequate Science of Learning." National Society for the Study of Education Yearbook 109, no. 1 (2010): 82-97.

Stevens, R., T. Satwicz, and L. McCarthy. "In Game, in Room, in World: Reconnecting Video Game Play to the Rest of Kids' Lives." In The Ecology of Games, edited by K. Salen, 41-66. Cambridge, MA: MIT Press, 2008.

Stevens, R., and S. Toro-Martell. "Leaving a Trace: Supporting Museum Visitor Interpretation and Interaction with Digital Media Annotation Systems." Journal of Museum Education 28, no. 2 (2003): 25-31.

Stocklmayer, S. M., L. J. Rennie, and J. K. Gilbert. "The Roles of the Formal and Informal Sectors in the Provision of Effective Science Education." Studies in Science Education 46, no. 1 (2010): 1-44.

Stone, L. D., and K. D. Gutiérrez. "Problem Articulation and the Processes of Assistance: An Activity Theoretic View of Mediation in Game Play." International Journal of Educational Research 46, nos. 1-2 (2007): $43-56$.

Straka, G. A. Informal Learning: Genealogy, Concepts, Antagonisms and Questions. Bremen, Germany: Institut Technik und Bildung (ITB) Forschungsberichte, 2004.

Strobel, K., B. Kirshner, J. O’Donoghue, and M. McLaughlin. “Qualities That Attract Urban Youth to After-School Settings and Promote Continued Participation." Teachers College Record 110, no. 8, (2008): 1677-1705.

Tenenbaum, H. R., and M. A. Callanan. "Parents' Science Talk to Their Children in Mexican-Descent Families Residing in the United States." International Journal of Behavioral Development 32, no. 1 (2008): 1-12.

Tharp, R. G., and R. Gallimore. Rousing Minds to Life: Teaching and Learning in Social Context. New York: Cambridge University Press, 1989. 
Thompson, C. C., and L. B. Diaz. "Building Identities as Experts: Youth Learning in an Urban After-School Space." In Technology and Identity: Constructing the Self in a Digital World, edited by Cynthia Carter Ching and Brian Foley, 75-109. New York: Cambridge University Press, 2009.

Thompson, S., and R. Bonney. "Evaluating the Impact of Participation in an On-Line Citizen Science Project: A Mixed-Methods Approach." In Museums and the Web 2007: Proceedings, edited by J. Trant and D. Bearman, 187-199. Toronto, Canada: Archives and Museum Informatics, 2007. http://www.archimuse.com/mw2007/papers/thompson/thompson .html.

Tseng, V., and E. Seidman. "A Systems Framework for Understanding Social Settings." American Journal of Community Psychology 39, no. 3 (2007): 217-228.

Vadeboncoeur, J. "Engaging Young People: Learning in Informal Contexts." Review of Research in Education 30 (2006): 239-278.

Vandell, D., and E. Reisner. Study of Promising Afterschool Programs: Key Findings from New Research on the Benefits of High-Quality Afterschool Programs. Irvine, CA: University of California, University of Wisconsin, and Policy Studies Associates, 2007.

Vandell, D. L., E. R. Reisner, and K. M. Pierce. Outcomes Linked to HighQuality Afterschool Programs: Longitudinal Findings from the Study of Promising Afterschool Programs. Irvine, CA: University of California and Policy Studies Associates, 2007.

Vandell, D. L., D. J. Shernoff, K. M. Pierce, D. M. Bolt, K. Dadisman, and B. B. Brown. "Activities, Engagement, and Emotion in After-School Programs (and Elsewhere)." New Directions for Youth Development 105 (2005): 121-129.

Vandenberg, B. "Real and Not Real: A Vital Developmental Dichotomy." In Multiple Perspectives on Play in Early Childhood Education, edited by O. Saracho and B. Spoedek, 295-306. Albany: SUNY Press, 1998.

Vásquez, O. A. La Clase Mágica. Mahwah, NJ: Erlbaum, 2003. 
Wai, J., D. Lubinski, C. P. Benbow, and J. H. Steiger. "Accomplishment in Science, Technology, Engineering, and Mathematics (STEM) and Its Relation to STEM Educational Dose: A 25-Year Longitudinal Study." Journal of Educational Psychology 102 (2010): 860-871.

Warren, B., C. Ballenger, M. Ogonowski, A. Rosebery, and J. HudicourtBarnes. "Rethinking Diversity in Learning Science: The Logic of Everyday Sense-Making." Journal of Research in Science Teaching 38 (2001): 529-552.

Watson, J. “If You Don't Have It, You Can't Find It: A Close Look at Students' Perceptions of Using Technology." Journal of the American Society for Information Science 49, no. 11 (1998): 1024-1036.

Weiss, H., and P. Little. "Why, When, and How to Use Evaluation: Experts Speak Out." Harvard Family Research Project Reports Series Issues and Opportunities in Out-of-School-Time Evaluation, no. 5. Cambridge, MA: Harvard Family Research Project, 2003.

Weiss, H. B., P. M. D. Little, and S. M. Bouffard, eds. Participation in Youth Programs: Enrollment, Attendance, and Engagement. Special issue of New Directions for Youth Development, Vol. 105. Hoboken, NJ: Wiley, 2005.

Whitehead, J., B. McLemore, and M. Orlando. World of Warcraft Programming. Hoboken, NJ: Wiley, 2008.

Wilson-Ahlstrom, A., N. Yohalem, D. Dubois, and P. Ji. From Soft Skills to Hard Data: Measuring Youth Program Outcomes. New York: The Forum for Youth Investment. 2011.

Wimer, C. "Learning from Small-Scale Experimental Evaluations of After-School Programs." Harvard Family Research Projects Reports Series Out-of-School-Time Evaluation Snapshot, no. 8. Cambridge, MA: Harvard Family Research Project, 2006.

Wimer, C., S. Bouffard, P. Little, and C. B. Goss. "Measurement Tools for Evaluating Out-of-School-Time Programs: An Evaluation Resource." In Harvard Family Research Projects Reports Series Out-of-School-Time Eval- 
uation Snapshot, no. 6. Cambridge, MA: Harvard Family Research Project, 2005.

Wimer, C., and B. Hull. Harnessing Technology in Out-of-School-Time Settings. Cambridge, MA: Harvard Family Research Project, 2006.

Yohalem, N. "Adults Who Make a Difference: Identifying the Skills and Characteristics of Successful Youth Workers." In Community Youth Development: Practice, Policy and Research, edited by F. A. Villarruel, D. F. Perkins, L. M. Borden, and J. G. Keith, 358-372. Thousand Oaks, CA: Sage, 2003.

YouthLearn Initiative. Model Technology Integration in Afterschool. Newton, MA: Education Development Center.

Zief, S. G., S. Lauver, and R. A. Maynard. Impacts of After-School Programs on Student Outcomes: A Systematic Review of the Campbell Collaboration. Philadelphia, PA: Campbell Collaboration, 2004. 



\section{Appendix C: Online Resources: Assessment, Funding, and Research}

Afterschool Alliance. http://www.afterschoolalliance.org

Afterschool Resources.http://www.statewideafterschoolnetworks .net

Annie E. Casey Foundation. http://www.aecf.org

Assessment Tools in Informal Science (ATIS). http://www.pear web.org/atis

Bill \& Melinda Gates Foundation. http://www.gatesfoundation. org/Pages/home.aspx

California Academy of Sciences. http://www.calacademy.org

Center for Assessment. http://www.nciea.org

Center for Informal Learning and Schools. http://cils.explora torium.edu

Coalition for Science after School. http://www.afterschoolscience. org

Digital Media Learning Central. http://dmlcentral.net Encyclopedia of Informal Education. http://www.infed.org/ index.htm

Exploratorium. http://www.exploratorium.edu

Futurelab. http://www.futurelab.org.uk 
Harvard Family Research Project. http://www.hfrp.org Humanities, Arts, Science, and Technology Advanced Collabora tory. http://hastac.org

Informal Learning Review. http://www.informallearning.com/ the-informal-learning-review.html

InformalScienceEducationEvidenceWiki.http://informalscience .org/research/wiki

Informal Science: Informal Learning Projects, Research and Evaluation. http://informalscience.org

Institute of Play. http://www.instituteofplay.org

Institute for Learning Innovation. http://www.ilinet.org

iRemix. http://remixlearning.com

John D. \& Catherine T. MacArthur Foundation. http://www .macfound.org

Journal of Science Education and Technology. http://link .springer.com/journal/10956

National Academies. http://www.nationalacademies.org

National Center for the Improvement of Educational Assessment. http://www.nciea.org

National Research Council. http://www.nationalacademies.org/ nrc

National Science Foundation Informal Science Education. http:// www.nsf.gov/div/index.jsp?div=DRL

National Science Foundation Innovative Technology Experiences for Students and Teachers (ITEST). See STELAR

New Media Literacies Community. http://www.newmedia literacies.org

Partnership for 21st Century Skills. http://www.p21.org 
Program in Education, Afterschool \& Resiliency (PEAR): Informal Science Education Assessment Database. http://www.pearweb .org

Relating Research to Practice: Current Research in Science Education. http://relatingresearchtopractice.org

Remediating Assessment. http://remediatingassessment.blogspot .com

STELAR (STEM Learning and Research Center). http://stelar.edc .org

Transformative Learning Technologies Laboratory. http://tltl .stanford.edu

U.S. Department of Education. http://www.ed.gov

U.S. Department of Education, Office of Educational Technology. http://tech.ed.gov

U.S. Department of Education-Reports. http://www2.ed.gov/ about/pubs/publications-reports.html

William T. Grant Foundation. http://www.wtgrantfoundation .org

\section{Examples of Out-of-School Learning Projects}

Computer Clubhouse Network. http://www.computerclubhouse .org

Digital Youth Network. http://digitalyouthnetwork.org FabLab@School. http://tltl.stanford.edu/projects/fablabschool Games for Learning Institute. http://g4li.org Healthy Youth Peer Education Program (HYPE). http://www .hypeprogram.org

LIFE Center: Learning in Informal and Formal Environments. http://life-slc.org 
Partnerships for Informal Science Education in the Community| CU-Boulder.

http://jila-pfc.colorado.edu/pisec/home

Quest to Learn. http://www.q21.org

Stanford Makers' Club. http://stanfordmakersclub.ning.com

University-Community Links. http://uclinks.berkeley.edu

You Media. http://youmediachicago.org

YouSTEM: Interest-Driven STEM Exploration Space. http://osep .northwestern.edu/projects/youstem

Youth Media International, Youth Radio. http://www.youth radio.org 


\section{Notes}

\section{Review of the Literature}

1. Scratch 2.0 was released in May 2013.

2. The platform for the online social network is Remix World (http:// remixlearning.com). Developed by Nichole Pinkard and her colleagues, the platform was designed specifically for use by educational institutions-schools, museums, after-school centers-and is customizable to fit the particular needs of each institution.

3. In relation to a broader analysis of the social organization of learning opportunities, Barron et al. (2014) discuss these and other mixedmethod approaches for studying the imaginative production, expertise, and relationships promoted in the face-to-face and online YouMedia environments.

\section{Conclusions and Recommendations}

1. Our bibliography does not focus on the evolving theoretical literature on validity in assessment, although we recognize its relevance and the convergence of some strands of this work with our own conclusions. 



\section{References}

Anderson, D., and S. Nashon. 2007. "Predators of Knowledge Construction: Interpreting Students' Metacognition in an Amusement Park Physics Program." Science Education 91 (2): 298-320.

Ash, D., R. Crain, C. Brandt, M. Loomis, M. Wheaton, and C. Bennett. 2007. "Talk, Tools, and Tensions: Observing Biological Talk over Time." International Journal of Science Education 29 (12): 1581-1602.

Austin, K., S. Ehrlich, C. Puckett, and J. Singleton. 2011. YouMedia Chicago: Reimagining Learning, Literacy, and Libraries. Chicago: YouMedia.

Barron, B., K. Gomez, N. Pinkard, and C. K. Martin. 2014. The Digital Youth Network: Cultivating Digital Media Citizenship in Urban Communities. Cambridge, MA: MIT Press.

Bauman, R., and C. Briggs. 1990. "Poetics and Performance As Critical Perspectives on Language and Social Life." Annual Review of Anthropology 19:59-88.

Behrens, J. T., R. J. Mislevy, M. Bauer, D. M. Williamson, and R. Levy. 2004. "Introduction to Evidence Centered Design and Lessons Learned from Its Application in a Global E-Learning Program." International Journal of Testing 4 (4): 295-301.

Bell, P., B. Lewenstein, A. Shouse, and M. Feder, eds. 2009. Learning Science in Informal Environments: People, Places and Pursuits. Washington, DC: National Academy Press.

Bethesda Softworks. 2006. The Elder Scrolls IV: Oblivion. 
Bevan, B., and V. Michalchik. 2012. "Out-of-School Time STEM: It's Not What You Think." In LOST Opportunities: Learning in Out-of-School Time, ed. B. Bevan, P. Bell, R. Stevens, and A. Razfar, 201-218. New York: Springer.

Blikstein, P. 2011. "Using Learning Analytics to Assess Students' Behavior in Open-Ended Programming Tasks." In Proceedings of the 1st International Conference on Learning Analytics and Knowledge, 110-116. New York: ACM Press.

Brandes, U., and T. Erlebach. 2005. Network Analysis: Methodological Foundations. Berlin: Springer-Velag.

Bransford, J. D., A. L. Brown, and R. R. Cocking, eds. 2000. How People Learn: Brain, Mind, Experience, and School. Washington, DC: National Academy Press.

Bruner, J. 1994. "The Remembered Self." In The Remembering Self: Construction and Agency in Self Narrative, eds. U. Neisser and R. Fivush, 41-54. Cambridge, UK: Cambridge University Press.

Burghardt, M. D. 1999. Introduction to Engineering Design and Problem Solving. Boston: WCB/McGraw-Hill.

Chen, M. 2009. "Communication, Coordination, and Camaraderie in World of Warcraft." Games and Culture 4:47-73.

Cole, M., and the Distributed Literacy Consortium. 2006. The Fifth Dimension: An After-School Program Built on Diversity. New York: Russell Sage Foundation.

Dahotre, A., Y. Zhang, and C. Scaffidi. 2010. "A Qualitative Study of Animation Programming in the Wild." In Proceedings of the 2010 ACMIEEE International Symposium on Empirical Software Engineering and Measurement, 1-10. New York: ACM Press.

Downing-Wilson, D. 2006/2007. "Revealing Shifts in Attitude among Undergraduates Participating in Academic Service Learning Programs." Operant Subjectivity 30 (1/2): 23-51. 
Downing-Wilson, D., R. Lecusay, I. Rosero, and M. Cole. 2012. “A Cultural-Historical Approach to University/Community Collaborative Interventions." In Encyclopedia of Cultural Psychology, ed. J. Valsiner, 885-898. New York: Oxford University Press.

Dym, C. L., and P. Little. 2000. Engineering Design: A Project-Based Introduction. Hoboken, NJ: Wiley.

Eccles, J. 1994. "Understanding Women's Educational and Occupational Choices." Psychology of Women Quarterly 18:585-609.

Eisenhart, M., and L. Edwards. 2004. "Red-Eared Sliders and Neighborhood Dogs: Creating Third Spaces to Support Ethnic Girls' Interests in Technological and Scientific Expertise." Children, Youth and Environments 14 (2): 156-177.

Fadigan, K. A., and P. L. Hammrich. 2004. "A Longitudinal Study of the Educational and Career Trajectories of Female Participants of an Urban Informal Science Education Program." Journal of Research in Science Teaching 41 (8): 835-860.

Fields, D., and Y. Kafai. 2007. "Tracing Insider Knowledge across Time and Spaces: A Comparative Ethnography in a Teen Online Game World." In Proceedings of the Eighth International Conference on Computer Supported Collaborative Learning, 199-208. New York: ACM Press.

Gallagher, J. J., and K. G. Tobin. 1991. "Reporting Interpretive Research." In Interpretive Research in Science Education, ed. J. Gallagher, 85-95. Manhattan, KS: National Association of Research in Science Teaching.

Gee, J. P. 2003. What Video Games Have to Teach Us about Learning and Literacy. New York: Palgrave Macmillan.

Gee, J. P., and D. W. Shaffer. 2010. "Looking Where the Light Is Bad: Video Games and the Future of Assessment." Epistemic Games Group Working Paper 6 (1): 1-20.

Glaser, B. G., and A. Strauss. 1967. The Discovery of Grounded Theory: Strategies for Qualitative Research. Chicago: Aldine. 
Goffman, E. 1974. Frame Analysis: An Essay on the Organization of Experience. New York: Harper \& Row.

Gutiérrez, K., B. Rymes, and J. Larson. 1995. "Script, Counterscript and Underlife in the Classroom: James Brown versus Brown v. Board of Education." Harvard Educational Review 65 (3): 445-447.

Gutwill, J. P., and S. Allen. 2010. "Facilitating Family Group Inquiry at Science Museum Exhibits.” Science Education 94 (4): 710-742.

Herr-Stephenson, B., D. Rhoten, D. Perkel, and C. Sims. 2011. Digital Media and Technology in Afterschool Programs, Libraries, and Museums. Cambridge, MA: MIT Press.

Hines, C. 2000. Virtual Ethnography. Thousand Oaks, CA: Sage.

Hsi, S. 2003. "A Study of User Experiences Mediated by Nomadic Web Content in a Museum." Journal of Computer Assisted Learning 19:308-319.

Hull, G., and M. James. 2007. "Geographies of Hope: A Study of Urban Landscapes and a University-Community Collaborative." In Blurring Boundaries: Developing Writers, Researchers, and Teachers: A Tribute to William L. Smith, ed. Peggy O’Neill, 250-289. Cresskill, NJ: Hampton Press.

Hull, G. A., and M. L. Katz. 2006. "Crafting an Agentive Self: Case Studies of Digital Storytelling." Research in the Teaching of English 41:43-81.

Hutchins, E. 1995. Cognition in the Wild. Cambridge, MA: MIT Press.

Ito, M., K. Gutiérrez, S. Livingstone, B. Penuel, J. Rhodes, K. Salen, J. Schor, J. Sefton-Green, and C. Watkins. 2013. Connected Learning: An Agenda for Research and Design. Irvine, CA: Digital Media and Learning Research Hub.

Kafai, Y. 2010. "The World of Whyville: An Introduction to Tween Virtual Life." Games and Culture 5 (1): 3-22.

Kafai, Y., and D. Fields. 2013. Connected Play: Tweens in a Virtual World. Cambridge, MA: MIT Press. 
Kafai, Y., K. Peppler, M. Alavez, and O. Ruvalcaba. 2006. "Seeds of a Computer Culture: An Archival Analysis of Programming Artifacts from a Community Technology Center." In Proceedings of the Seventh International Conference of the Learning Sciences, ed. S. Barab, K. Hay, and D. Hickey, 942-943. Mahwah, NJ: Erlbaum.

Kafai, Y. B., K. Peppler, and R. Chapman, eds. 2009. The Computer Clubhouse: Creativity and Constructionism in Youth Communities. New York: Teachers College Press.

Kafai, Y. B., K. A. Peppler, and G. M. Chiu. 2007. "High-Tech Programmers in Low-Income Communities: Creating a Computer Culture in a Community Technology Center." Communities and Technologies 2007:545-563.

King, A. 1990. "Facilitating Elaborative Learning in the Classroom through Reciprocal Questioning." American Educational Research Journal 27:664-687.

Kuhn, A., B. McNally, S. Schmoll, C. Cahill, W. Lo, C. Quintana, and I. Delen. 2012. "How Students Find, Evaluate, and Utilize Peer-Collected Annotated Multimedia Data in Science Inquiry with Zydeco." In Proceedings of the 2012 Annual Conference on Human Factors in Computing Systems, 3061-3070. New York: ACM.

Leander, K., and K. McKim. 2003. “Tracing the Everyday 'Sitings' of Adolescents on the Internet: A Strategic Adaptation of Ethnography across Online and Offline Spaces." Education Communication and Information 3 (2): 211-240.

Little, P., C. Wimer, and H. B. Weiss. 2008. "After-School Programs in the 21st Century: Their Potential and What It Takes to Achieve It." Harvard Family Research Project Brief, Issues and Opportunities in Out-ofSchool Time Evaluation, No. 10, 1-12. Cambridge, MA: Harvard Family Research Project.

Mahn, H., and V. John-Steiner. 2013. "Vygotsky and Sociocultural Approaches to Teaching and Learning." In Educational Psychology, ed. W. M. Reynolds and G. E. Miller, 117-146. Vol. 7 of Handbook of Psychology, 2nd ed., ed. I. B. Weiner. Hoboken, NJ: Wiley. 
Mahoney, J., R. Larson, and J. S. Eccles, eds. 2005. Organized Activities As Contexts of Development: Extracurricular Activities, After-School, and Community Programs. Hillsdale, NJ: Erlbaum.

Maloney, J. H., K. Peppler, Y. Kafai, M. Resnick, and N. Rusk. 2008. “Programming by Choice: Urban Youth Learning Programming with Scratch." In Proceedings of the 39th ACM Technical Symposium on Computer Science Education, 367-371. New York: ACM Press.

Maxwell, J. A. 1996. Qualitative Research Design: An Interactive Approach. Thousand Oaks, CA: Sage.

Merriam, S. B. 1998. Qualitative Research and Case Study Applications in Education. San Francisco: Jossey-Bass.

Michalchik, V., and L. Gallagher. 2010. "Naturalizing Assessment." Curator 53 (2): 209-219.

Mislevy, R. J., R. G. Almond, and J. F. Lukas. 2004. “A Brief Introduction to Evidence-Centered Design." Los Angeles: Center for Research on Evaluation, Standards, and Student Testing. (ERIC Document Reproduction Service No. ED483399)

Mislevy, R. J., and G. D. Haertel. 2007. "Implication of Evidence-Centered Design for Educational Testing." Educational Measurement: Issues \& Practice. http://www.em2007.mpg.de/files/MislevyHaertel.pdf.

Nacu, D., N. Pinkard, R. Schmidt, and K. Larson. 2012. "Remixing iRemix: Data Visualizations to Understand Learning and Development in Online Social Learning Networks." Paper presented at the Digital Media and Learning Conference, San Francisco.

Oakes, J. 1992. “Can Tracking Research Inform Practice? Technical, Normative, and Political Considerations." Educational Researcher 21 (4): 12-21.

Quintana, C., C. Cahill, A. Kuhn, S. Schmoll, and A. Pompe. 2010. "Zydeco: Using Mobile and Web Technologies to Support Seamless Inquiry between Museum and School Contexts." In Proceedings of the Ninth International Conference on Interaction Design and Children, 174-177. New York: ACM Press. 
Rahm, J. 2002. "Emergent Learning Opportunities in an Inner-City Youth Gardening Program." Journal of Research in Science Teaching 39 (2): 164-184.

Resnick, M., N. Rusk, and S. Cooke. 1998. "The Computer Clubhouse: Technological Fluency in the Inner City." In High Technology and LowIncome Communities, ed. D. Schön, B. Sanyal, and W. Mitchell, 266-286. Cambridge, MA: MIT Press.

Salen, K., R. Torres, L. Wolozin, R. Rufo-Tepper, and A. Shapiro. 2010. Quest to Learn: Developing the School for Digital Kids. Cambridge, MA: MIT Press.

Scaffidi, C., and C. Chambers. 2012. "Skill Progression Demonstrated by Users in the Scratch Animation Environment." International Journal of Human-Computer Interaction 28 (6): 383-398.

Schön, D. A. 1983. The Reflective Practitioner: How Professionals Think in Action. New York: Basic Books.

Schön, D. A. 1985. The Design Studio: An Exploration of Its Traditions and Potentials. London: RIBA Publications.

Shaffer, D. W. 2005. Epistemography and the Participant Structures of a Professional Practicum: A Story behind the Story of Journalism 828. Madison: University of Wisconsin Center for Education.

Shaffer, D. W. 2006. How Computer Games Help Children Learn. New York: Palgrave Macmillan.

Shaffer, D. W. 2007. "In Praise of Epistemology." In The Design and Use of Simulation Computer Games in Education, ed. Brett E. Shelton and David A. Wiley, 7-27. Rotterdam, Netherlands: Sense.

Shaffer, D. W., and J. P. Gee. 2012. "The Right Kind of GATE: Computer Games and the Future of Assessment." In Technology-Based Assessments for 21st Century Skills: Theoretical and Practical Implications from Modern Research, ed. M. Mayrath, J. Clarke-Midura, and D. H. Robinson, 211228. Charlotte, NC: Information Age. 
Shaffer, D. W., D. Hatfield, G. N. Svarovsky, P. Nash, A. Nulty, E. Bagley, K. Frank, et al. 2009. "Epistemic Network Analysis: A Prototype for 21stCentury Assessment of Learning." International Journal of Learning and Media 1 (2): 33-53.

Shute, V. J. 2007. "Tensions, Trends, Tools, and Technologies: Time for an Educational Sea Change." In The Future of Assessment: Shaping Teaching and Learning, ed. C. A. Dwyer, 139-187. Mahwah, NJ: Erlbaum.

Shute, V. J. 2008. "Focus on Formative Feedback." Review of Educational Research 78 (1): 153-189.

Shute, V. J. 2011. Stealth Assessment in Computer-Based Games to Support Learning: Computer Games and Instruction. Charlotte, NC: Information Age.

Shute, V. J., E. G. Hansen, and R. G. Almond. 2008. "You Can't Fatten a Hog by Weighing It—or Can You? Evaluating an Assessment for a Learning System Called ACED." International Journal of Artificial Intelligence in Education 18 (4): 289-316.

Shute, V. J., and R. Torres. 2012. "Where Streams Converge: Using Evidence-Centered Design to Assess Quest to Learn." In Technology-Based Assessments for 21st Century Skills: Theoretical and Practical Implications from Modern Research, ed. M. Mayrath, J. Clarke-Midura, and D. H. Robinson, 91-124. Charlotte, NC: Information Age.

Shute, V. J., and M. Ventura. 2013. Stealth Assessment: Measuring and Supporting Learning in Video Games. Cambridge, MA: MIT Press.

Shute, V. J., M. Ventura, M. I. Bauer, and D. Zapata-Rivera. 2009. “Melding the Power of Serious Games and Embedded Assessment to Monitor and Foster Learning: Flow and Grow." In Serious Games: Mechanisms and Effects, ed. U. Ritterfeld, M. Cody, and P. Vorderer, 295-321. Mahwah, NJ: Routledge, Taylor and Francis.

Shute, V. J., M. Ventura, and R. Torres. 2012. "Formative Evaluation of Students at Quest to Learn." International Journal of Learning and Media 4 (1): 55-69. 
Spradley, J. P. 1979. The Ethnographic Interview. New York: Holt, Rinehart and Winston.

Spradley, J. P. 1980. Participant Observation. New York: Holt, Rinehart and Winston.

Squire, K. 2006. "From Content to Context: Videogames As Designed Experience." Educational Researcher 35 (8): 19-29.

State, R. E. 1995. The Art of Case Study Research. Thousand Oaks, CA: Sage.

Steinkuehler, C. A. 2004. "Learning in Massively Multiplayer Online Games." In Proceedings of the Sixth International Conference of the Learning Sciences, ed. Y. B. Kafai, W. A. Sandoval, N. Enyedy, A. S. Nixon, and F. Herrera, 521-528. Mahwah, NJ: Erlbaum.

Steinkuehler, C. A. 2005. "Cognition and Learning in Massively Multiplayer Online Games: A Critical Approach." PhD diss. Department of Curriculum and Instruction, University of Wisconsin-Madison.

Steinkuehler, C. A. 2006. "Why Game (Culture) Studies Now?" Games and Culture 1 (1): 1-6.

Steinkuehler, C. A. 2008. "Cognition and Literacy in Massively Multiplayer Online Games." In Handbook of Research on New Literacies, ed. D. Leu, J. Coiro, C. Lankshear, and K. Knobel, 611-634. Mahwah, NJ: Erlbaum.

Steinkuehler, C. A., and C. C. Williams. 2009. "Math As Narrative in WoW Forum Discussions." International Journal of Learning and Media 1 (3). doi:10.1162/ijlm_a_00028.

Strauss, A., and J. Corbin. 1998. Basics of Qualitative Research. 2nd ed. Thousand Oaks, CA: Sage.

Svarovsky, G. N., and D. W. Shaffer. 2006a. "Design Meetings and Design Notebooks As Tools for Reflection in the Engineering Design Course." Paper presented at the 36th ASEE/IEEE Frontiers in Education Conference, San Diego. 
Svarovsky, G. N., and D. W. Shaffer. 2006b. "Sodaconstructing an Understanding of Physics: Technology-Based Engineering Activities for Middle School Students." Paper presented at the 36th ASEE/IEEE Frontiers in Education Conference, San Diego.

Traphagen, K., and S. Trail. 2014. How Cross Sector Collaborations Are Advancing STEM Learning. Los Altos, CA: Noyce Foundation.

Urciuoli, B. 1995. "The Indexical Structure of Visibility." In Human Action Signs in Cultural Context: The Visible and the Invisible in Movement and Dance, ed. B. Farnell, 189-215. Metuchen, NJ: Scarecrow Press.

Van Maanen, J. 1988. Tales of the Field. Chicago: Chicago University Press.

Wells, G., and G. Claxton, eds. 2002. Learning for Life in the Twenty-First Century: Sociocultural Perspectives on the Future of Education. Oxford, UK: Blackwell.

Wilensky, U. 1999. "GasLab: An Extensible Modeling Toolkit for Exploring Micro- and Macro-Views of Gases." In Computer Modeling and Simulation in Science Education, ed. N. Roberts, W. Feurzeig, and B. Hunter, 151-178. Berlin: Springer Verlag. 